
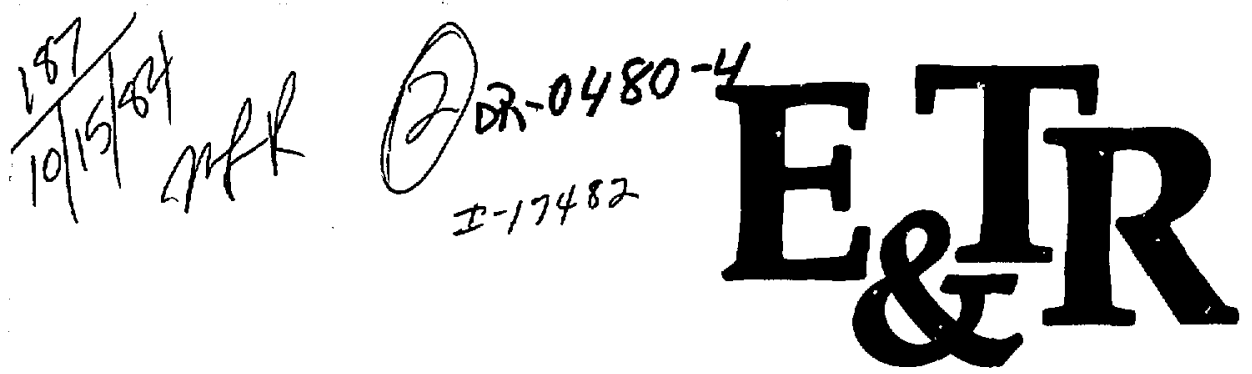

Energy and Technology Review Lawrence Livermore National Laboratory July 1984

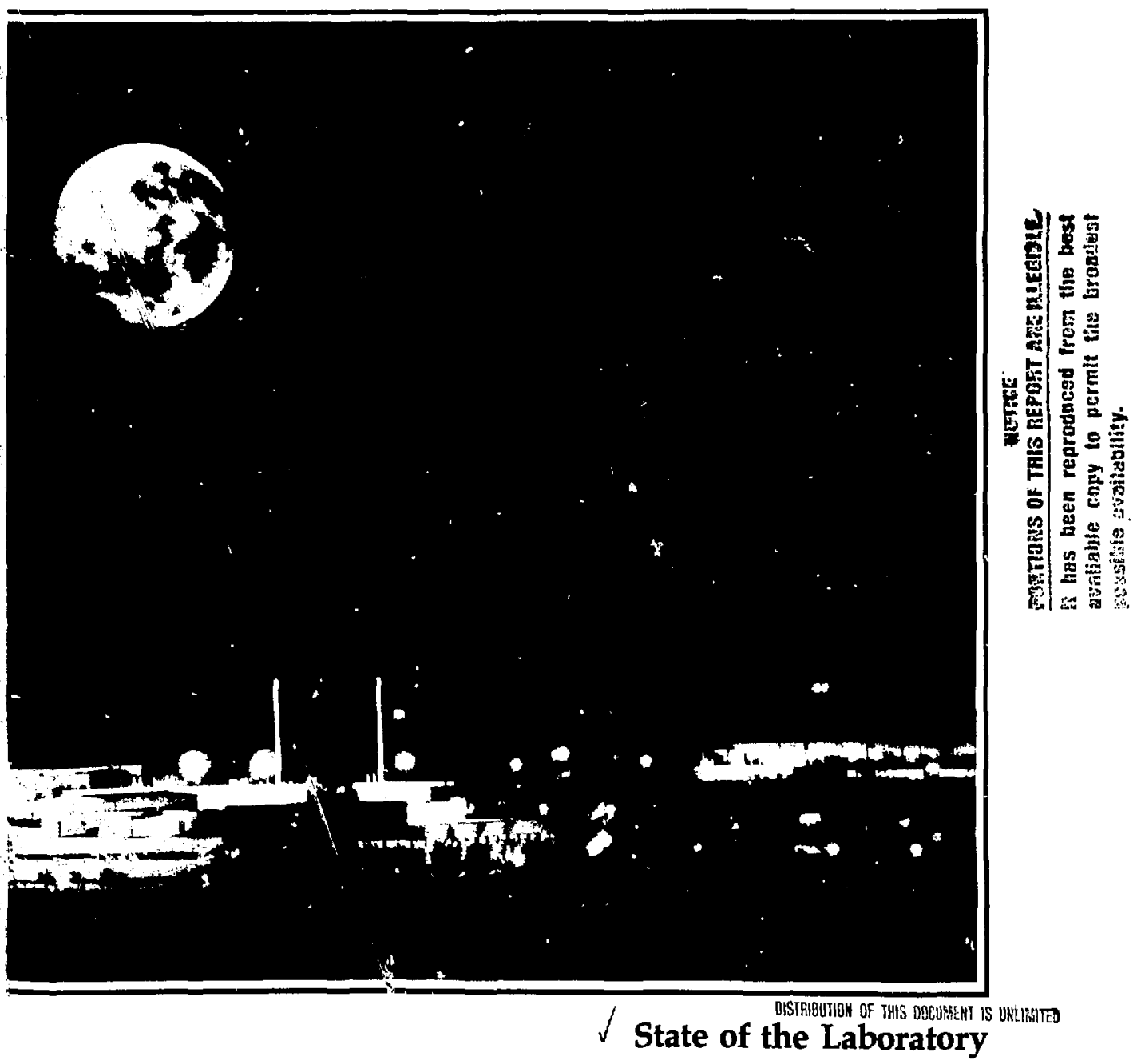




\title{
Energy and Technology Review
}

Lawrence Livernote National Laboratory

July 1984

\author{
UCRLL-52000-01-7 \\ 1305001472
}

State of the Laboratory

\section{Laboratory Achievements}

Each year, Director Roger Batzel addresses the LLNL staff on the state of the Laboratory and the achievements of the past year. On May 17, 1984, Dr. Batzel reported on the estimated budget for fiscal year 1985, which includes an $8.5 \%$ increase in operating funds, and on recent progress in our major programs. In this issue, we summarize Dr. Batzel's address and present a sampling of Laboratory achievements.

\section{DISCLAIMER}

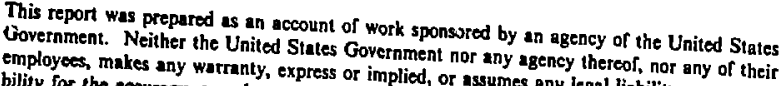
bility for the accuracy, completeness, or usefulness of any information, liability or responsiprocess disclosed, or represents that its use would of any information, apparaius, product, or ence herein to any specific commercial product, process, infringe privately owned rights. Refermanufacturer, or otherwise does not necessarily constitute or imply its endorsement, recomand opinions of authors expressed herein do not necessarily any agency thereof. The views United States Government or any agency thereof. 


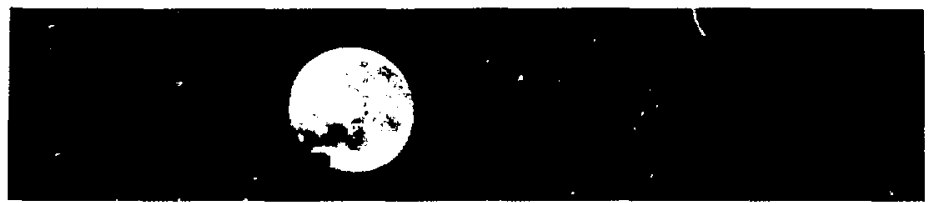

\section{State of the Laboratory}

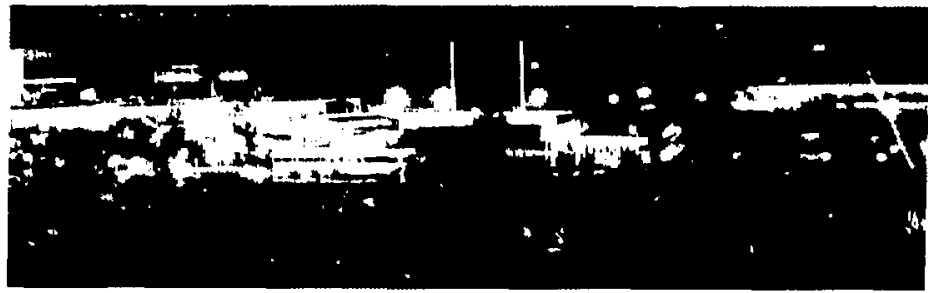

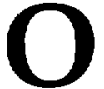
n May 17, 1984, in his annual state of the Laboratory address, Director Roger Batzel summed up the past year by saying, "This has certainly beer? a good, productive year for all programs at LLNL. We all have good reason to take pride in the substantial accomplishments made this past year in weapons research and in our other areas of scientific endeavor.... At the same time, we must recognize that this Laboratory, along with other government laboratories and private industry, finds itself operating in much more challenging and often difficult circumstances."

In reviewing the projected budget, Dr. Batzel said that the total funds for fiscal year 1985 will be $\$ 852.9$ million, up by about $12.5 \%$ from fiscal year 1984 (Fig. 1). A substantial portion of this increase is earmarked for construction and will fund several major new construction projects, including the High Explosives Applications Facility, plus some investment in the Laboratory as an institution, including a new medical facility. The budget also inciudes $\$ 7$ million in fiscal year 1984 and $\$ 17$ million wa fiscal year 1985 for the initial purchase of buffer land along the west, north, and south boundaries of the Laboratory. Operations, the largest budget item and the one that includes employees' salaries, is projected to increase by about $8.5 \%$ from $\$ 631.3$ million in fiscal year 1984 to $\$ 684.9$ million in the 1985 fiscal year (Fig. 2, Table 1). The largest programmatic increases are slated for weapons lesearch, up about $13 \%$ from last year, and for work for other government agencies, up just over $27 \%$. (The rate of inflation must, of course, be factored in with these budget figures to determine the real levels of supp rort.)

In tern's of enuploy'ment, this level of funding will make possible a slight increase in full-time equivalent positions. About 500 to 600 new people will be hired, largely to replace those people retiring or departing for other reasons.

The past year was remarkable for the achievements of our technical programs. We successfully met the denlanding deadlines of the deployment schedules for the warheads for the groundlaunched cruise missile, the Peacekeeper (MX) missile, and the modem strategic bomb. New L.LNL-developed 
technologies promise to make nuclear weapons safer to handle and more resistant to potential interference or attempted use by terrorists. At Site 300 , the recently completed Flash X-Ray Facility is providing us with extremely useful information to complement our weapon modeling studies. Scientific and engineering studies conducted in the past year or two are beginning to show what may be possible for nuclear-driven directed-energy weapons for ballistic missile defense. "The understanding and potential of these new concepts and advanced techologies is fundamental to the future defense posture of the country. Both the possibility and the desirability of ballistic nissile defense need further research, and 1 believe it is inperative that the United States maintain a major effort in this area of technology."

Major successes were achirved in the laser isotope separation program, which is in the midst of demonstrating its potential for uranium and plutonium enrichment. Achievements include continuous operation of the SPP/IIVenus laser with autcinatic frequency, power, and bean:-quality control, significant increases in the power of the copper-vapor lasers, and good agreement with models for the firstphase testing of a liquid uranium collector. These achievements continue to increase the reliability and efficiency of the process while reducing the expected cost of building and operating a laser isotope separation plant.

In inertial confinement fusion, a number of successful experiments were conducted with the Novette laser including demonstration that the shift from infrarad light to light of higher frequencies (green or blue) greatly reduces plasma instabilities during irsplosions. In addition, the Nova laser will soon be completed and, next year, will be able to deliver $150 \mathrm{TW}$ of power to the fusion targets. "This is a very significant stride forward that will add greatly to our understanding of these complex processes. ... Nova should have significant applications for laser fusion power as well as for weapons research."

We have obtained encouraging results in magnetic fusion with the Tandem Mirror Experiment-Upgrade (TMX-U). For the first time ever, researchers achieved a thermal barrier in the end

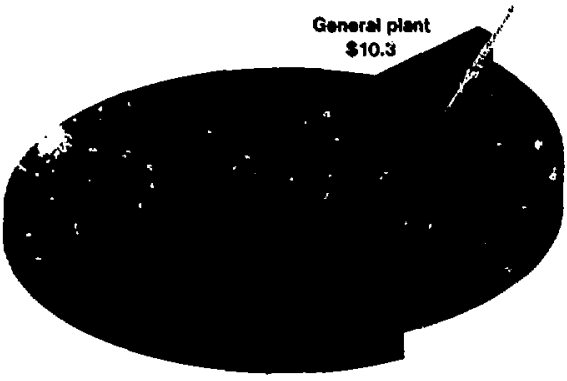

Fig. 1

Lull expenditurea for fieced your 1905 (in mimions of dollers); thit yeur's budget totis $\$ 952.5$ mimion.

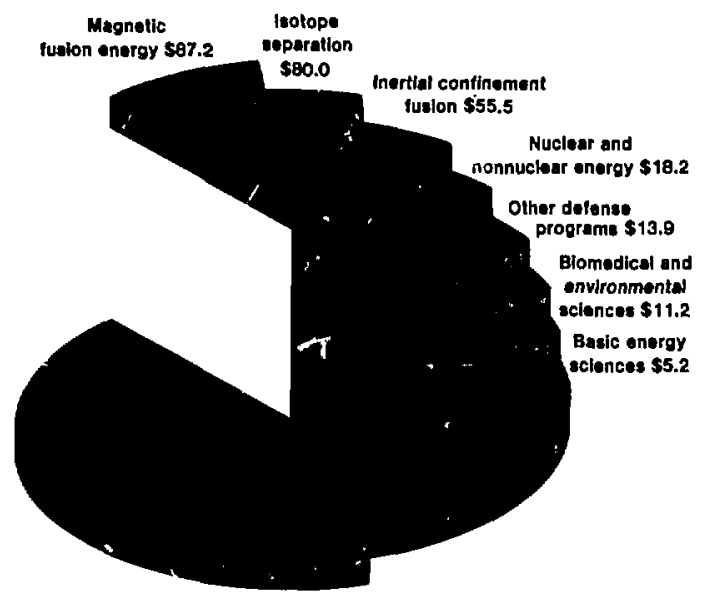

Fig. 2

LuM. operating expeditures for fhacel year 1985 (in millions of dollare); thit year's operations budget totale $\$ 684.9$ million. 
plugs of the TMX-U using a combination of microwave, neutral-beam, and radiofrequency heating. These thermal barriers appear to hold the promise of greatly increased efficiency for future tandem-mintor fusion reactors. Good progress also is being made toward the completion of the MFTF-B, our nextgeneration magnetic-fusion test facility.

Our biomedical researchers have made significant advances in developing ways of measuring genetic damage to human cells. They also have developed a flc : cytometric method that will have

Table 1 LLNL program funding (in snillion of dolian).

\begin{tabular}{|c|c|c|}
\hline Defense programs & & \\
\hline Weapons & $\$ 250,9$ & $\$ 284,1$ \\
\hline Inertial confinement fusion & 58.7 & 55.5 \\
\hline Isotope separation & 34.0 & 25.0 \\
\hline Verification and control & 10.5 & 12.3 \\
\hline Safeguards and security & 1.4 & 1.4 \\
\hline Defense waste management & $=$ & 0.2 \\
\hline Subtotal & 355.5 & 378.5 \\
\hline \multicolumn{3}{|l|}{ Fossil energy } \\
\hline Coal gasification & 2.0 & 2.0 \\
\hline Oil shale & 2.4 & 2.4 \\
\hline Gas stimulation & 0.7 & 0.7 \\
\hline Liquefied gaseous fuels & 2.3 & 2.0 \\
\hline Subtotal & 7.4 & 7.1 \\
\hline \multicolumn{3}{|l|}{ Conservation and renewable energy } \\
\hline Transport energy conservation & 0.4 & 0.4 \\
\hline Energy storage systems & 1.7 & 1.6 \\
\hline Geothermal & $=$ & 0.2 \\
\hline Subtotal & 2.1 & 2.2 \\
\hline \multicolumn{3}{|l|}{ Energy research } \\
\hline Magnetic fusion & 58.1 & 71.1 \\
\hline Magnetic fusion coniputer center & 13.6 & 16.1 \\
\hline Energy sciences and nuclear physics & 4.9 & 5.2 \\
\hline Health and environmental research & 8.8 & 8.5 \\
\hline Subtotal & 85.4 & 100.9 \\
\hline \multicolumn{3}{|l|}{ Nuclear energy } \\
\hline Advanced isotope separation & 67.3 & 55.0 \\
\hline Commercial nuclear waste & 8.9 & 8.9 \\
\hline Subtotal & 76.2 & 63.9 \\
\hline \multicolumn{3}{|l|}{ Policy, safety, and environment } \\
\hline Environmental activities & 2.9 & 2.7 \\
\hline Other work for the DOE & 18.6 & 20.3 \\
\hline Reimbursable projects and work for others & 83.2 & 109.3 \\
\hline Total & $\overline{\$ 631.3}$ & $\overline{\$ 684.9}$ \\
\hline
\end{tabular}


special significance for tive early detection of cancer and the treatment of cancer patients. The Laboratory's high standing in biomedical research was underscored by the selection of Mort Mendelsohn, Associate Director for Biomedical and Environmental Sciences, to chair the Health and Environmental Research Advisory Committee, a Department of Energy panel chartered to examine the Department's entire spectrum of life science research,

In our nonnudear energy projects, significant strides have been made in the underground gasification of coal deposits using the LINL-rieveloped Controlled Retritting Injection Point (CRIP) concept, a method by which we can retract the point of steam and oxygen injection into the coal, making it possible to burn one volume of fresh coal after another. In our oil-shale rescarch, improved processes have eliminated sulfur contamination both in the end product and in the gases released during combustion.

In its work for other govenment agencies, the Laboratory has made a number of notable achievements. Work for the Nuclear Regulatory Comnission has included assessing the area around the Nevada Test Site for possible storage of nuclear waste and determining the potential for earthquakes in the eastern United States and the safety implications for some of the older nuclear power plants there. In a major engineering achievement for the Department of Deferse, the Large Optics Diamond Turning Macline, the largest precision lathe of its kind in the world, became operational this past year. In another significant effort for the Department of Defense, the Advanced 'Test Accelerator attained full energy, and experiments in the propagation of electron beams in air are expected to begin shortly.

Some outstanding achievements in chemistry and materials science and in engineering also were made this year. A microdryer fo: enclosures designed by a Laboratory scientist was nam:ed by Industrial Research and Development magazine as one of the year's most significant inventions in the nation. Other scientists have used innovative processes like ion implantation and rapid solidification to develop new types of materials, alloys, and explosives. "Our engineers have shown innovation and creativity in designing and developing new tools of the trade." These include very fast, high-voltage photoconductive switches for the Nova laser system, gallium arsenide microcircuits that are many times faster than conventional sil?con circuits, and a number of ingenious micromachining techniques.

"From the earliest years of the Lalooratory, conputers have played an inlegral role in our weapons design work and, increasingly, in other research as well. The Laboratory has consistently been a world leader both in speed and in total capacity of installed computers." In keeping with this policy, we installed a Cray $\mathrm{X}-\mathrm{MP}$ this year; this computer is a multiprocessur machine at the forefront of the technology.

Moving on to more general issues affecting the laboratory, the Director emphasized that security for employees and facilities and the health of employees and the surrounding conmunity always have been paramount considerations. "Nevertheless, we must reexamine our procedures to respond to the new standards being set by regulatory bodies and to the threat of terrorism . ... I have charged Jack Kahn with the technical management responsibility for this program." He continued, "We are devoting increased funds and attention to security and safeguards. We are responding to the increasingly stringent requirements laid down by agencies regulating the environment and to litigation arising from alleged harm which former employees received while working at the Laboratory . ... We must also recognize that the world-wide threat of terrorism cannot be ignored. No one likes to change his work habits or life style, but there is no choice. It is better to adapt in our own way, in a planned fashion, than to be confronted with a threat for which we might be inadequately prepared." Changes in environmental regulations will affect how the national laboratories conduct their business. "On the whole, our systems and procedures have been satisfactory, but we need constant, 
thorough reexamination. It is becoming increasingly difficult to keep up with developments in regulation."

Dr. Batzel touched on the issue of collective bargaining at the Jaboratory. "During this past year, the employees of the Lahoratory voted on the guestion of establishing collective bargaining units, and they voted overwhelmingly against exclusive representation. The greaterthan-90\% voter response was gralifying. We learned a lot ahout ourselves during the campoigh. We've continued to improve our mamagement practices, including communication and managenent development, so that our employees' faith in current Laboratory management is justifiesi and upheld."

The present contract between the University of Califomia and the Department of Energy governing the University's management of the Laboratory will soon be due for reconsideration; the contract calls for the University to decide by October 1, 1985. if it wishes to terminate the relationship. "As in the past, our views on this important issue will be presented to the University. . . As we are all aware, opinions vary among the members of the Board of Regents regarding the continued managenent of the two auclear weapons laboratories by the University. We will be altempting to make sure that all the Regents and other key University leacters are fully informed about the I.ahoratory and its work, and we hope to resolve any doubs and misunderstandings."

Dr. Batzel conduded his atdress by saying, "This Luboratory includes many pieces of very advanced and complex equipment, from tiny sensors to enormous lasers. $Y(u)$ it is essentially a gathering of people who apply their brond range of advanced and complex skills to the projects at hand, making possible the excellence of achievement that has become the hallnark of the Laborntory." 


\section{Laboratory Achievements}

To fulfill its programmatic commitments for defense and energyrelated research, LLNL applies a wide spectrum of resources and skills drawn from scientific, engineering, and technical disciplines. This issue of the Energy and Technology Review presents a sampling of the Laboratory's achievements during fiscal year 1984 in the design and development of nuclear weapons and other defense-related research, in the application of our unique experience and capabilities to investigations aimed at helping the nation meet modern-day energy needs and to monitoring and maintaining the quality of the enviromment, and in carrying out a variety of projects for other Federal agencies. These highlights of this year's Lahoratory accomplishments are grouped according to the chief sponsors of the work described, the Assistant Secretaries of the U.S. Department of Energy and the Federal agencies who have supported individual programs. 


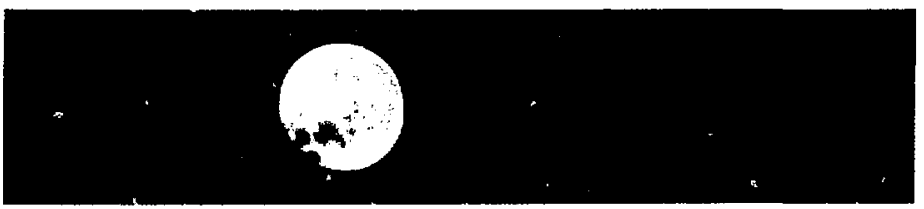

\section{Defense Programs}

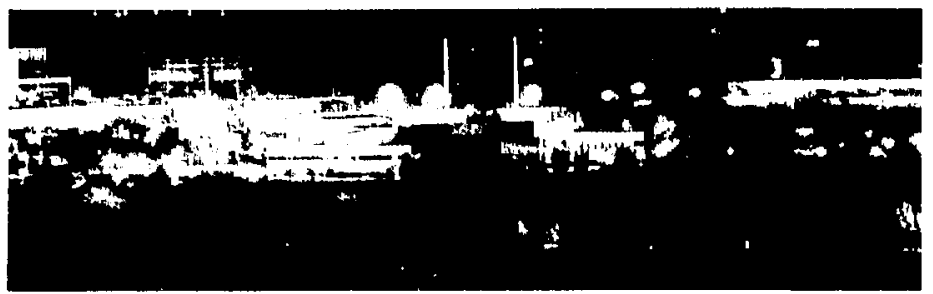

\section{I}

\section{mproving Fiber-Optics Diagnostics} in underground nuclear tests typically rely on coaxial cables to trarismit electrical signals from detectors underground to recording facilities on the surface. Poor high-frequency transmission in these long cables can severely limit the signal bandwidth available in a data channel. In contrast, optical fibers that transmit light signals from detector to recording station are potentially capable of transmitting very wide (multigigahertz) bandwidths. For this reason, we are applying fiber-optics technology to improve our ability to transmit and record diagnostic data.

To realize the full potential of this teclinology, however, we inust observe certain constraints. An optical signal must reside in the deep red or nearinfrared region of the spectrum. Also, because a light signal passing through an optical fiber is dispersed, its component wavelengths being smeared in time (the speed of light in a medium depends on its wavelength), its spectral width must be effectively narrow. However, as the streak camera, our principal recording instrument, is relatively insensitive in the infrared region, of the spectrum, these constraints often pose recording problems. This insensitivity, tom ther with ineificiencies in converti w nuclear radiation to light and in coupling light into the fibers, can produce signal levels lower than desired. To solve these problems, we have applied two techniques: streak equalization and parametric frequency up-conversion.

Streak Equalization. Streak equalization enables us to erihance light levels by taking a much larger spectral "bite" of an optical signal, thus gathering more light while maintaining an effective narrow spectral width. We do this by reconstructing a fast optical pulse that has been smeared in time by transmission through a dispersive fiber.

The temporally broadened light pulse from the downhole optical fiber is dispersed with a grating onto a linear array of optical fibers (see figure). The 
DEFENSE PROGRAMG

$\%$ inuclear Testing

ENERGY PROGRAMS

WORK FOR OTHEISS degree of dispersion and the number and size of the fibers are carefully chosen to preserve the effective spectral witth desired. Each fiber intercepts only a narrow slice of the spectram at a given wavelenglin. By trimming each fiber to a length appropriate to the transit time of the wavelength of light it Iramsmits, we an matly compensate for the differences in total fither transit tince caused by dispersion.

When emly a narrow band of wavelengths is used, sach filver in an artiny provides a more fasthful representalion of the time history of the downhole light sorurce, bet tho resulting inlensity is weak. The stroak comera enables us to combine, with the proper time correlation, the !'ght octput of all the fibers in an ar.ay, thes completing reconstruction $\mathrm{c}$ the dispe sed spectrum. In this technique, light from the fiber atray generates electrons when it impinges on a photocathode. The sweeping streak camera deflects the electrons to a piosphor for recording. With proper tinning of the sweep speed, electrons generated at the photocathode by the shorter-wavelength light wiil experience a stronger deflection than will the earlier-arriving electrons generated by longer wavelenglhs and thus will be deflected more. The result is that the hater electroms will spatially coincide with the earlier olectrons at the phosphor, completing the recsistertetion process and producing a strong, tomporally sirort pulse.

Eovalization could be attained with the fiber artay alome, if the strenk camera were not the recorder, or by the streak camera slone if sweep speed and grating disfersion were chosen very carefully. By' combining these technigues, we traves increased our operating flexibility in three ways: by decoupling the grating dispersion from the camera sweep speed, by eliminating line necessity for having

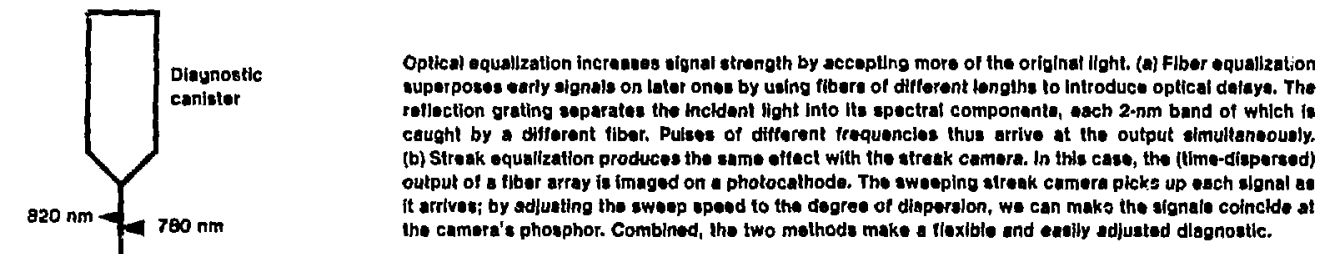

(a)

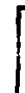

(b)

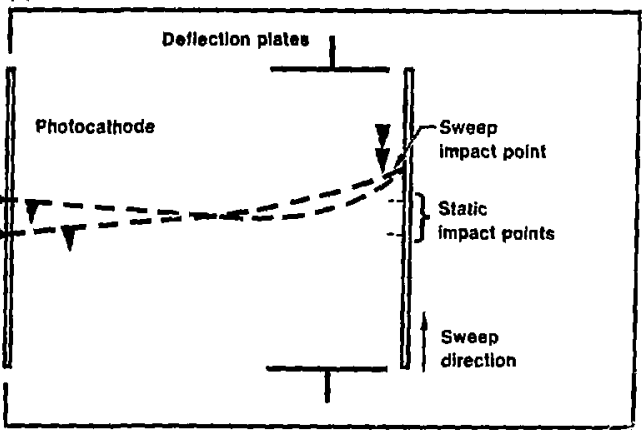

Streak tube 
the grating very cinse to the streak camera, and by providing a means, through trimming fiber lengths, to finetune the system.

We have fielded 26 streak equalizers on two Nevada Test Site events in the past year. The time response (width of the system inpulse response) of the measurement systens was about $250 \mathrm{ps}$. Without the equalizers, the impulse "arponse wiuld have been fen times lurger, or equit.alent to that of a typical conxial calle dingnositic.

l'arametric Frequency UpConversion. Userul as it is, spectal equalization may not provide a bandwidth sufficient for some dingensotic applications. To achieve ceven greater bandwidth capacity, it will he necessary to eliminate from optical fibers a phenomenon called modal dispersion. Motal dispersion results when sone light ravs transmitted by a fiber undergo multiple reflections from its walls. This ricochet effect forces some rays to travel farther than others, inducing a time broadening of fast-pulse information. The only way to elininate this effect is to use filvers so thin-called single-mode filers-that they allow only one type of ray to propagate through them. Singlemode silica filers with a diameter of 5 to $10 \mu \mathrm{m}$ recently have become commercially available, and it appears that the necessary supporting teclunology now exists.

There are, however, serious obstacles to applying this mew teclmology. Silica fiber has a transmission-loss minimum in the wavelength regime of 1300 to $1600 \mathrm{~nm}$, well into the infrared. Unterstandably, fiber manufacturers have tried to exploit this fact in their designs of single- and multiple-mode fikers. As a result, all available singlemode fiber is desirned for operating in this regime. (Evel, cually it may bo zone difficult to find even multimode fiber that is optimized for shorter wavelengths.)
As noted above, the sensitivity of a streak caniera falls of dramatically at longer wavelengths. Because such a comera relies on the photoslectric effect, fundamontal physical considerations make the quantum yich wanishingly small in the 1300- to $1600-4 m$ regime. How then, call we use the streak comera in conjunclion with the very high bandwith-distance product of singlemole fibers? The answer may lie in exploiting a nemlinear oplical phesumenom.

Nomirienar oplics emahles us to connert inlrared plotons in a signtal to blue pholons, which are then recorded by a streak camera with high stantum efficiency (the guantum efficiency of photoemission increastes substantially for incident lowe light). This phenomenon is called parametric frequency upconversion. When infrared photons carrying data are combined with a very intense laser beam in a nonlinear cystal, each infrared photon combines with one of the many photons in the laser beam, protucing is single photon of higher energy (and thus shorter wavelength) thall either. This process is similar to the generation of second-harmonic photons (Energy' and Terhnology. Review, UCRL-52000-82-8, August 1y:2, p. 19), routinely done with our Novette laser. ln the present case, however, the input infrared signal may bo arbitrorily weak, and only the pump must be intense. Pieliminary experiments with our Phoenix laser have demonstrated that this process can be carried out with a quantum arficiency of several percent. We are quite oftimistic that further work will enaibie as to transmit and record data with ri:ultigigahertz bandwidths. L

Key Words: camers-streak: cqualization-optical

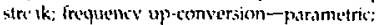
optical filuer; laser-Novelte, Phomin. 
IOIINSI PROX:RAMS V. i, int

ENERGY PROGRAMS WORK FOR OTHERS

Bchematic dingrem of the theresolved opectromoter. X roye etthing the bent quartz crystal are dieperaed into en onergy epectrum. They pese through a megnetic itedd that removes Compton slectrons and throwgh a thin titenium foll that atope viste right. Then thoy strike the photocethode of the ear mented, gated microchennet plate that converts them into en etectron image. Atter ampiliteation in the miorochennel plate, the efectrons generale Hoht imege in the phosphor. The coherent opticestrber bundis plpes this image to the elactrontc cemsa $f x$ tranemtecion to the recording equipinent at the eurtece.
$T$ ime-Resolved X-Ray Spectroscopy

We have developed an advanced electro-optical technique with which we can transmit and record more than 500 channels of time-resolved data through a single cable. This system will provide laboratory-qualily $x$-ray spectra in a nuclear-test environment, enabling us to make important new tests of our nuclear design cotes.

The new technigue combines microchannel-piate $x+$ ray gletectors with a sprecial video readout system (a highspeed electronic camera) used in neutron imaging experiments. Each microchannel plale has siveral million $12-\mu \mathrm{m}$ holes threugh it, each of which functions as an independent electron menliplier when the entrance end of the hole is at a high negative potentia! with reverect to the exit end. $X$ rays from a bent-crystal spectrometer first pass through a nagnetic field that removes accompanying Compton electrons and through a thin litanium foil to stop visible light; the $x$ rays then fall on the photocathode of the microchan inel plate, generating an electron image of the spectrum (sce figure), wh chtain time

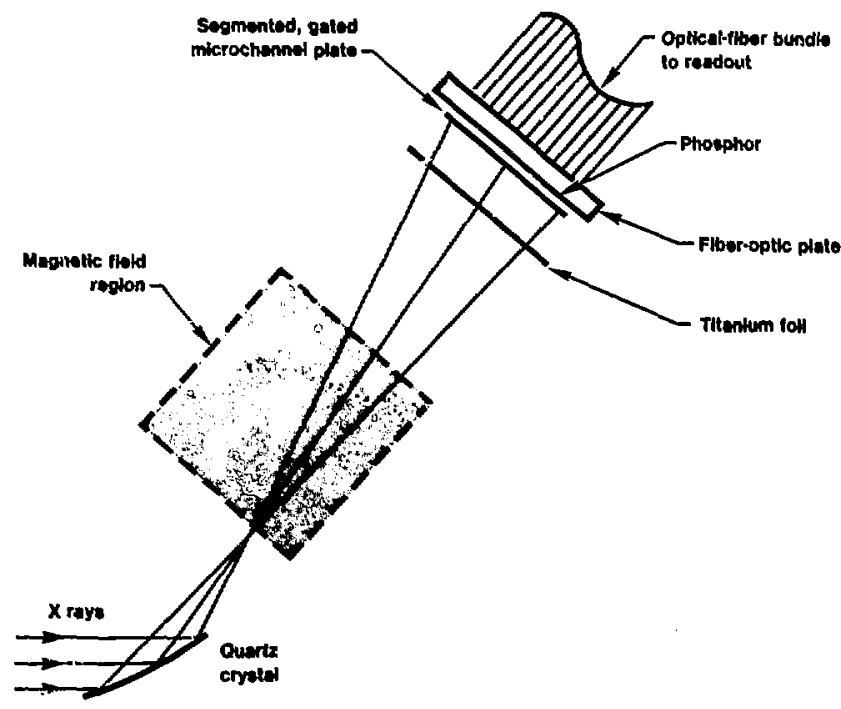

resolution by sequentially pulsing the voltage on a series of five narrow photocathode strips on the front of each wafer, arrayed at right angles to the spectral lines, turning on one set of microchannel photomultipliers after another,

On the exit side of each microchannel plate is a phosphor on which the antplified electron image, bearing the spectral information, appears as a visible image. Optical fibers rearrange this image to sit the format of the camern and transfer it, at the speect of light, to a photectiode array by way of a galed image intensifier, which provides a second stage of amplification and helps reject background radiation. The trimsmitting electronics must digitize the data from the photodiote arrays and send it to the recorting eipuipment at the surface in less than 3 ms, before the entire downhole system (bent-crystal spectrometer, high-speed pulser, nicrochamel plates, photodiode arrays, uptical fileers, transmitting electronics, and all) is destroyed by the shock wave froin the nuclear explosion.

We have already used these gated microchannel-plate $x$-ray detectors successfully in laboratory measuiements. Anong ofher things, we have obtained $x$-ray spectra from Z-pinch and laserproditced plasmas with time resolutions (Gating tines) less thin 2 ns. In a typical experiment, we measured the $x$ rays from a krypion plasma in the spectral range from 1.5 to $2 \mathrm{keV}$, obtaining sufficient detail to watch the evolution of the complex enission spectrum from highly ionized krypton atoms.

To produce this spectrometer, we drew on the experience and technical developments of many Laboratory groups. In particular, the remote transmission of coded visual images with a fast electronic camera was developed to provide two-dimensional pictures of nuclear experiments. Our development, in turn, is proving useful to other programs. The basis of our time resolution, the new kind of fast highvoltage pulser, is already finding many other applications, $\mathbf{w}$

Key Words: electro-optics; nuclear test diagnostic; $\mathrm{x}$ ray-deteclor, time-resolved spectrometer. 
$\mathbf{N}$ ew Gamma-Ray Diagnostics

The deuteriun-tritium fusion reaction emils a high-energy gamma ray with a probability of about $10^{-5}$. By measuring the intensity of this $16.7-\mathrm{MeV}$ ganma-ray flux, we can directly determine the fusion reaction rate as a function of time. Because of its relatively low production probability, however, this fux is typically much weaker than that of the lower-energy gamma rays ( 1 to $5 \mathrm{MeV}$ ) generated by fission or by nonelastic interactions of neutrons with matter. A detector of fusion-produced gamma rays, therefore, must strongly discriminate against pholons of an energy below $16 \mathrm{MeV}$. During the past year, we have applied two such diagnostic systems to different regions of the ganma-ray spectrum.

In the FUDGE (IUSion Diagnostic Gamma Experiment) technique, spectral isolation and energy definition are provided by a Compton-electron nagnetic spectrometer. Compton electrons ejected by collimated gamma rays from a heryllium ioil in a diagnostic line of sight are analyzed in a magnetic field and focused onto a detector array (see figure). Because the electron energy is proportional to the energy of the incident photon, a detector can be positioned with respect to the analyzed and focu'ed ejectron bean so that it detects only $16.7-\mathrm{MeV}$ ganima rays.

An effective and inexpensive alternative to the complex but precise FUDGE technique is a threshold Cerenkov detector. Such a detector discrinimates against photons below a selectable energy. As in FUDGE, gamma rays from the nuclear source eject Compton electrons from a beryllium foil. The -lectrons enter a gas-filled chamber where (if their speed is greater than the speed of light in the gas) they generate Cerenkov radiation, largely in the visible spectrun. As the speed of light in the gas depends on its composition and pressure, we can adjust the minimum electron speed (and therefore the incident-photon energy) to which the detector responds. The intersity of the Cerenkov light produced is proportional to the total flux of gamma rays with energies ahove the threshold. The

Cerenkov light is detected by conventional photosensitive detectors.

Our current effort is aimed at making these diagnostics convenient to implement and the data easy to interpret. This entails standardizing the hardware design, tocumenting calibration techniques, and generating, computer software to aid in designing experiments and amalyzing data. 15

Key Words: Corenkon threshoth detedto: Comptom upectrouneter: FUDCE: gamma-ray detection.

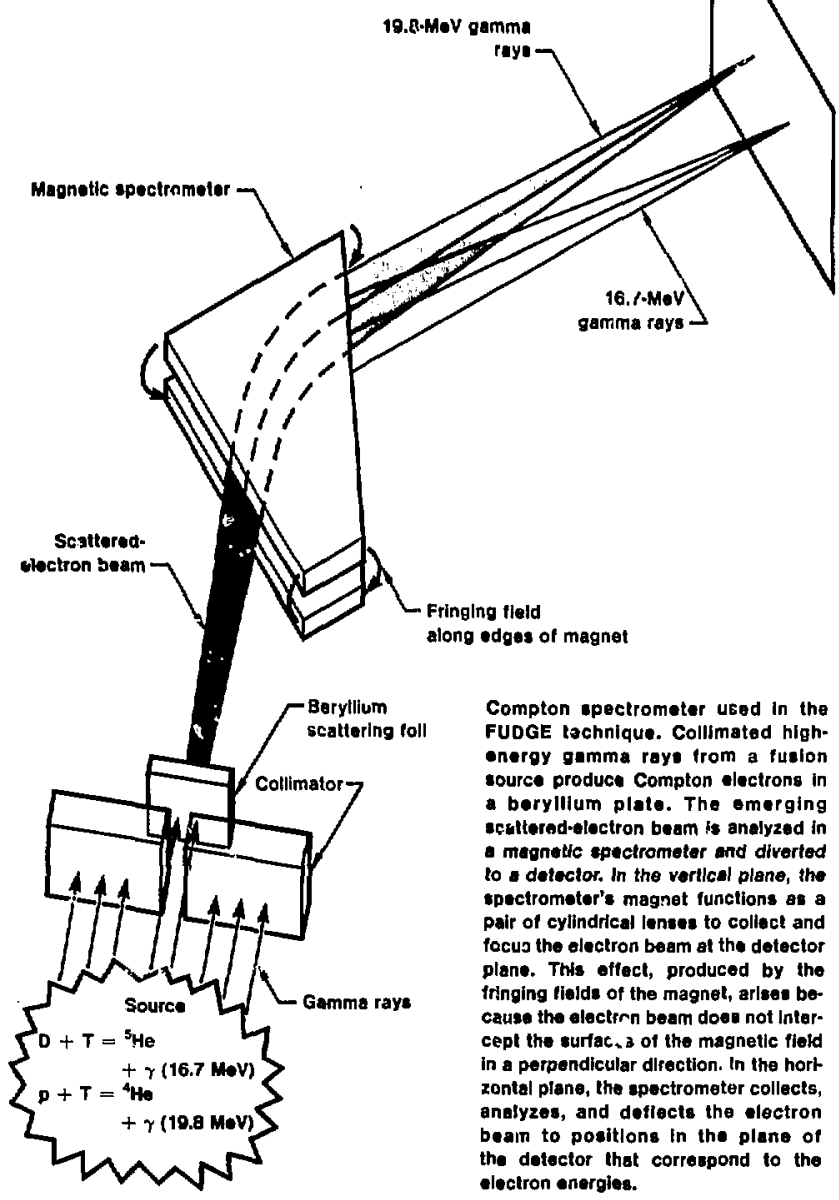


G ypsum Plugs for Emplacement Holes

To ensure that no radioactive gases are released from an underground nuclear test, the emplacement hole is backfilled with a variety of materials, in a process called stemming. Although the largest fraction of stemming is done with granular materials, several components of the stemming design act as gas seals or structural features. The material commonly used for this purpose has been an epoxy resin, a cross-linked polymer. After detonation, the discrete epoxy layers-called plugs-resist gas flow and support stemning materiais above should the column of material below collapse.

During the past year, we decided to use cement-based materials rather than epoxy for the plugs, primarily to reduce costs. Our search focused on gypsum concrete, which is composed of industrial-grade plaster of Paris and coarse aggregate. This material has significant advantages over other candidates such as Portland cement. Among these are its low heat of hydration (an expected peak of $65^{\circ} \mathrm{C}$ when mixed with aggregate), its fast set time (15 to 30 minutes), and its high early strength (about $9 \mathrm{MPa}$ compressive strength two hours after mixing). The constete expands by about $0.3 \%$ during the curing process, coupling the plug mechanically into the wall of the bore hole,

Several field tests have established a method of enplacing the gypsum concrete. The gypsum slurry is blended and pumped to the level of the plug through a tube suspended in the emplacement hole, and the coarse aggregate is simultaneously dispensed over a weighing conveyer. The viscosity of the gypsum slurry is low enough that it mixes thoroughly with the aggregate. Core samples of the cured concrete from field tests reveal a compressive strength at least as great as that measured in laboratory samples,

The gypsum concrete was first applied in the Agrini Event, March 1984. The plugs functioned as intended and successfully prevented gas flow up the emplacement hole. The low cost of the plug material (about one-tenth the cost of a given thickness of epoxy) has enabled us to to emplace conservatively large structural features intended to improve the survivability of the stemming column, A key component of the new plans is a plug just above the diagnostics canister that is expected to contribute significantly to preventing early gas flow up the stemming column. 1

Key Words: Agrini Event; epoxy resin; gypsum concrete; stemming, 
in marked contrast to the older results, with a median of $1.5 \times 10^{12} \mathrm{~m}^{3} / \mathrm{g}$ and a wide range of helium- 4 content. It is not vet clear whether the difference is due to an antalytical discrepancy or to a sampling artifact. We are attempting to reconcile the results.

\section{Estimating Fusion Helium-4}

Production. The second element in the correction for radiogenic helium-4 is estimating the amount of rock degassed. A lower limit is set ly the melt volume, typically 07 to $1 \mathrm{kt}$ of rock per kilolon of yiuld $\Lambda$ reisonable upper limit is $3 \mathrm{kt}$ of rock per kiloton of yield (the estimate used in containment calculations of the amount of rock heated to a temperature sufficient to evolve carbon dioxide from carbonates). We have chosen for a working value the median: $2 \pm 1 \mathrm{kt}$ of rock per kiloton of yield. Together with our analytical results, this value gives $2 \pm 1$ litres of helium-4 per kiloton of device yieid in the cavity gas from rock degassing. Since the typical helium-4 residual per kiloton of thermomiclear yield is 50 to 100 litres, an uncertainty of this magnitude is inmocuous except in nuclear designs with a very high fissionto-fusion ratio.

Ideally, we would like to compare this result with measurements made on rock and gas from an event in which the device production of helium-4 is zero. In practice, however, we must look for events with a high fission-to-fusion ratio. One such event was conducted with prompt gas sampling in 1983. In that event, the amount of helium- 4 was measured using helium- 3 as a tracer in eight pronpt samples of good quality. Corrections made for neutron capture and device-produced helium- 4 amounted to more than $80 \%$ of the nonair heliunn- 4 present. Assuming the balance to be from the rock anci taking the detonationpoint core analysis as representative, we conclude that helium-4 was released from $2.8 \pm 2.1$ 'st of rock per kiloton of device yield. The lange uncertainty is compounded from the estimated precision of our rock analyses, the air correction, and the device-related production, and is magnified by the necessary subtraction of comparable values. Nevertheless, this is the best such measurement made to date, and it nicely confirms our predictions.

This result now' enables us to correct, with greater confidence, measurements of device-produced helium-4 for radiogenic helium-4 released from rock, thereby improving the accuracy of our thermonuclear-yjeld diagnostics. $t$

Kiy Words: helium-4-fusion: yield measturement-themonuclear.
DEFENSE PROGRAMS

iuclear Iesting

ENEIRGY PROGRAMS WORK FOR OTHERS 


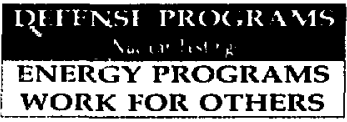

N ew Gas-Sampling Conduit One technique for measuring the thermonuclear yield of a nuclear device is prompt gas sampling, in which gas samples are retrieved from the explosion-produced underground cavity and analyzed for helium-4 content (see the preceding article). Over tite ytais, we have developed a reasonably reliable prompt-sampling system that uses cablesupported hose to extract gas samples. However, this system only turely enables us to retrieve samples after the stubsidence chimncy forms ahove the detonation point. This feature imposes an unpredictable time limit on the collection of samples.

To overcome this limit, we recently redesigned the sampling hose to provide a stronger, more flexible, and sleeker conduit able to survive subsidence in several emplacement configurations. Design criteria included a significant improvement in strength and flexibility, minimal degradation of presubsidence sampling capability, protection of the hose and elestrical caibing, and lower total emplacement cost with respect to the cable-supported system.

Conduit Design. The figure shows the design details of the new conduit. At the core of the new assembly is a 14-conductor electrical cable; 12 wires service four downhole pressure transducers, and the other two are pulsed to continuously record the electrical length of the cable. (Pull tests indicate that when failure occurs, the cable's electrical length reflects the physical length of the hose.) Surrounding the electrical cable and inside the polyurethane hose are three counter-laid layers of twisted wire strands. These support the hose against crushing. In the second layer, alternate strands are absent; gas flows principally through these gaps between the strands. Outside the hose is the external armor, consisting of 20 wire ropes $6.4 \mathrm{~mm}$ in diameter. The ropes are constrained by a loose-mesh steel braid, and the entire external structure is gasblocked to prevent the uncontrolled transport of cavity gases. The system is fabricated in 600-m lengths and cut to the desired length for each event in order to eliminate hose couplings downhole. The externa! armor is also the principal strength member of the new system. Pull tests indicate that the breaking strength of the new system is alout 100 tonnes. The burst pressure of the hose is $20 \mathrm{MPa}$; the outside diameter is $5 \mathrm{~cm}$, the same as for the old conduit.

In the 4h conciuit system, the hose was supported by an internal wire rope. The electrical cables were extemal. Tensile loads were transmitted through the hose to the intermal cable, Couplings were spaced at 6 to $25 \mathrm{~m}$ along the hose to allow field assembly and to facilitate handling; they also provided movementresistance points along the hose. Hose damage occurred at the hose couplings at a tensile stress of about 9 tonnes. Because they were external to the wire rope, the hose and the electrical cables were vulnerable to damage from relative ground motion. Common failures included loss of electrical signals and opening to air at significant distances from the cavity.

Both the new and the old systems incorporate two vacuum-demand valves to control gas flow in the conduit. The valves in the now system provide separate internal terminations for the external armor, the hose, and the internal support strands. Electric cables are gasblocked, and two pressure transducers are located inside the housing, which is also the tension member. These valves are the only interruptions in the otherwise continuous conduit.

Field Tests. The new conduit design, together with one of the old designs, was first fielded in the Laban Event (August 1983). The identically configured systems were both emplaced to a depth of $286 \mathrm{~m}$. Eithcr system could be diverted to the sampling pumps to collect gas samples for later analysis. Pumping began at three minutes after zero time. Two minutes later, unusually high downhole pressure (more than $3.5 \mathrm{MPa}$ ) forced closed the vacuum-demand valves of the old system. Although the new system also registered high pressure (2.6 MPa), gas flow continued. Samples were later obtained from the old hose system when the downhole pressure ebbed sufficiently to enahle gas flow. Sampling was ended 
when both systems showed air in the noses.

Detailed analyses of the gas samples have failed to detect any subtle differences in the sampling performance of the two systems.

Both systems appear to have shortened at the initial ground shock, the new hose by about $28 \mathrm{~m}$ and the old hose by about $67 \mathrm{~m}$. The flow in both was restricted compared to predetonation performance. The downhole electrical cable serving the old hose was lost during subsurface stubsidence at 75 minutes, and the old hose opened to air above the upper vacuum-demand valve at $\mathbf{8 0}$ minutes during surface subsidence. The new hose withstood subsurface sulsidence lut lost communication with cavity gas at 82 minutes.

Subsidence after the Laban Event occurred in two distinct stages.

Subsurface subsidence at 75 minutes disrupted external electrical cables to $74 \mathrm{~m}$ below ground, and at 80 minutes the ground surface dropped suddenly and precipitiously. The surface drop, which was unusually extreme, stretched or broke all downhole calles. Both surface hoses connected to the sampling systems were stretched tight to the crater edge. We pulled the electrical cable to the new hose back to the recording trailers and fcund that it had broken at the transition socket to the internal cable. The electrical cable in the old hose had broken off and disappeared into the crater. Safety considerations prevented entry of the crater for further investigation.

On the basis of the timing of events, it is likely that the old hose failed during surface subsidence, and the new hose may have survived. If, in time, we are able to enter the crater, we will attempt to reconnect to the new hose to determine whether its armored portion is still intact.

Since the Laban Event, we have successfully tested the new conduit on two more nuclear events. Conduit performance was similar to that observed on the first test. In all three fieldings, we observed early shortening of the electrical cable and constricted gas flow.
Prompt gas samples were obtained from all events before subsidence, although in one case arrival was late and quality was poor. In all three events, the new conduit appears to have survived subsidence in the upper portion of the emplacement hole. In the two events since the Laban Event, the new conduit was electrically shortened at subsidence but survived to grenter depth than would have the old design. One of these provided useful samples after subsidence.

Performance of the new conduit is clearly stperior to that of the old. We have redesigned the internal electrical conductors to improve performance characteristics and to make a more. reliable measure of the physical huse length. Other improvements include protection of the system against constriction, isolation from the stemning, and judicious location of vuheralyle points to maintain maximum conduit length. With these improvements, and with the experience gained in field tests, we hope to fieid a configuration that can obtain useful post-subsidence gas samples with high reliability.

Key Words: conduil; gas sampling; Laban Event.

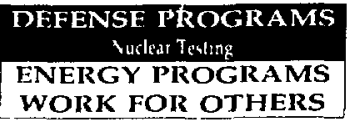

Dasign of our new condult for promptgos sempling. The oxternal armor gives the conduit greater tenalle etrength and protects the electrical components.

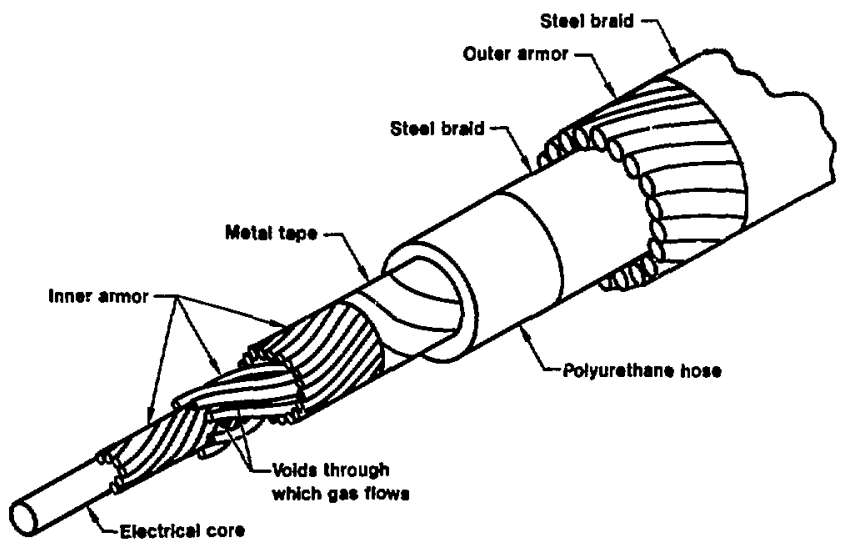


L aser Optical Line of Sight In a typical underground nuclear test, various diagnostic

instruments view the experiment through several lines of sight. To obtain highquality ciata, some instruments must be aligned very precisely with the porion of the experiment they are intended to view. The canister that houses the diagnostic instruments is large (up to $34 \mathrm{~m}$ long and $2.5 \mathrm{~m}$ in diameter), quile massive (well over 2010 lonnes, in some instances), and is buried under many tonnes of stemming material when the emplacement hole is backfilled. In addition, it is subjected to thermal gradients before it enters the downhole environment. These mechanical and thermal loads can induce significant deflections of the diagnostics canister, causing misalignment of its instruments. Proper canister design can ninimize this problent. To study canister deflection with a view to improving its design, we need some means of remotely measuring its angular and lateral displacements downliole.

The Laser Optical line of Sight (LOLOS), conceived and develnped hy LLNL, is designed to resolve a latera! displacement of $25 \mu \mathrm{m}$ and angular deviations of $10 \mu \mathrm{rad}$. The measurement system consists of two stabilized heliumneon laser sources, eight sensol inudules, a data-acquisition system, and a minicomputer for data processing. Each laser beam illuminates a separate line of sight, one above and one below the center bulkhead of the canister. Four sensor modules are mounted on the canister in each line of sight (see figure). In a sensor module, the position and angle of incidence of the laser beam are measured with two lateral-effect detectors. The electrical output of each photodetector is digitized and sent via cable to a 100 -channel data recorder on the surface. The data channels are then read out sequentially to a minicomputer for processing to provide deflection information.

Source Laser. Each laser source in the LOLOS consists of two 5-mW heliumneon lasers, one primary and one redundant, shar: ig a beam-stabilizing system. A laser source emits a highly collimated beam about $1.2 \mathrm{~mm}$ in diameter with a divergence of $1.0 \mathrm{mrad}$ full angle and a beam-angle fluctuation of $20 \mu \mathrm{rad}$ within a half-angle relative to the static beam alignnent.

Because the distance of a source from a sensor may be greater than $12 \mathrm{~m}$, we must stabilize the laser beam to prevent it from wandering. The beam stability system consists of:

- A 5:1 expanding lelescope.

- A closed-toop intensity control system.

- A closed-loop angular control sy'stem with a quadrant detector, a focusing lens, and a de motorized nitror momnt.

- $A$ closed-loop, trio-dinesisional, lateral translation system with a quadrant detector and a pair of de motorized translation stages.

Our design goal was to stabilize the bestin's lateral displacement to $2.5 \mu \mathrm{m}$ and its angular displacement to within $2 \mu \mathrm{rad}$.

Sensor Module. A I.OI.OS sensor module contains two photodetectors, one to measure lateral displacement and the other to measure angular tilt (figure). The laser source beam is reflected onto an objective lens, where it is focused and recollimated by a second lens onto a beam-splitting cube. The beam splitter transmits one-half of the incident laser light to the lateraldisplacement detector and reflects onehalf to a third lens, where it is focused onto the tilt photodetector. All mensuiements are made relative to motions at the objective lens of the sensor. The figure also shows the coordinate system, witt, lateral displacenent occurring in the $x-y$ plane. Rotation about the $x$ and $y$ axes represents angular deflection in the $\pm \neq$ and \pm 0 directions, respectively.

It is difficult to obtain silicon-wafer photodiodes that are linear throughout and that have contact wires that are symmetrically spaced on the silicon surface. We therefore use a unique calibration process to normalize each photodiode in the entire alignment system. After calibration in the lateral and angular axes, the sensor modules are mounted on the canister. 
Field Testing. We fielded the LOLOS for the first time on the Laban (1983) underground nuclear test. Strain and temperature measurements were performed on the diagnostics canister in its downhole environment. Static deflection measurements made with the LOLOS agreed well with predictions based on a finite-element model. Induced thermal-load tests showed that thie canister was deformed $0.25 \mathrm{~mm}$ for every degree Celsius of temperature difference across its surface. Defiections measures during emplacement and stenming to the top of the canister showed scaled alignment shifts of as much as $9.1 \mathrm{~mm}$. Partial load re]ease of the emplacement string resulted in a scaled alignment change of $2.1 \mathrm{~mm}$.

Our first field test of the LOLOS system has successfully demonstrated the technique and has made an important contribution to our understanding of canister deflection. Future LOLOS-instrumented nuclenr events will provide additional data, moving us toward our goal of maintaining precise alignmem of diagnostics in a downhole environnent.

Key Words: allgnment-mullisensing; dhognosticsalightument; laster optical line of sight (LOICG).

\begin{tabular}{|c|}
\hline DEFENSF PROGRAMS \\
vulea Iesting \\
\hline ENERGY PROGRAMS \\
WORK FOR OTHERS
\end{tabular}

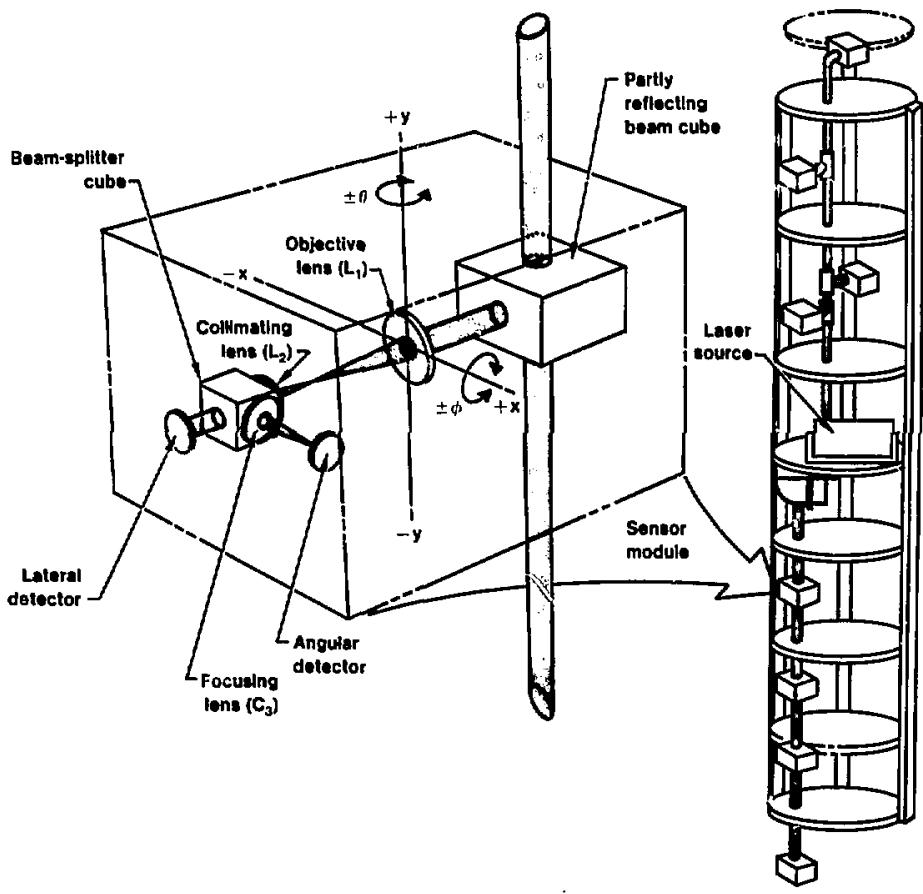

The LOLOS syetem, designed for precisely measuring downhole allgnment of a diagnontics caniater, consiats of two source lasers and eight delectlon modules. As shown in the entergement, esch asnsor module containa two photodeteclors, one to moasure lateral displacement and the other to measure angular tilt In two directions. The collimated laser beam is eplit, one-half tranemitted to the latorat-dieplecement detector and onehelf reflected onto the tilt detector. The coordinate aystem for the senser module also is shown. Lateral displacement is mesoured in the $x-y$ plane, angutar tilt ( $\phi$ and $\theta$ ) by rolation about the $x$ and $y$ axes. 


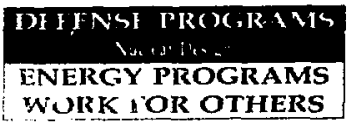

I mproved Calculations of Ion Transport

Because underground nuclear tests are quite expensive and are limited in number, it is important to gather as many kinds of information from each test as possible. The more details of an explosion that we can measure, the more details of our computer calculations we can check and the more accurate and productive we can make our matlicmaticul models and design codes,

One kind of dingnostic measure that has long been used is the amount and variety of unusual radionctive isotopes that are produced in the nuclear explosion. Wo generally include, in and around our test devices, measured quantities of elements specially selected for their nuclear properties and the identifiability of their isotopes. Afterward, small samples of the radioactive debris re analyzed by radiuchemistry to determine the kinds and amounts of tracer isotopes present.

Some of these tracer isotopes are made by neutren capture, some when the nucleus of an atom is struck by a fast-moving ion (e.g., the positively charged nucleus of a hydrcgen or helium atom). We have recently improved our mathematical model for calculating the motions of these fast-moving ions.

Because neutrons are uncharged, they are unaffected either by the electrons around an atom or by the positive charge on an atom's nucleus. The first of these immunities enables them to pass readily through materials that would stop a charged particle; the second enables them to approach the nucleus tosely even at low energies. Therefore, neutron reactions take place throughout the mass of a material and can produce relatively large amounts of radioactive debris.

Hydrogen and helium ions also can produce radioactive debris, but they operate under a double handicap. Being charged particles, they lose energy rapidly as they pass through matter. Furthermore, their positive charge prevents them from approaching another nucleus closely enough to have a nuclear reaction with it unless they are moving very fast. Hence, they must either react quickly, while they still have most of their initial energy, or not at all. As a result, the amount of radioactive material firmed by ion interactions is relatively small and hard to detect.

However, the special properties of charged-particle nuclear reactions provide kinds of information about the nuclear test that it would be impossible to derive from neutron-induced reactions alone. Our postshot radiochemistry analyses of nuclear-device perfornance have become so sophisticated that we are able to detect the products of charged-particle reactions. To use the information provided by these ion-induced reactions, we must be able to describe in detail the circumstances under which they took place. Many of these circumstances have to do with the ion's rate of energy loss, making it necessary for us to make the best possible calculations of the motions of energetic hydrogen anu helium ions through matter.

Part of the difficulty in doing this accurately has to do with the state of the matter through which the ions are passing. The rate of energy loss in matter depends strongly on the ionization state of the matter, which in turn depends on its temperature. It is easy to make experimental measurements of energy loss in ordinary (cold) matter, which is not ionized, but it is virtually impossible to do the same on matter that is many times hotter than the surface of the sun; hence the need for theoretical calculations.

The sinplest case to solve theoretically, the one treated in our old model, occurs when the medium through which the charged particle moves is completely ionized (that is, it is so hot that there is nothing left but bare atomic nuclei and free electrons). A great many complicated phenomena can take place in this situation; the cloud of free electrons can interact as a whole with the charged particle, there can be waves and resonance phenomena, and so on. The old model handled these phenomena adequately in many situations.

If, however, the medium is only partially ionized, a whole new set of complications arises. The electrons are 
free to react as before, but there are also bound-electron phenomena to take into account. The numbers of bound and free electrons and the average ion charge depend on the material, the density, and the temperature of the medium.

Very accurate theoretical calculations of the slowing-down rate can be done for this situation, but these calculations are too expensive to be repeated for each of the thousands of ions we might track in the calculation of a nuclear explosion. Therefore, we developed a new nodel that uses approximations to quickly give results that still are accurate enough in such partially ionized situations. This new model includes terms for the electron contribution to the slowingdown rate that were originally developed for tracking ion beams in inertialconfinement fusion calculations (see R. More et al., LLNL Rept. UCRL-87147, 1982). The expensive calculations can be used to check on the results generated by the quicker, approximate model.
The new model includes interactions of energetic ions of hydrogen and helium with bound clectrons, free electrons, and ions of the medium. It applies to all the fast ions produced directly in nuclear reactions or indirectly by collisions with fast neutrons that came from other nuclear reactions. The figure compares the range of protons (hydrogen ions) as a function of energy in aluminum at a temperature of one million degrees, calculated by the old and new models. (In terms of the degree of ionization, this still is not a very high temperatture.) This figure illustrates that linese new transport calculations ellable us to deduce more detailed information from the nuclear test data.

Key Words: computer modeling; ion transfort: reaction--charged-particie, ion-indured radiochenistry.

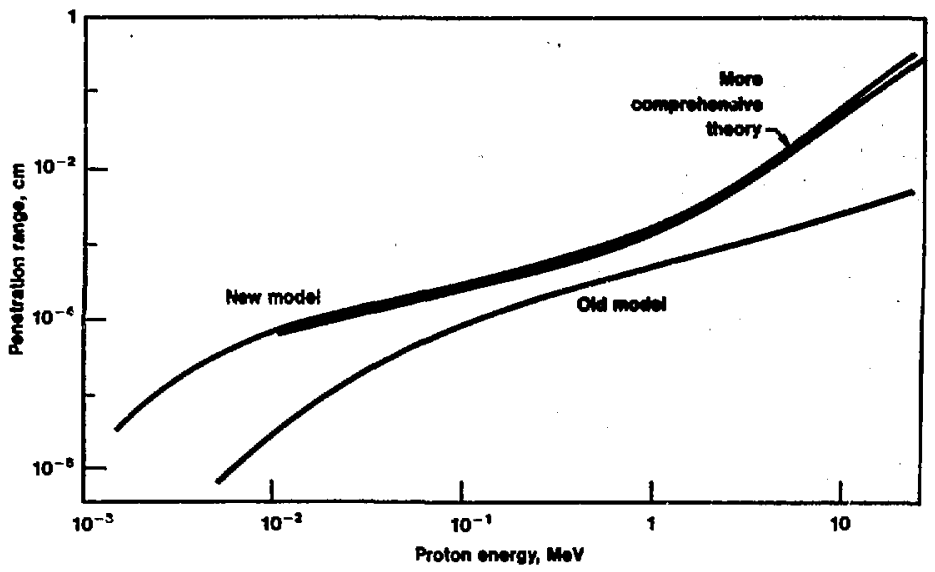

Ponetration range of protons as a function of easioy in chuminum at a denatty of $2.7 \mathrm{mg} / \mathrm{m}^{3}$ and a tempera ture of a mimion degrese, celculated by the old and the new mathemetices modsle end by the more comprehenelve theory. Beceuse siminum at thl lomperature bo only sbout one-helf tonked, the cecump-

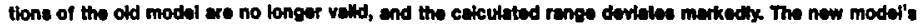
reutte, however, egree very closely with the reavile celculated by the more comprehendie theory. (The dotalied calculation was done by menbers of the Lewer Fuilon Progrem.) 
DEFENSI PROX,RAM

Yut in !n

INEIRGY PROGRAMS WORK FOR OTHERS
G

\section{LAM}

We have developed a new code called GLAM that uses an integral-equation approach to solve the steady-state equation of energy transfer in cylindrical coordinates, assuming that the geometry can be described by a straightline mesh with a given source and cross-section distribution. Basically, the code calculates the intensity of ratiation along a given ray (direction) and then, using a numerical cpladrature schemo, integrates the var ous angular moments of the intensity to abtain the energy, fux, and presstwe tensor. In the quadralue stheme, the inlepration extends over the entire boundary and over all azimuthal angles along which the observation point can "see" the houndary points. In a practical problem. the outer boundary is a material woll, and we are colculating the properties of the radiation field (energy density, energy flux, pressure tensor) at any point inside the boundary.

If the volume of the problem is emply, so that radiation simply streams from one point on the wall to another, the radiation intensity at any point takes on a prescribed value that depends only on the boundary temperature. GI.AM has an option that calculates germetrical view factors (defined as the iraction of radiation leaving one surface that is received by another) for any pair of two-dimensional azimuthally symmetric sixfaces. View factors also are extremciy useful in calculations of radiant heat transfer and of free-molecule flow (wherein the mean free path of the molecule is significantly larger than the dimensions of the system) in the design of vacuum systems.

In . ny cases of interest, however, the rac: tion will be scattered, alosorbed, and reradiated instead of nerely streaming. To deal with such problems, we had to extend the GLAM code to include calculation of emission and scattering scurcus.

For emission sources, a simple quadrature (integration) gives the adiation intensity along the length of a given ray. This makes it necessary to calculate the path length of a ray as it traverses a given zone (which may be different for every zone). Aside from the complication of determining the path lengths, the integration of the angular moments is the same as in the vacuum (streaming) case.

Further, although we consider the propertics to be uniform throughout a given zone (but different from zone to zone(2), it is unnecessary to consider that the emission changes abruptly from zone to zome. Wo obtain more realistic results when we allow the enission sources to vary' linesaly across the zone. Also, in criter to consicter energy-depenetent protilems, we provided GI. $\Lambda M$ with a multigroup option.

GLAM has provisions for calculating either angle-dependent (Thomson) or isotropic scattering. For Thomson scattering, the calculation requires a prior kriweledge of the pressure enersor, whereas for isotropic scattering it needs only an a!pisoximation of the energy density. (lt may seem circuitous that we need to know the pressure tensor to cinculate the pressure tensor, or the energy density to calculate the energy dessify, hut this is, a general property of scattering calculations. What really happens is that we can input a crude estimate of the energy density, for examp!e, and CLAM will calculate the pressure tensor and the energy flux and refine the original imput as well.)

SLAM also includes a simple model representing "cold" or "down" Compton scattering, in which energetic photons lose en sy by interacting witin cold electrons. Furthermore, in this model ive represent the Compton cross suction by the sum of two terms, the usual Themson cross section and the angle avernge (integral) of a term composed of the Klein-Nishiria cross section minus the Thomson cross section. (This assumes that all of the angular dependence of the scattering collision is embodied in the Thomson cross section.) We are planning to incorporate a Fokker-Planck treatment that will enable us to calculate "up" scattering, in which hot electrons contribute energy to photons that interact with them.

In summary, GLAM is a working syst'm that can be used to calculate the various moments for the time- 
independent equation of energy transfer for azimuthally symmetric problems. In particular, because of its unique method of calculating cut. off ang!es, GLAM provides accurate view factors that can be used in conjunction with hent-lransfer calculations. In addition, GLAM's integral

D esign of Fission Devices Nuclear designers must strive to understand the basic physics of our nutear warheads under a variety of changing conditions. We have established foimal programs tr irvestigate soveral major areas of nuclear weapon c'sign in which our knowledge is still mostly empirical, We are making significant progress in these areas throligh laboi, tory experiments and underground nuclear tests and through the development of improved data bases and more sophisticated calculational toois. Some highlights if this year's accomplishments follow.

Wo established LX-14 (a plasticbonded explosive consisting of $95.5 \%$ HMX and $4.5 \%$ Estane binder) for use in modern st:ategic weapons with Site 300 hydrodiagnostic tests in weapons geometry otherwise identical to earlier tests with $1 . X-10$. LX-14 is a wellcharacterized conventional high explosive, slightly less energetic than LX 10 but with better mochanical and approach enables it to obtain accurate answers for specialized problens 15

Key Words: anmputer ende- - Cil AN; energy

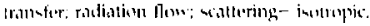
hhomest? hatusling saffety properties than the. $1 . X-10$ or 1 ' $3 X$ X 9414.

We also designed, tested, and evaluated a prototype of a versatile new family of light-weight, low-yidel fission dovire nom application of this it might be in a modern atomic demolition munition. It might also serve as the warhead for an sntisatellite weapon or a missile designed to destroy tactical ballistic missiles in flight

In one of our Nevada tests, a fissior device provided sensitive measuremerts of plutoniun's equation of state at pressures and densitjes typical of modern fission weapons but at higher tempreatures. Because the data highlight possible uncertainties in our knowledige of plutonium's equation of state, this test has stimulated much activity in this area.

linally; we made significant progress in using explosion codes to model the performance of boosted fission weapons. $L$

Key Words: compuler modoling; fission device; high explesive-1.X-10, 1.X-14, P'BX 9404; tquation of state $\rightarrow$ plutemium.
DFFENSE PROGRAMS

Uus lear Design

ENEIRGY PROGRAMS

WORK FOR OTHERS 


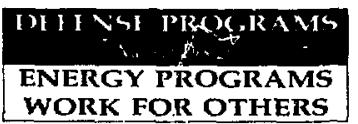

$\mathbf{N}$ eutron Transport Modeling

The ability to simulate complex physical experiments on our supercomputers enables us to gain information that may be difficult or too expensive to obtain from actual experiments. The interactions between meutrons and the matter they move through play a key role in many of the experiments so modeled, We have developed a new calculational approach that promises to markedly expand the range of pliysics questions involving neutron transport that can be addressed with compuler simulations.

Up to now, our more advanced simulation codes have used a Monte Carlo (random walk) approach to simulate neutron transport. A Monte Carlo calculation tracks a large number of "sample" neutrons, each representing many physical nettrons, as they pass through a material and randomly collide with atomic nuclei. Each sample neutron has a statistical probability of traveling a certain distance before encountering a nucleus, and the results of the encounter (c.g., the type of reaction, the number of resulting particles and their energies and angular distribution) are also governed by a statistical distribution. This powerful method is still unsurpassed for some types of experiment, but for others the statistical uncertainties it generates mask the very effects we are trying to study.

An alternate approach is to treat the neutrons as a continuous fluid whose diffusion is governed by a set of partial differential equations. Since there is no general analytic solution for these equations, we must solve them numerically. We chose to use a numerical technique called the finiteelement method, in which the solution to the entire problem is obtained by linking together a large number of simple functions, each of which extends over only a small zone out of the problem's total volume.

In the standard way of doing this, each simple function depends on all of its neighboring functions. The drawback of this approach is that if function $A$ depends on function $B$, then function $B$ not only depends on function A (bad enough) but also on the influence of function $B$ on function $A$, and of $A$ on $B$ and so on ad infinitum. This relationship, reminiscent of a dog chasing its tail, greatly complicates the calculation and makes the task of determining the simple functions too time consuming and expensive to be practical.

Using the neutrons-as-fluid analogy; we have found an efficient method for determining the simple functions. In this method, exch simple function depends on oniy those of its neightors that are supplying it with neutions. (The neighbors that are accepting nettrons can take any number, so their state does not influence the dynamics of the function under consideration.)

This formulation of the problem greatly reduces the coupling between the functions, simplifying and specding the calculation. Function A may depend on (be receiving neutions from) B, C, D, and $E$, but none of them depends on (sends neutrons back to) $\mathrm{A}$. This eliminates the back-and-forth interactions that characterize the conventional finiteelement method. The resulting modified finite-element method is free of the statistical errors asscciated with the Monte Carto approach and is more than fast enough for common use.

With this new capability, we are able to solve problems by means of numerical sinulation that were formerly beyond our grasp. Furthermore, although we have used it only for calculating neutron transport, it should be applicable to radiation and charged-particle transport problems as well. We look forward to extending the benefits of this innovation to other transport problems of importance to Laboratory programs. L

Key Words: computer modeling-finite-element, Monte Carlo; neiltron transport; neutrons-as-fluid analogy. 
$\mathbf{L}$ ine Transport Theory

In many studies of how matter and electromagnetir radiation interact, especially in a very dense plasma, it is permissible to make the simplifying assumption of local thermodynanic equilibrium (LTE). This assumption makes it possible to calculate, knowing only the locil density and temperature and using the well known formulas of stalistical mechanics, the number of ions in the plasm that are in any particular quantum state. When the plasma is more tentrous or is balhed in very intense radiation, however, the simplicity of I.TE must be replacest by the methods of mon-LTE physics, which require a detailed accounting of all the processes that take an ion from one state io another (figure).

Non-LTE situations abound. For exanuple, the process that turns electrical enery into the light we see from a fluorescent fixture is non-LTE. Non-LTE methods are essential in predicting the behavior of lasers, which operate by creating an inverted population, that is, a high-energy state occupied by more atoms than are in a lower energy state, the oppusite of what happens in LTE. (Laser light is produced by the transition of atoms from the upper state to the lower.)

The most difficult aspect of non-LTE to model, namely line transport, is the way light emitted at a discrete wavelength travels through a plasma. Radiation is readily absorbed and reradiated in a plasma, so each photon travels only a short distance in a given direction and then darts off in another. The radiation spreads through the plasma as the result of a great many of these randon zigzag paths. Furthermore, the reradiated photon is probably not the same as the absorbed photon. It can have a slightly different wavelength (shorter or longer), and the distance it travels before being reabsorbed depends strongly on this wavelength. In this situation, the very few photons that can travel the longest distances dominate the spreading process.

Our goal is to produce a versatile computer code for treating a wide range of non-LTE problems. One step has been to make extensive modifications to the existing non-LTE code ETLA to allow it to work reliably on the most difficult problems and to treat a much more varied assortment of problems than it could lefore. This new ETLA converges much more quickly and over a wider $\therefore$ inge of input variables than its predecessor. This flexibility and added capacity make it a robust and generally useful tool.

Another step is to speed up the solution of the large system of linear algelraic equations that arises when one follows numerically the erolution of the populalions of the ionic stites. The improvements here are incremental but important when the number of atomic states becomes very large.

A major barrier to extending nom-LTE calculations to more complicated physical situations is the high cost of finting the radiation field where there are many spatial zones and many spectral lines to ho considered. We are developing innovative methods of solving the transport equation to surnount this barrier. $v$

Key Words: computer code-ETI.A: line transport: physics-non-1.TE; plasma.

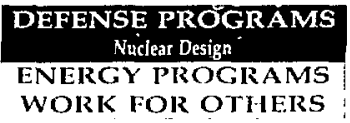

Simplifled calculation of the tranaport of four hypothetical spectral lines (wavalengthe 821.4, 818.1, 689.0, and $578.8 \mathrm{~nm}$, trom top to bottom, far loft) through a slab of nodium gas of uniform density, plotted as the ratio of non-LTE to LTE values. Deep in the slab (to the right) both ausumptlons glve the same result, but the LTE aneumption becomes lose and lose valid as wo approach the surface (lell) where radiation oscapes Ireely, whare the LTE asuumption is ofl by a factor of 20 to 100 , depending on the wavelength.

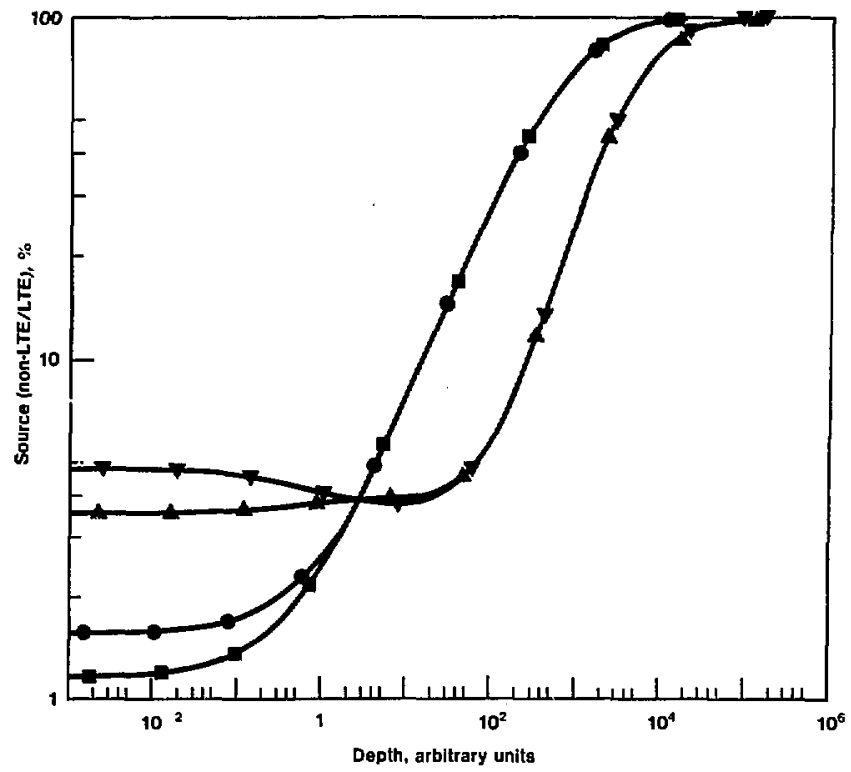




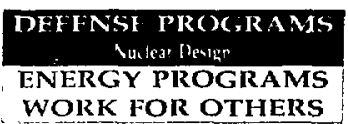

Relative error In the total photon energy as a function of time (in arbitrary units) for two different Fokker.Planck calculations of a Compton scattering problem compllcated by absorption. Even at early time, the error using the now nonWinear formulation th about ono-half that with the older unear calculation, and the error continues to decrease with time.
$\mathbf{N}$ onlinear Fokker-PIanck Equation

The radiant heating of thermal free electrons in a plasma by Compton scattering of photons with a distribution of energics (e.g., blackbody radiation) is a complex process governed by nonequilibrium statistics. The energy distribution of the photons evolves toward the Bose-Einstein equilibrium determined by the electron temperature and the number of photons. We sometimes model this nontinear process with a Fokker-Planck equation.

Any robust numerical implementation of the Fokker-Planck equation (that is, one that is able to handle a wide range of input varialiles without crashing) must:

- Conserve photons (in other words, keep their number constant and neither manufacture nor lose them).

- Olotain the correct Bose-Einstein equilibrium. (The equilibrium case is known independently because it can be calculated relatively easily. It represents the limit that the Fokker-Planck calculation must eventually reach.)

- Produce accurate second-order estimates of photon energy on nonuniform meshes.

- Maintnin positive values for the photon energy distribution. (There is no such thing as a photon with negative energy. If a computation indicates that there is, it lias to be wrong.)

The older scheme for calculating radiant heating of electrons was based

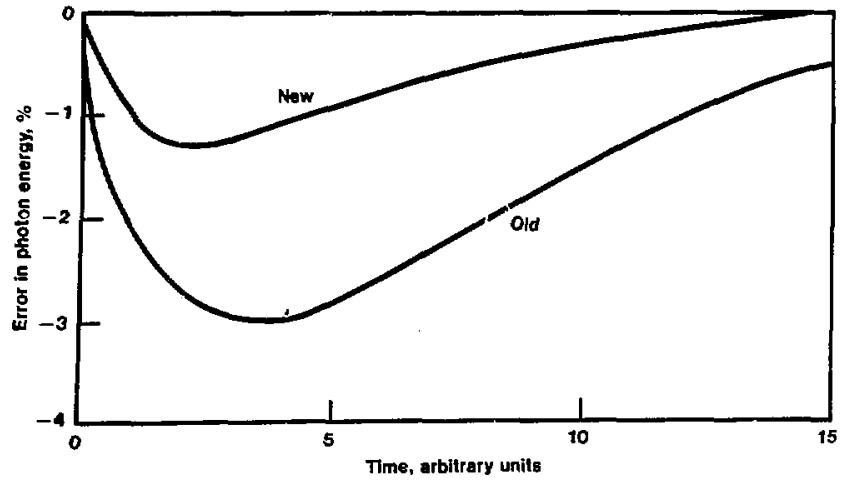

on linear Fokker-Planck equations and it had all of the above attributes, for linear conditions. When extended to the nonlinear case, however, it developed two complications. For one, it required the calculation of the constant that characterizes the Bose-Einstein equilibrium corresponding to the number of photons in the distribution and the electron temperature. Because this constant can be obtained only by solving a complicated nonlinear equation, it was often more expedient to approximate it crudely. When the approximation was too crude, however, the second complication arose.

The second complication was the need to approximate the solution to the discretized nonlinear looker-Planck equation l'y an iteration involving a sequence of linear problems, each of which contained the above-mentioned constant. The results of these iterations could sometimes become negative, making the calculation diverge instead of converging on a soiution.

We have developed a new numerical scheme that is simpler to implement, never leadis to negative values of the photon distribution, and appears to be more accurate. It is simpler to implement because it solves for the constant directly rather than through an auxiliary equation. We also can show that the linear problem solved in each iteration will always have a politive solution.

The greater accuracy of this new method is illustrated in the figure for a calculation of the total photon energy as a function of time for an upscattering problem (photons gaining energy from hot electrons) with absorption. Both calculations (old and new method) used the same set of 40 photon energy groups. The figure plots the relative etror in the two calculations as a function of time, and the improved accuracy shown is typical of what we found over a wide range of test problems. $L$

Key Words: Compton scattering-photon; radiant heating-electron; nonlinear Fokker-Planck equation. 
B eam-Driven Diode Experiments

In cooperation sith Sandia

National Laboratory, Albuquerque, we have performed an experiment to measure the effectiveness of magnetic insulation and to calpbrate a new particlein-cell simulation code. The experiment consisted of bombarding a metal plate, falling freely in a vacuum, wilh a brief but intense pulse $(50 \mathrm{~ns}, 80 \mathrm{kA})$ of energetic protons (1.5 MeV) from Sandia's HydraMITE accelerator. We mossured the protential of the plate with a voltage divider connecled by a fine wire. The HydramITE is a tesi motule for the l'roton Beam lusion Acceleration I, a light-ion driver for inertial-confinement fusion experiments, that produces a $\mathbf{5 0}$-ns electrical pulse of $1.5 \mathrm{MV}$ and $400 \mathrm{kA}$. We coupled it to an ion source known as the B-Theta diode, developed at Come'll University, that produces an intense beam of protons.

In the photograph, the plate in the background (with what look like circular grooves) is the B-Theta proton source. The heav' curved rods carry the currents that produce the magnetic insulation. The semicircular piate beshind the magnet windings lut in front of the proton diode plate is one-half of the collector plate. The radial wires form the ground plane of the experiment.

Upon being struck by the proton beam, the collector plate reaches a positive votential of 0.5 to $1 \mathrm{MV}$. The resulting high electric fiekt draws from the walls of the experiment chamber a cloud of electrons that, in the alsence of a magnetic field, would discharge the late potential. The toroidal magnetic rield opposes their motion and tries to turn them back, providing the magnetic insulation.

The new particle-in-cell code is fully relativistic and is designed to calculate the interactions of electrons with electromagnetic fields inside a conductive cavity. The cole calculates the motions of the electrons under their own inertia and the forces exerted on them by the electromagnetic fields. As time advances, the code alternately "pushes" the particles to their new locations and then recalculates the changing electromagnetic ficids in the cavity. for economy, each particle in the code represents about a trillion real electrons in the experiment. On a Cray computer, a calculation involving ahout a million particles takes about 10 hours.

The simulations correctly reproduce the measured voltage on the free-falling plate for the case of a weak proton buam (1hdow the spate-charge limit). They also prisict correctly an instability in the dectron flow that allows the electrons to sneak atross the magnetic barrier when the current densily of the proton bon is shove line spaco-charge limit, defonting the maynetic insulation. With the code thus calibristed for this simple geomelry, we san calculate with confidence othey" more complex magnetic-insulation prothlems.

Key Words: beam-drisen ditude: computer cudeparticle-jn-cell; HydraNtTe; magnelic imsulation.
DEFENSE PROGRAMS vuclear Design

ENEIRY PROGIRAMS WOIRK FOIR OTHEIRS

Phoiograph of the beam-driven diode experiment during assembly. The back plate (with circular lines) gonerates an Intente proion beam when pulsed to high positive potantlal, Heavy currento through the curved rode generate a toroldel magnefic field for magnetic insu. lation. An isolated sollector plate conly half of it is shown, being set in place) is raised to a high potential by proton bombardment.

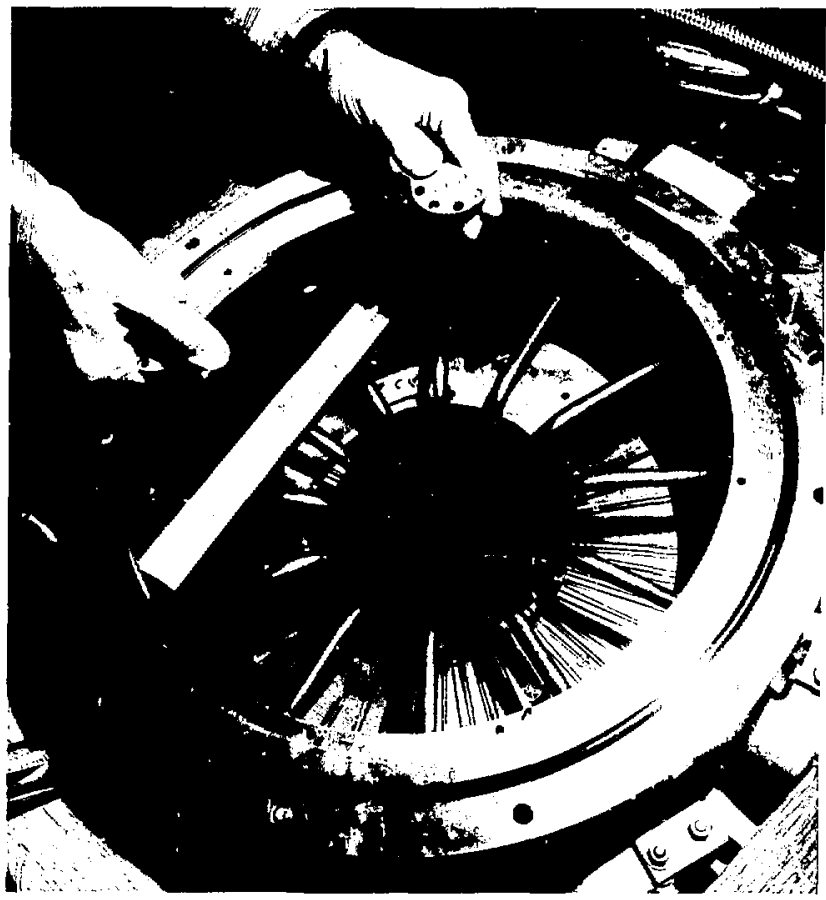


DEFENSE PROGRAMS

vitclear nesign

ENERGY PROGRAMS WORK FOR OTHERS
D eep Interior Radiographs with the FXR

To verify all the theoretical work, computer simulations, and engineering calculations involved ist nucloar design, we fire monnuclear models of each new device, made with mock fissile materials, at our explosives test facility at Site 300. To see whetl:er the device is performing according to sperifications, we need to pere doep inside the exploding system and take a smapshot of its inlermal components. On of the best woses of doving this is with $x$ rays in a lectmigue called nash mediograply.

Ha. h radiograptwy requires a briof but inlense butst of high-enengy r ravs, precisely lined to arrive just when the core of the device should have reached its densest configuration. Our old machine used a $100-\mathrm{MeV}$ electron linear accelerator to supply the high-energy eiectrons to make the $x$ rays. These $x$ rays penctrated only the thinmer parts of the experiment and were stopped by the thicker core. The resulting silhouette was incapable of showing the inportant internal details of the core.

Our new flash $x$-ray (FXR) linear induction accelerator, completed in 1983, is far more efficient because it is specifically designed for flash $x$-ray service. It produces 4 to $5 \mathrm{~Gy}$ ( 400 to $500 \mathrm{racl}$ ) of $x$ rays at a range of $1 \mathrm{~m}$, compressed into a 70-ns time interval. It focuses $150 \mu \mathrm{C}$ of $18-\mathrm{MeV}$ electrons onto a 3-min spot of the target, producing about $1.2 \times 10^{12} \mathrm{x}$-ray photons traveling within 1 deg of the machine axis with energies between 1.8 and $10 \mathrm{MeV}$, the energy range most important for deeppenetration radiography. With this flux, the penetrating power of the FXR is alsout ten times that of the older machine.

Radiography of a very thick object is not simply a matter of having energetic enough $x$ rays to penetrate it and to expose a film or other detector. First of all, the outer parts of the device are hundreds of times more transparent to $x$ rays than the core. We must severely collimate the beam to avoid sending too much radiation through these outer parts; otherwise, $x$ rays scattered from them would obliterate the faint inage mate by $x$ rays coming through the core.

Another difficulty is that the electron spot at the $x$-roy'-forming target of the accelerator is finile, which terds to blur the images in the radiograph unless the film is very close to the device. Honever, the film must survive the experiment, which ustally involves heary anounts of high explasive. If we insert a slout shield between she film and the device, we san place the fitm much oloser than would otherwise be possible.

Also, it is a challenge to decide how to use mont officently the few $x$ rays that do penetrate the linick core without scattering. In our firsl working test with the FXK machine, we used a stach of .1 .3 films intortenved with metal and seintillator screens, bveii so, we captured only about $20 \%$ of the $x$-ray photons. $W^{2}$ are working to dovelop new imaging techniques that produce better contrast without degrading resolution.

In preporation for this first working test, we spont two months trying different radiographic geometrics on a static (nomexploding) mock-up of the device and testing the properties of the $x$ rays from the fXXR machine. We used computer simulations to calculate the effectiveness of the film protection and carried out several explosive teste at other bunkers to check the calculations. We still could not be sure that the film would survive the real test, however, beause of inevitable differences between the mock-lips and the actual device, nor could we feel certain that our scattering tests with a static mock-up could simulate the real test closely mough to assure that we would obtain a good radiograph.

The shot fired on September 16, 1983. was a success, however. Since neither the FXR nor the radiographic lechnology to go with it is optimized yet, we should soon be able to double our radiographic capability. In addition, once bunker 801 at Site 300 has been completed, we will be athe to diagnose a hydrodevice test simultaneously with radiography, photography, laser velocimetry, and electric shock-wave probes. 1

Key Words: exploding dovice; flash radiography; $F X R_{;}$linear induction accelerator; $x$ riny-imaging. 
$\mathbf{N}$ uclear ImpedanceMatching Experiment We have performed an imperance-matching experinent, using the hydrodynamic shock generated by a nuclear explosion, to ohtain inportant information on the equations of state of materials used in the weapons program. The equation of state (EOS) of a material describes how its demsity varies as a function of applied plessure. Information of this soll is vital in designitng components that will be subjected to explosiog compression.

Pat of the purpose of the experiment was to qualify alumioum as an standard at these extreme pressures. We chose alumion for a standard beciutse its electronic configuration is relatively simple. It has recently become pessible to calculate the EOS of a material with a simple electronic configuration from first principles. This enables us to calibrate the experimental results, which would otherrise be purely relative.

We arranged the experiment so that the shock passed first through an aluminum lase plate $20 \mathrm{~mm}$ thick and then through samples of aluminum, beryllium, copper, and molybdemum $15 \mathrm{~mm}$ thick, arrayed in concentric circles on the base plate. The compressilvilities are setemined indirectly by measuring the velecily of the shock in each of the various materials. To do this, we placed 79 electrical shorting pins at strategic points throughout the base plate and specimens. (A pin is a miniature switch that closes when it is struck by the shock wave, changing the impectance of a circuit and sending a signal to the recorting oscilloscope.)

Wo also used the signals from the pins to investigate the unifomity and tilt of the shock wave. (Ideally; the shock wave should be a perfect plane exactly parallel to the front face of the base plate.) Our preliminary analysis of the data indicates that the shock wave was tilted by a very small angle (1.6 mrad) and that distortion of the shock wave was acceptaily snall.

The figure plots signal arrival times as a function of depth in the base plate and specimen for a velocity measurement in aluminum. The reference plane (zero on the vertical scales is the interface between the aluminum sample and the aluminum base plate. The linear fit to the data indicates that the shock wave uas steady: We obtained an arerage value of $28.0 \pm 0.1 \mathrm{~km} / \mathrm{s}$ for the shock velocity in aluminum. Our messured shock velocily in molybdenum was $20.5 \pm 0.1 \mathrm{~km} / \mathrm{s}$.

Acoording to the above-montioned theoretical calculations, the -hoch-wave velocity mossured in alummun in this experiment comesponde fo a shexk prossure of $1.37 \mathrm{TP}$ a 1.3 .7 million atmosplineses) and a 2.8 -fold compression. Fon molydemum, the correspoutimg values were a pressidre of 2.50 ( 5 Ta and a 2.4-fold compressicon. Theses pressures ame

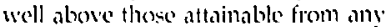
comecivable laboratory experiment. We have other similar experiments under wa or plomed that will extend shock f i data to higher pressures and other materials. Le

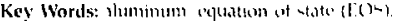

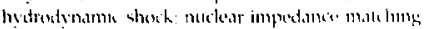
("xperiment.
DEFENSE PROGRAMS Nuclear Design

ENERGY PROGRAMS WORK FOIR OTHERS

Shock-arrival times ve depth for a nuclear-generated shock wave in alumtnum. The measured thock velocity was $28.0 \pm 0.1 \mathrm{~km} / \mathrm{s}$, indicatlng a pressure of $1.37 \mathrm{TPa}$ and a 2.B-fold compression. We can calculate the compressibilities of olher materials as a function of pres. sure by measuring how rapidly they transmit a shock and comparing the values with the velocity in aluminum as a reference standard.

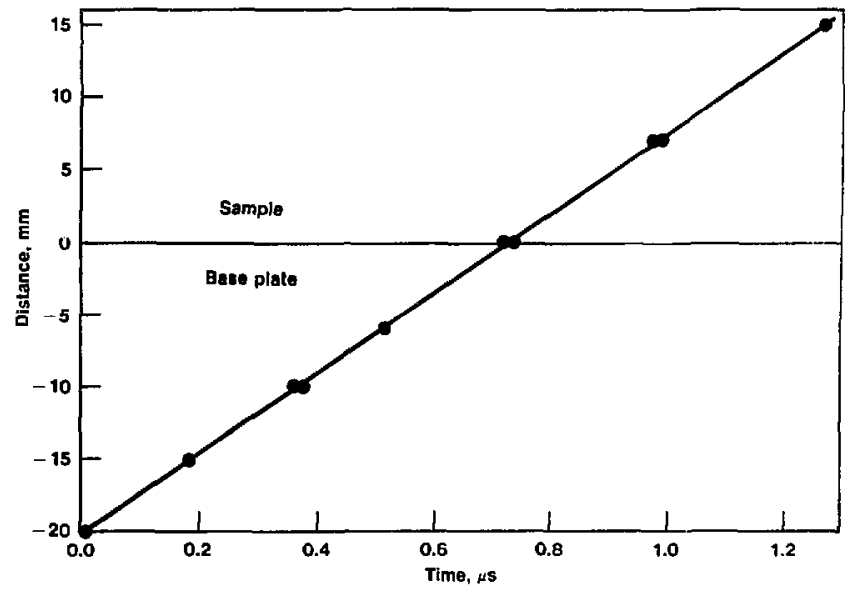




\begin{tabular}{|c|}
\hline DF FFNSF PROGRAMS \\
1t!han tPplation, \\
ENERGY PROGRAMS \\
WORK FOR OTHERS \\
\hline
\end{tabular}

Photograph of $B 83$ impact test unit landing on a rigld stesl plate in a drop teat. These drop teste were designed to produce major etructural damage and or fallures to defino and, where possible, improve bomb capabillty. The BB3 is the firet laydown bomb deaigned to survive Impact on structural hard and irregular targets. The bomb case and ather specific components undergo gross deformation, enabling the nuclear syutem and bomb eloctrical aystem to remain functicnal.
B 83 and W84

Tivo LLNL/Sandia National laboratories weapon

development programs passed a najor nilestone in September 1983. The B83 modem strategic lomb and the W84 warhead for the ground-launched cruise missile (GLCM) entered Department of Energy (DOE) weapon program Phase 6 (quantity production).

B83. The $B 83$ is a new high-yield stategic bomb that is intended to replace a number of versions of the much older B28 and B43 bombs, It will be carried primarily on SAC aircraft: the B-52C (replacing the B28), the FB-111 (replacing the B+3), and the new B-1B. The B83 provides major improvements in nuclear and high-explosive sofety, economy in the use of special muclear materials, and significant increases in operational reliability and nexilility.

The $B 83$ incorporates the full range of fuzing options, including free-fall airlurst, (parachute) retarded airburst, and free-fall groundburst, but its primary delivery modo is (parachute) retarded

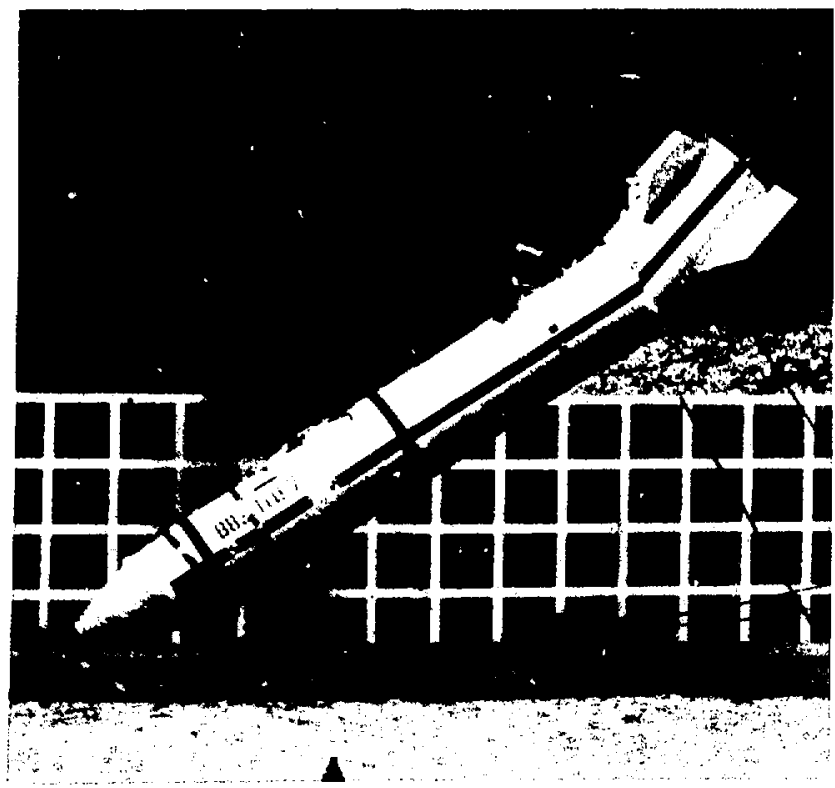

delayed groundburst (laydown). The retardation system and the structural design of the B83 permit delivery from altitudes as low as $45 \mathrm{~m}$, minimizing the vulnerability of delivery aircraft to defensive measures and allowing full use of aircraft capabilities. The bomb is designed to survive impact velocities in excess of $30 \mathrm{~m} / \mathrm{s}$ with detonation delayed 40 to $120 \mathrm{~s}$ to allow safe escape of the delivery aircraft.

The $B 83$ is a lineal descendent of the $B 77$ high-yield bomlo. Phase 3 development engineering of the $B 77$ was assigned to LINNL/Sandia in April 1974. The progran was canceled on cost grounds in December 1977 and reinstated in January 1979 as the B83, which incorporated a simpler retardation and electrical system. The basic nuclear design was developed during the B77 program. Much of the nuclear testing was completed during the accelerated high-yield test program in 1975-1976 and during a windup phase of the B77 program in 1978. Aclievement of the yield, material economy, and flexibility required a number of innovative design approaches that have now become standard modern design technology.

The B77/B83 was the first system to enter development engineering with a commitment to the use of an insensitive high explosive (IHE). Following initial work at Los Alamos, we developed and thoroughly characterized a TATB-based explosive, comlsining the inherent insensitivity of TATB to the thermal and mechanical stimuli of potential accident situations with initiability and mechanical properties suitable for a weapon that must function over a wide range of thermal and mechanical environments. Successful hydrodynamic and nuclear test programs have played a major role in making IHE and IHE implosion systems part of standard DOE weapons technology.

The $B 77 / B 83$ is the first laydown bomb designed by LLNL/Sandia and the first bomb designed, from the start, to survive impact on structural hard and irregular targets. Normally, weapon design aims to avoid even incipient yielding of structural elements. Design for laydown survivability, however, is 
somewhat analagous to designing an automobile to crush progressively in an accident while maintaining the integrity of the passenger compartment. The bomb case and other specific components can undergo gross deformation, enabling the nuclear system and bomb electrical system to remain functional. The B77/B83 program has both stimulated and benefited from the development of the finite-element structural calculations that accurately model large deformations in two- and three-dimensional geometries. The test program that evaluated and certified the structural capabilities of the bomin also has a novel orientation. Using rigid stee] plates and rigid steel bats as targets, the drop program was designed to produce major structural damage and/or failures in order to define and, where possilble, improve bomb capability (see figure).

The $B 83$ is a complex system; substantial Livermore effort will continue to be required to monitor production quality, simplify production processes, and initiate the quality-assurance evaluation of new production and stockpile weapons. Our past ten years of effort have produced major advances in nuclear design and in IHE and mechanical-design technology. They have provided the Air Force with more capability than any previous bomb and with the ability to use the full capabilities of our present and projected bombers.

W84. Responsibility for Phase 3 development engineering of the W84 warhend for the ground-launched cruise missile was assigned to LLNL/ Sandia in October 1978. The GLCM is a ground-mobile tactical nuclear system, to be based in NATO countries, that provides survivability, accuracy, and the capability to strike fixed theater targets with nuclear weapons. The W84 is carried in a derivative of the Tomahawk missile. Four missiles are carried and launched from a mobile transportererector-launcher (TEL); the dispersal capability of the mobile TEL and launch control center (LCC) enhances prelaunch survivability.

The design and evaluation program has been guided by the special requirements placed on a forward(theater-) based system. These include the second Livermore use of an IHE implosion system and enhanced weapon control capabilities. The compact warhead packaging has required an unusual degree of synchronization of innovative physics and engineering design, which has been validated by an extensive nuclear, hydrodynamic, functional, and envirommental test program.

The WS4 program has generated many spitt-ofs, muging from major improvements in weapon control technology to new standard approaches to mechanical support of an IHEE implosion systen. Perhaps the most farreaching development has been the mechanical safe and arm device (MSAD), a multistage detonator that is normally stored with critical explosive components out-of-line; arming requires a unique mechanical signal (generated by a unique electrical signal). The MSAD serves as a nuclear-safety strong link, integral with the implosion system, that cannot be bypassed. The use of an MSAD initiation system provides nuclear system safety independent of any conventional strong links in the firing system and assures the safety of even a bare nuclear system sulijected to arbitrary electrical inputs (such as lightning). An extensive test program has demonstrated MSAD integrity (and safety) under extreme environments in which the nuclear system would be functionally destroyed.

The MSAD has become the new baseline for initiation and safety in LLNL weapons.

W84 production is supporting the required initial operational capability schedules for GLCM system deployment. Continuing LLNL efforts are required to assure early production quality, assist in developing improved fabrication techniques, and establish initial postdevelopment, nuclear-system qualityassurance testing.

Key Words: Lomb-laytown, strategic; B28; B43; BT; 883; ground-lameled cruise missile (GLCM) insensitive high txplosive (JHE); mechanical sofe and arm device (MSAD); W84. 


\section{DEFENSE PROGRAMS}

Military Applications

ENERGY PIROGRAMS

WORK FOR OTHERS

\section{Trategic Penetrator Weapons}

As potential strategic targets become harder or go underground, they become less vulnerable to air shock and more susceptible to destruction by ground shock or cratering. Superhard silos for intereontinental ballistic missiles (ICI3Ms) can probably be huilt to survive air shock jusi heyond the crater radius of systems like the Peacekerper (MX) missite. A warhend that com penetrate soil, soff rocks, or ite (in polar regions) would weigh more then a regular starheas, but detomation helow the surface improves the efficiency of energy ontupling to the ground by a factor grenter than ten.

Under the build-dowst proposed in the START arms negotintions, it would become important ? achiave high singleshot kill probabilitie, that is, to colstain maxinum military efiectiveness within a constraint on the total number of warhends. Earth-penetrating warheads can do this, even if missile accuracies are not improved beyond current capability. Penctriting weapons alsn can mitigate cerlain global collateral effects of a mudear exchange; a weapon detonated heneath the surface would be much less likely to start fires than the same weapon detomated at or ahove the surlace.

Because of tiveir potential for providing addtitional capability to our strategic forces, we are pursuing a program to investugaie atesign limits and the military utility of such earthpenetrating weapons. During the past year we have:

- Optimized the warhead design of s shock-hardened nuclear penetrator werpon.

- Devoloped (wilh Sandia National L aboralories) a stod penedrator case ant lested it to alrout $8(0)\left(1 . \mathrm{m} / \mathrm{s}^{2}(8(1) 0(1)-g)\right.$ decoleration.

- Reassesised cratering and hard-silo vulnerability using computer simulations.

- Identified reontry babicle/missile systems that could meet the requirements for destroying high-priority underground targets.

These efforts have also contributed to the U.S. assessments of Soviet threats to the suprithard silos uncter study for the Peacekeeper and new small ICBM missiles.

Key Words: cratering; hround shock; mistile-

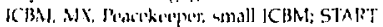
negeliatiens: neperharet silo: warluend-earth. penetratings. 
P eacekeeper Warhead We were assigned the responsibility for the development of the W87 warlead, for deployment in the Peacekeeper (MX) missile, in February 1982. The Peacekeeper is a four-stage intercontinental ballistic missile designed to modernize the U.S. ICBM force and is significantly advanced over the existing Minuteman missile in range, accuracy, and payload capability. It is planned to carry ten independently targetable Mk21 reentry vehides, ench containing a W87 warhead, over ranges grealer than $8000 \mathrm{~km}$. Thus, the W87 wartead will become an inportant part of the U.S. strategic deterrent.

During the past two years, we have completed work on the warhead design and have logen the production engineering phase of the work. An extensive joint Department of Energy/
Depnitment of Defense (DOE/DOD) test program to validate the $W 87$ warhead and the Mk2l reentry velnicle is now !nder way. Five test flights of the missile have already taken place (see figure). The first lest flight of the mock W87 warhead and Mk21 reentry vehicle occurred on the fifth missile test. Informalion received to date indicates that the Mk2l reentry vehicle performed very well.

Meanwhile, we are conducting viloration, shock, thernal, and nuclear. environment fests of lhe warthead and its components, Most of these tests will be compleled within the next year. We also ne working closely with the DOE production plants where the production engineering work and the tool and gauge procurement ate under way. $L$

Key Words: missile-MIX, Peacekenerer; reentry' rehiclt-Nk21; w87.

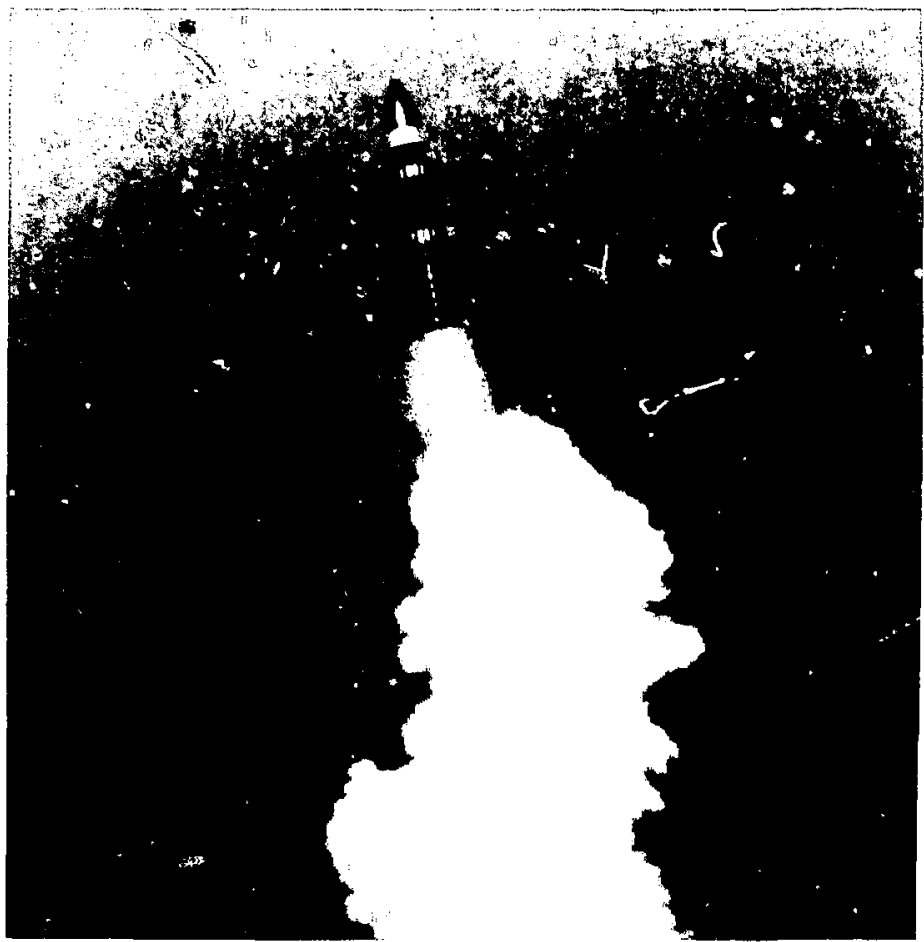

The successful second test flight of the Peacekeeper (MX) missfle from Vandenberg Air Force Base in California. The missile delivered six unarmed test reentry vehicles to the Kwajalein Mlssile Test Range $7600 \mathrm{~km}$ away; the flight took about 30 minutss. When deployed (in 1986), this misuile will carry ten Mk21 reentry vehicles, each armed with a W87 warhead. 
I) I I NSI PROXIR A MS

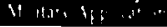

ENERGY PROGRAMIS

WORK FOR OTHERS
W 82 Accomplishments In Congressional comments appended to the 1984 fiscal ycar Defense Authorization Bill, the Department of Defense was directed to terminate its research and development on the W82 artillery-fired atomic projectile. Although no such specific direction was given to the DOE concerning its research and development, the protuction finding for this warliend was elininated by Congress. The DOE therefore has planned to terminate its W82 research and development effort in fiscal year 1984 in concert with the DOD.

In our termination program, we are concentrating on those activities in which we have already made most of our investnient, those that have applications to weapon technolngy in general, and those that are important for preserving the capability to resume the program at some future time if Congress should so direct.

A major activity planned for this year is a series of structural tests in which various mock W82 projectiles are fired virtually straight up and then fall back to earth retarded by a parachute. Upon recovery, the test unit is dismantled and inspected to assess the effects of the high

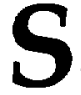

\section{mall Intercontinental} Ballistic Missile

The Presidential Commission on Strategic Forces (the Scowcroft commission) recommended that a small, survivable, land-based intercontinental ballistic missile be developed, and Congress has tied the construction and deployment of the Pearekeeper (MX) missile to this development. The Air Force Ballistic Missile Office has begun a development program for such a missile, to be armed with a single warhead and to be ready for operation in the early $1990 \mathrm{~s}$. We have begun work on the design of the warhead for such a missile.

As presently envisioned, the small ICBM would be carried in a hardened mobile launcher, essentially a heavily armored truck equipped with a mechanism for raising the missile to launch position. Fleets of these launchers stresses of gun launch. Most of these test projectiles were fabricated last year, but the tests were delayed by problems with the parachute recovery system. We expect to complete these tests this year.

We have successfully completed our first series of ballistic firings, in which mock W82 rounds are fired downrange. One of the military requirements is that the W82 should be practically indistinguishable from the conventional M549 projectile in ballistic performance. These early tests indicate that this requitement is heing met.

We have completed groundenvironment vibration tests, and we expect to complete ground-environment shock tests this summer. We have demonstrated the adequacy of several weiipon components and have begun tests of others. Because some of the latter tests involve long-term storage, we will continue low-level maintenance and monitoring of these tests past the end of fiscal year 1984. (Current congressional activities indicate that the W82 program will be reinstated in fiscal year 1985.)

Key Words; artillery-fired alomic projectile; M549 projectile; W82.

would be based at various points throughout the western states, making a potential aggressor's chances of destroying enough of them to prevent a retaliatory attack very uncertain. As a backup, the possibility of basing some of these missiles in superhardened silos atso is being considered.

Techrical considerations as well as public law have set the gross mass of the missile at $13.5 \mathrm{Mg}$. Key issues for the mobile system are safety and security of the warhead, concerns that we will address in our warhead design. In addition, we will participate in studies to assess the survivability of the small ICBM in both forms of basing, mobile and fixed. $\boldsymbol{G}$

Key Words: hard mobile launcher; missile--ICBM MX, Peacekeeper, small ICBM. 
A ntisubmarine Warfare To secure our tactical nava] forces and the undersea leg of the strategic triad from the evolving Sovjet submarine threat, the Navy must maderuize its antisulomarine warfare capabilities. The current inventory of antisubmarine nuclear weapon systems includes the W55 SUBROC, which is launched from a submatine tube, emerges from underwater, and reenters the water to attack a submerged sulmarine, the W44 ASROC, a surfacelaunched antisulomarine missile, and the B57 air-delivered depth boinb. All three systems are approaching olssolescence and will have to be replaced.

We have invested considerable effort analyzing methods to maximize the

\section{dvanced Air-to-Surface Missile \\ We are participating in studies} that may lead to the development of a muclear warhead for an advanced air-to. surface missile. The stated goals for the new missile are reduced size, longer range, and increased accuracy. This missile would replace the aging shortrange attack missile (SRAM) currently carried as a standoff weapon for the B-52 and FB-111 bombers that constitute the airborne segment of the nation's strategic triad of forces.

Specifically, we have developed conceptual designs for the warhead that promote the overall operational value of the advanced air-to-surface missile. The warhead designs include greatly enhanced safety and security features not found in the existing W69 warhead used in the SRAM.

There are several reasons to develop such an advanced missile. Foremost among them, the list of targets to be held at risk by this nation's strategic deterrent is undergoing important revisions. This is a consequence of the hardening of highvalue assets, such as strategic missiles and conmand centers, against blast overpressure and the development of other systems that rely on mobility to ensure survival. In addition, manned effectiveness of our antisubmarine weapons while minimizing collateral damage to our own forces. On the basis of this analysis, we have developed a single common warhead that, with only slight modifications, could meet the requirements of all three missions. Such a common warhead would reduce costs, simplify Navy operations, and reduce stockpile surveiliance recuirements. The new warheads should be avilable in the sarly 1900s. L

Key Wordst B57; surface-launched missilem ASROC; sulmarine-latunched missile-SUBROC; 1144 ; W55.

penetrating bombers will continue to lend important balance to the strategic triad if doctrinal questions can be resolved to permit exploitation of their mission flexilility and the flight crews' initiative. Also, damage assessment of hard targets and aim-point refinement against mobile targets will, perhaps, be best accomplished by advancedtechnology bombers, such as the B-1B, with low radar detectability and equipped with standoff weapons that have flexible trajectory capabilities.

The advanced air-to-surface missile will provide the Air Force with an altitude-penetration-and-return-to-target capability. The enhanced delivery accuracy and various advanced warhead options will give the missile a substantial hard-target capability. In addition, by developing tactics that incorporate advanced sensor technology, it would be possible to exploit the missile's flexible routing to provide the bombers with an effective real-time targeting capability. $\mathbf{t}$

Key Words: aircraft-B-52, FB-111, B1-B; advanced. technology bomber; air-to-surface missile; shortrange altack missile (SR,M).
DEFENSE PROGRAMS

Militar Applications

ENERGY PROGRAMS WORK FOR OTHEIRS 
DDEFENSE PROC:RAMS

Mililan tpplitation:

ENERGY ROGRAMS WOIRK FOIR OTHEIRS
P ropagation of Intense Microwaves through Air We are continuing to investigate, both experimentally and theoretically, the propagation of short, high-power microwave pulses tinrough the atmosphere. $A$ pulse of electronagnetic energy can severely damage a solict-state vlectronic system in various ways, primalily by inducing destructive overvollages, an effoct knower as EMP (clectromngnetic pulse). To assess low meste of a threat a microwave werpon would present to carthbound computers. radar, and communicotions equjpment. we need to know how much energy and peak power con be transmitted through the atmosphere.

We have developed a medinemsional mathematical model that simulates the passoge of a plane-wave beam of nicrowaves through the atnosphere, taking into account such variables as heam intensity and waveform, atmospheric pressure, and ambient frev-etectron density. In passing through the atmosphere, the electric fields of a nicrowave beam accelerate the ambient free electrons. If the field is intense enough, the electrons may bain enough energy to ionize the molecules with which they interact, liberating additional electrons in a cascading avalanche that can absorb significant amounts of energy from the microwave beans.

In our model, we treat the clectrons as a fluid and calculate their sffect on the passing wave by simultoneously solving Maxivell's equations and the clectronfluid equations. These fluid-model calculations show that although large portions of the initial energy are absorled by the avalanching electrons, the main effect is to erode the tail of the pulse; it takes time to get the avalanche started, and during that time an appreciable part at the beginning of the microwave pulse sneaks through to propagate over greal distances. During the past year, we have improved our model to include relativistic effects, binabling us to study very intense heams that accolerate ciections to energies in the neighthorterod of $500 \mathrm{keV}$.

In our concurrent experimental efiotl, we have combuned to stuty the propigation of short, high-power microwave pulses in a section of air. filled waveguide. in our most recent meastu'ements, we have studied, overt a brond pressure range, the energy that short pulses can carry hefore the electron avalanche cuts them off. $B y$ comparing our experiments with the results of the fluid-model calculations, we can evaluate the validity of the montel. !! is of particular interest that the nodel indirectly assumes that most of the electrons in the avalanche reach a Maxwellian enargy distribution. However, it appears experimentally that for very short pulses, this condition may not hold.

Our experimental results lius far agree gualitatively with the modeled prestictions, but it is not yet possible to make a thorough comparison lencause the microwaves in the experiments are not truly nane waves. We are appusaching this difficulty from both sides, designing experimental motifications that will more closely approximate plane-wave propagation and extending the model to the twodimensional case to simulate the nomuniform beams obtained in the laboratory. L

Key Words: computer modeling; electromagnetic pulse (EMI); microwawe-atmospheric propagation. 
in many enclosed systems, it is vitally important to suppres. corrosion reactions among the various $c$ miponents. The main villain in promoing these unwanted chemical reactions is water vapor. We cammot wholly avoid the presence of water, however. Even if we could make soals that were $100 \%$ perfect, lhere would still be the water vaper that is gradually fiven off by some of the materials that must be used in weapon systens. Thus, sone kind of drying agent must be included. Chemical drying agents, useful w., they are, are not suitable for our purnoses. They benc to be heavy and bulky, to have a limited alsorption capacity (they' have to be changed from time to time), and to leave just enough moisture in the air to continue to be troublesome. We therefore undertook a new approach.

The iteal dryer would he small, light, made of inert materials, and have unlimited water-removal capacity. It would consume very little power and continue to function down to a very low vapor pressure of water. It might also be used to measure the remaining water vapor content.

Thanks to the development of a new kind of plastic film, Nafion, we have developed a close approximation of an ideal dryer. "vafion is a Teflon-like perfluoror olymer with a sulfonic acid side chain. The perfuoropolymer part giv'es it the chemical resistance and inertness of Teflon, and the sulfonic acid side chain makes it alssorb and hold water vapor as avidly as concentrated sulfuric acid, ciown to a dewpoint substantially below $-40^{\circ} \mathrm{C}$. Furthermore, the alssorbed water redistributes itself throughout the plastic so that water taken up on one side of an imperneable film migrates to the other.

Nafion also becomes conductive in proportion to the amount of water absorbed, and the current alectiolyzes the water into lydrogen and oxvgen without affecting the plastic. Thus, we have a very good mechanism for concentrating the water vapor from an enclosed volume and converting it into hydrogen and oxygen which can then diffuse harmlessly into the surrounding air.

How good is it? A Nafion film less than $1 \mathrm{~cm}^{2}$ in area can handle about $15 \mathrm{~mA}$ of current, which would dispose of about 27 grams of water per year. The actual amount of water we must dispose of is less than 2 grams per year.

What about maisture from the oulside? To prevent this movisture from saturating the system, we add a thin film of flumesilicone polymer thet is permeable lo lyydrogen and oxygen but not to walen. This allows the electrolysis products to escapes but prevents water from entering.

What about the hydrogen and oxygen that diffuse the wrong way, back into the device? Replacing traces of moisture with an explosive mixture of hydrogen and oxygen may seeni impractical at first glance, but we can avoid the problem by providing a catalytic converter, a thin layer of palladium black, that recombines the gases into water. Then, these water molecules diffuse back to the Nafion membrane where half of them are reieased to the outside and the other half repeat the cycle. This constant partial recycling of the absorbed water reduces the punping efficiency of the microdryer ly haif, but it neatly prevents the accumulation of explosive gases.

For mechanical support, we sandwich the Nafion film between two disks of porous nickel. The result is the chemical analog of a diode, in that it passes water in one direction only. The resemblance to a sweat gland is not coincidental, since this inspired the design.

Built of nickel and inert plastics, the device is quite immune to enviroumental attack. It is small, simole, rugged, and operates at temperatures ranging from -70 to $+100^{\circ} \mathrm{C}$. It indicates the amount of water present by the amount of current it draws, helping us to detect sources of water such as leaks in the outer skin and internal chemical decomposition. The microdryer design recently received the IR-100 award from Industrial Research and Development. Ig

Key Words: microengineering; miniature dryer; Nafion; sensor-moisture. 
DEF INSF PROCIR AMS

Minlare tgf ladtume

ENERGY PROGRAMS

WORK FOR OTHERS
W orld-Wide Effects of a Nuclear Exchange A potentially important consequence of a large-scale nuclear exchange may be a large number of urban and forest fires. If there werc enough of them, their smoke could significantly reduce sunlight for weeks or months, with potentially serious effects on the climate and hiosphere. Recognition of this possibility has spurred considerable 'nterest in slutying the potential glohal-scale physical conseguences of a nuclear exchange, We have conducted an intensive review of stuties undicrway by other groups and have contributed to the research in this subject by applying our capabilities in atmospheric modeling and analysis.

If the smoke reaches high altitudes and is not rapidly scavenged from the atmosphere, a blanket of dense smoke could darken the skies over large areas and substantially reduce the amount of sunlight reaching the surface, leading to cooling. Freezing temperatures in summer, predicted in some calculations, could destroy much plant life. Reduction in light levels could interfere with photosynthesis, slowing the growth of plants. If such effects were prolonged, the resulting disruptions might be severe enough to destroy food crops and severely stress some animal species, leading possilly to some extinctions.

There aie major uncertainties in estimating the magnitudes of these physical and biological effects, arising from the number and variety of the assumptions that must be made. These assumptions include the characteristics of the exchange, the amount of smoke generated, the size distribution of the particles, the composition of the smoke, the heights to which the smoke plumes rise, the rate at which the smoke spreads, how fast the smoke would be removed by precipitation, etc. None of these factors can be predicted with very great certainty.

One aspect of our efforts has been to review the assumptions others have made and to ascertain how important each of these many factors is in determining the resulting climatic perturbation, A second approach has been to recheck independently the ralculations of other groups, accepting the basic assumptions made therein, to determine if their calculated atmospheric responses are generally correct.

Studies using our extensive modeling capabilities, developed over the past decate, indicate that very large amounts of smoke could inteed induce significantly cooler weather, but these motels also contain many traditional assumptions that are appropriate only if the climato perturbations being studied are relatively small. However, because the perturbations we are calculating are large, these assumptions tend to break sown. Thus, it is clear that new and greatly intproved modtels are needed before realistic estimates can be made of the extent and duration of smokeincluced changes in the world's climate.

In addition to consideri. 'o the effects of smoke, we have studied the potential results of other side effects of a nuclear exchange. Among these are gaseous emissions from fires that may lead to photochemical smog, fireball-created nitrogen oxides that can deplete ozone and absorb sunlight, entrained dust that can scatter sunlight, and radioactive fallout. Although estimates of these effects are also uncertain, it appears that none of them is likely to have a more significant hiological effect than the smoke. One possible exception would be regional radioactive "hot spots" that could occur when a rain system scavenges a lot of fresh airborne radioactive debris (rainout), hut these would occur in only limited areas.

We are emharking on a program, coordinated with other research groups outside LLNL, to evaluate the underlying assumptions and upgrade the models used in making these calculations. Our aim is to improve the estimates of all of the atmospheric effects and their possible biological consequences so as to provide a reasonable understanding of the potential effects of a nuclear exchange beyond the combatant nations. $L$

Key Words: atmospheric modeling; climatic change; nuclear exchange-environmental results. 
$\mathbf{T}$ ransition Radiation

When an electron crosses the boundary between two media that have different dielectric constants (e.g., from vacuum into a metal or vice versa), it encounters a rapidly changing electric field. Th: boundary between the two media can be thought of as a mirror, with an image (positive) charge approacling from the other side and meeting the real slectron (negative charge) at the surface. The two charges coming together constitute a collapsing dipole (like an antenna), and the interaction of the electron with the surface entits dipole radiation.

For low-energy electrons, this transition dipole radiation is emitted in a plane at right angles to the direction of motion of the electron. If the velocity of the electron is a significant fraction of the speed of light, the radiation is shifted forward relativistically into a hollow cone whose opening angle is approximately equal to the ratio of the rest mass of the electron to its energy. For high-energy electrons, the opening angle of the cone becomes very small, strongly concentrating the radiation (see figure). Furthermore, if we use as the medium a metal foil of the correct thickness, we can achieve constructive interference between the transition radiation emitted from its front and back faces, greatly enhancing the radiation intensity at a characteristic frequency.

We have performed pilot transitionradiation experiments with high-energy electrons from our electron-positron linear accelerator, using stacked foils of various materials, and have observed transition radiation at energies near $1 \mathrm{keV}$ (soft $x$ rays). The foil materials used included beryllium, carbon, magnesium, and aluminum. The energies of the electrons were about 17,25 , and $54 \mathrm{MeV}$ (approximately 34,50 , and 108 times the electron rest mass, respectively). In these experiments, we were able to measure variations in the intensity, energy spectrum, and angular distribution of the radiation as we varied the experimental conditions. Preliminary analysis of these experimental results indicates excellent agreement with our theoretical calcul: tions, giving us great confidence in our interpretation of the data.

Because the radiation is so intense and forward-directed, it shows great promise as a copious source of soft $x$ rays for a number of important practical applications. One application of particular importance to Laboratory progran's is the calibration of $x$-ray detectors. A possible application of conmerciai and industrial value is $x$-ray lithography of semiconductor materials. In conventional methods of microchip manufacture, visible or ultraviolet light shining through a lithographic mask transfers the intricate designs to the photoresist to produce microcomputer circuitry. A major limitation on the size of individual lines and components, and hence on the number and complexity of the circuits that can be printed on a single chip, is the wavelength of the light used. $X$-ray lithography has long been pursued as a way of making ever smaller circuit elements, but the failings of conventional $x$-ray sources have made it impractical. The intensity and monochromaticity of the transition radiation we have observed suggest that the ideal source may have been found. $L$

Key Words: linear acceleralor; transition radiation; x ray-delector, lithography; soft.
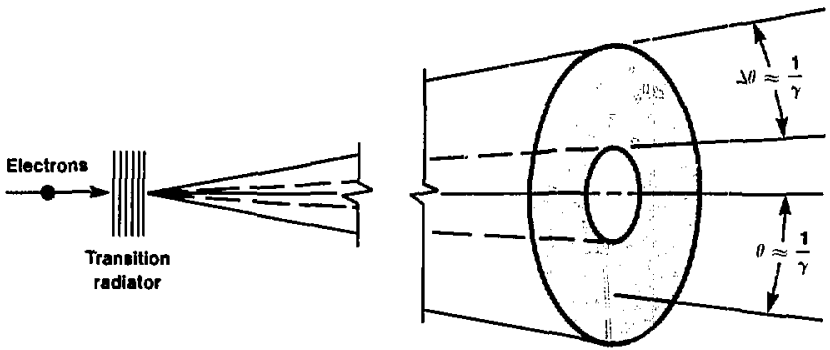

The cone of transition radlation produced by an electron passing through a s.ack of metal foils in vacuum. The opening angle of the cone has been greatly exaggerated for clarity. For 50-MeV electrons, the opening angle $\theta$ and the variation about the opening angle $\Delta \theta$ are both about $10 \mathrm{mrad}$. (1/q is the ratio of the rest mase of the electron to its energy.) 
$\mathbf{N}$ ova Laser Facility The Nova laser facility will provide fusion researchers with a powerful new tool for studying nuclear weapon physics and inertial confinement fusion. Nova is a Congressional line-item project; construction will be completed by the and of October 1984. Following a short activation period, we will begin significant target experiments early in 1985. Nova will consist of ten beams able to concentrate 100 to $150 \mathrm{~kJ}$ of energy in $3 \mathrm{~ns}$ and 100 to $150 \mathrm{TW}$ of power in 100 ps upon experimenta] targets, and will provide irequency conversion of the fundamental laser wavelength $(1.05 \mu \mathrm{m})$ to its second and third harmonics $(0.53$ and $0.35 \mu \mathrm{m})$.

Currently, eight of Nova's ten beams have been conpletely assembled and test fired at about one-half power through the $20-\mathrm{cm}$ aperture stages (midway through each laser chain). Installation of the final aperture amplifiers has begun, and four beam lines are completely installed. The target chamber has been installed and aligned and has been certified for high-vacuum operation (see figure). We have also begun assembly of the frequency conversion components and the target focusing apparatus. Nova's ancillary subsystems (controls, power conditioning, alignment and diagnostics, data handling) are functional and will be completed simultaneously with the laser system. Two of Nova's beams have been operating for more than a year in the Novette experimental program. These beam-line components will be installed in Nova during the summer of 1984.

On the basis of our experience with Novette, we predict Nova's peak output at $0.35 \mu \mathrm{m}$ to be $70 \mathrm{~kJ}$ in $1 \mathrm{~ns}$, completely consistent with Nova line-item specifications ( 40 to $70 \mathrm{~kJ}$ in $3 \mathrm{~ns}$ at $0.35 \mu \mathrm{m}$ ). With Novette's demonstrated performance at 1.05 and $0.53 \mu \mathrm{m}$, we are confident that Nova's operating points will fall within the line-item specifications of 80 to $120 \mathrm{~kJ}$ in $3 \mathrm{~ns}$ at $1.05 \mu \mathrm{m}$ and 50 to $80 \mathrm{~kJ}$ in $3 \mathrm{~ns}$ at $0.53 \mu \mathrm{m}$.

Our initial experiments with Nova will be directed toward studying the physics of high-gain targets (that is, targets that produce significant

thermonuclear energy). These

experiments will evaluate potential fluid physics issues associated with fluid instabilities, mixing, symmetry, and center spot ignition. We will use Nova to verify our implosion calculations by using scale models of these targets. With Nova, we expect to show that the laserplasma interaction over scale lengths of interest for high-gain targets (about $1 \mathrm{~cm}$ ) is well controlled, that the ablation pressures and efficiencles are consistent with the requirements of high-gain targets, and that the compression reguirement of 1000 times liquid density is compatible with fluid physics.

Key Words: high-gain target; inertial confinement fusion; laser-Nova, Novetle.
IDFIFNSE PRC)(;RA NIS Inerlai l unt nem, nt I U

ENERGY PROGRAMS WORK FOR OTHERS
The Nova target chamber in tio carly stages of installation. The terget chamber has now been Installed, sligned, and certlfied for high-vacuum operation. Construction of the entire Nove laser facility $w \mid l l$ be completed in late October 1984 and experimentation wIII begin early in 1985.

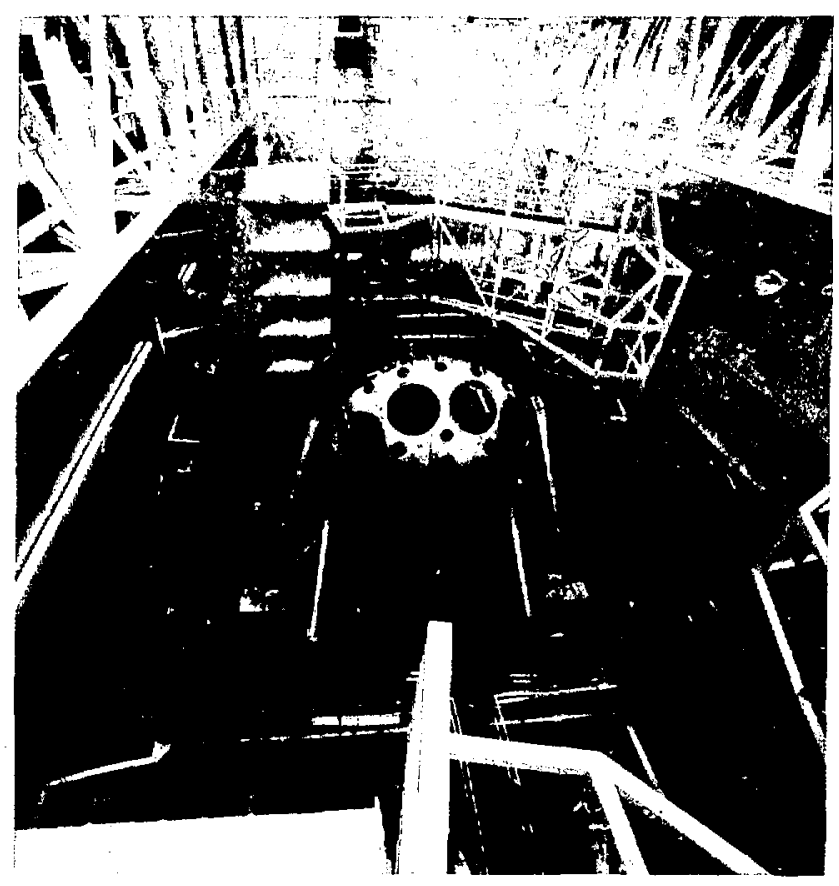


S ol-Gel Coatings

The high-energy fusion-research lasers at LLNL contain a great number of transmitting optical elements such as lenses and windows. The power output of these solid-state lasers often is constrained by the fact that optical components are subject to damage by laser light. Antireflection surfaces are especinlly critical components because, typically, they receive the highest fluence loading of all surfaces in the laser amplifier chain and have the lowest damage threshold.

To create antireflection surfaces, the neutral solution process was developed by Schott Glass Teclnologies, Inc., for use on the Novette and Nova lasers. In this process, changes in reflectance are produced by acid attack of the surface of the optical component by neutral or weakly alkaline solutions of salts. A finely porous, low-index layer is formed by the competing processes of partial leaching and total dissolution, giving the surface layer a smoothly graded index of refraction and consequently very low reflectivity. Although this process is quite satisfactory for the homogenous borosilicate-glass laser components, it cannot be used on the fused-silica optical components required by Novette and Nova to operate at $0.35 \mu \mathrm{m}$. (Fused silica is the only material presently capable of transmitting the high-intensity $0.35-\mu \mathrm{m}$ laser pulses.)

To make antireflective surfaces on fused-silica optical components, we have developed coatings of porous silica using the sol-gel process. This process consists, in general, of polymerization of a viscous liquid sol of alkoxysilane with other metal alkoxides or metal salts in alcohol solutions to form a transparant gel. Our coatings are derived by conversion of tetraethyl silicate to silica by hydrolysis and condensation. Two different types of coating are possible depending on whether an acid or a base catalyst is used.

Initial development of the acid-catalyzed process was done by Westinghouse Research and Development Center. The hydrolysis reaction proceeds through the formation of an organosilane polymer intermediate. The coating is applied by dipping the fused-silica surface in this intermediate polymer. The thickness of the coating is controlled by the viscosity of the siloxane polymer and the rate of withdrawal of the substrate. The coating is dried and subsequently degraded to porous silicon dioxide by sintering at $450^{\circ} \mathrm{C}$. The porosity of the coating is increased and the refractive index reduced by etching with hydrofluoric acid until it becomes antireflective. This acid-ratalyzed sol-gel coating has demonstrated laser damage thresholds well above the $5 \mathrm{~J} / \mathrm{cm}^{2}$ required by Novette and Novn for 1-ns pulse operation.

The second sol-gel process uses a base catalyst. In this case, the hydrolysis reaction is favored over condensation, and a colloidal suspension of silicon dioxide particles is fonned instead of the intermediate siloxane polymer. This reaction nas been used by others to produce silica particles with diameters of 0.5 to $2 \mu \mathrm{m}$. Because of their large scattering losses, such large silica particles are unsuitable for antireflective coatings for ultraviolet light. However, we have discovered that by using small quantities of water and high concentrations of ammonia, we can produce a colloidal suspension of silicon dioxide with particle sizes in the $0.05-\mu \mathrm{m}$ range. The coating is applied by dipping the fused-silica surface into the silicon dioxide colloid; no subsequent heating or acid etching is required to produce the antireflective coating. This base-catalyzed sol-gel coating thus opens the possibility of directly coating the potassium dihydrogen phosphate (KDP) crystals used to frequency convert the laser light to its short-wavelength harmonics. Direct coating of the KDP crystais would eliminate the need for the complex cells filled with indexmatching fluid contained by thick fused-silica windows. $b$

Key Words: antireflection conting; fused silica; laser-Nova, Novette; potassium dihydrogen phosphate (KDP); sol-gel process. 
DEFENSI PIROCRAMIS Inerlial cunfinement lusion

ENERGY PROGRAMS WORK FOR OTHERS

The Cascade concept for converting inertially confined fuslon energy into chamber rotates along its horizontal axis, fusion fuel pellets are injected from one end at a rate of five per sec. ond. Laser or ion beams ignite and compress the tuel pellete. Solid gran. ules of $\mathrm{Li}_{2} \mathrm{O}_{1}$ about the size of sand grains, are injected tangentially through each end of the chamber and are hold against the chamber wall by its rotation. As they cascade axlally from the ende of the chamber to the center, they absorb heat and breed tritium ss they are exposed to the fusion reactlons. At the center, they are ejected into a stationary granule calcher; after heat and trillum are exiracted from the granules, they are reinjacted into the chamber. electrical power. As the football-shaped

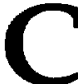

\section{ascade}

A centrifugal-action, solid-

blanket reaction chamber called

Cascade is one of the most recent and promising concepts for converting inertially confined fusion energy intu electrical power. $A$ key advantage of the Cascade reactor is its increased safety; insteat of the liguid lithium called for in olher fusion reactor concepts, raising potendial safety problems, Cascade uses granules of solid lithitum oxide $\left(\mathrm{l}_{2} \mathrm{O}\right)$ to breed tritum. Designed is produce $1 \mathrm{GW}$ of electrical power, the Cascade reactor offers improved power-plant efficiency, the high outlet temperature of the $\mathrm{Li}_{2} \mathrm{O}$ granule blanket $(1200 \mathrm{~K})$ making feasible the use of helium gas turbines.

In the Cascade concept, a football. shaped chamber rotates along its horizontal axis (see figure) at about thirty revolutions per minute. A vacuum is maintained inside the chamber, and fusion fuel pellets, each with a nominal yield of $600 \mathrm{M}$ ], are injected horizontally from one end at a rate of five pellets per second. Liser or inn beams are used to compress and ignite the fuel pellets.

Solid granules of $\mathrm{Li}_{2} \mathrm{O}$, about the size of sand grains, are injected tangentially through each end of the chamber at shout the same peripheral speed as the granules inside the cliamber. The granules, held against the wall of the chamber by its rotation, cascade axially from the ends of the chamber to the

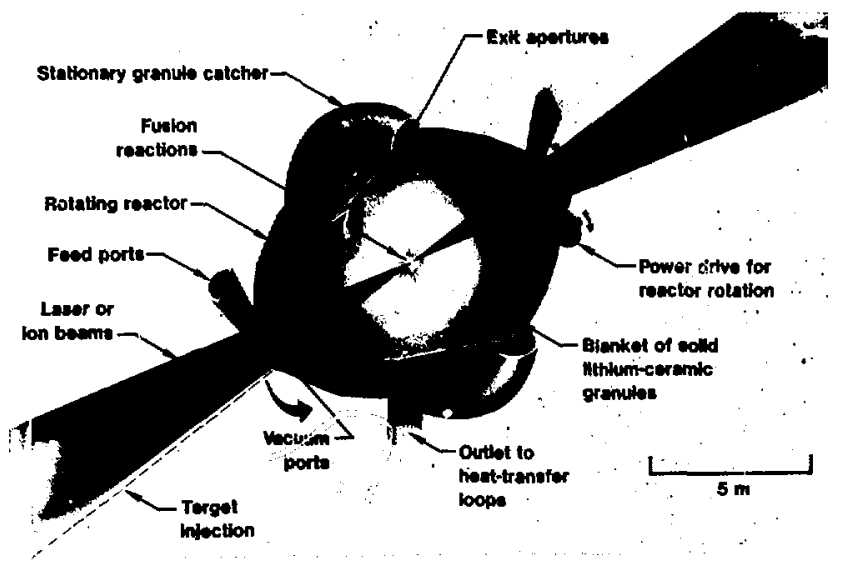

center, where they are ejected through apertures into a stationary granule catcher. Heat and tritium are then extracted from the granules, after which they are reinjected into the chamber. $A$ constant blanket thickness (of about $1 \mathrm{~m}$ ) of the loosely packed $\mathrm{Li}_{2} \mathrm{O}$ granules provides prolection of the chanber wall from the high-energy neutrons generated during the fusion process. lithium oxite was selected for its very high tritium breceding ratio of about 1.4 , although other solid brecders (such as $\mathrm{LiAlO}_{2}$ with a ratio of about 0.9) also can be used if neutron multipliers are incorporated.

We calculate that the Cascade reactor chamber will expertience only low to moderate stresses during operation. Shock-wave propagation to the chamber's structural wall resulting from the deposition of $x$ rays, debris, and neutrons in the solid $\mathrm{ij}_{2} \mathrm{O}$ granules will produce only moderate stresses (about $10 \mathrm{M}$ तa). Stresses generated by the weight of the lithium oxide and by rotation of the chamber itself are calculated to be only $8 \mathrm{MPa}$. These low stresses allow considerable flexibility in the design of the chamber wall. Presently available steel may be used with nominal external cooling, or more exolic materials such as silicon carbide ma) be used without external cooling.

Our recent work has focused on optimizing the Cascade reaction chamber-its radius, wall thickness, blanket outlet temperature, etc. Our objective was to design a minimum-sized reaction chamber that can last the entire thirty-year lifetime of the power plant and can be built with present-day materials and manufacturing techniques. As a result of this study, the revised Cascade chamber volume is reduced to $50 \%$ and the blanket volume to $60 \%$ that of the originai concept. In turn, this reduces the vacuum pumping and cooling requirements, tritium inventory, heat loss from the chamber, and cost. This confirms our belief that the Cascade concept is an exciting new design for safe and efficient reaction chambers for future commercial fusion-power generation. $\mathrm{b}$

Key Words: Cascade concept; incrtial confinement fusion (ICF); reactor-breeder, fusion. 
$\mathbf{P}$ hotoconductive Switches Pulse shaping is becoming increasingly important to extract nuximum energy from the anplifiers on the Nova laser. $A$ key component of the electrical pulse-forming networks usert to drive the Pockels cells that shape the laser optical pulses is a silicon photoconductive switch, which consists of a block of highly resistive semiconductor material with contacts at two ends (sere figure). Because of its high resistivity, this block of semicontuclor conducts very little current and acts as a normally open circuit switch. The switch is tumed on (closed) by illuminating the block with laser light, which generates the charge carriets in the semiconductor.

Using our seniconductor processing technology, w'e have faloricated silicon switches measuring about 3 by 6 by $0.25 \mathrm{~mm}$ that can stand off more than $10 \mathrm{kV}$ when turned off and generate electrical pulses with 100-A peak currents and less than 100-ps rise times when switched on by a short laser pulse. Our switches require less than $150 \mu \mathrm{J}$ of light energy to turn then on. Pulse lengths of several hundreds of nanoseconds have been achieved using light pulses shorter than 1 ns, which is extremely useful in our work. Our best switches have achieved an off-resistance of greater than $500 \mathrm{k} ?$ and an on-resistance of less than 152. These switches are smaller and their rise times are faster than other similar electrical components, such as a silicon controlled rectifier. We selected silicon because of the long lifetime of its carriers.

Although conceptually very sinzple devices, there are a number of complex problems associated with the $10-\mathrm{kV}$ photoconductive switches. For example, making good contact to a highly resistive material is not a trivial task. Past experience has shown that charge injection at the contacts can cause the leakage currents of these switches to be orders of magnitude higher than would be expected theoretically. We have found that the introduction of very minute amounts of gold by thermal diffusion (less than $1 \mathrm{ppm}$ ) substantiaily reduces this leakage current. However, the introduction of gold also decreases the carrier lifetime in silicon, causing substantial decay of the electrical pulse that is generated.

We have solved this problem of the trade-off between leakage current and carriet lifetime by locally diffusing gold just at the contacts. IVe have been able to reduce the leakage current to almost its theoretical value with carrier lifetines two and a half times higher than was possible with earlier, tuniformly gold-diffused switches. We are now experinenting with olher techniques of reducing current injection, and therefore leaknge current, that hold promise of achieving even higher carrier lifetimes.

We have also fabricated gallium arsenicle photoconductive switches for applicalions where rapict decay of the electrical pulse is needed. Gallium arsenide, because of its much shorter carrier lifetime, produces fast-turn-off switches. Turn-off times of less than 1 ns call be achieved, ts

Key Words: pulse shaping-electrical, laser optical; phonoconductive strilch; laser.

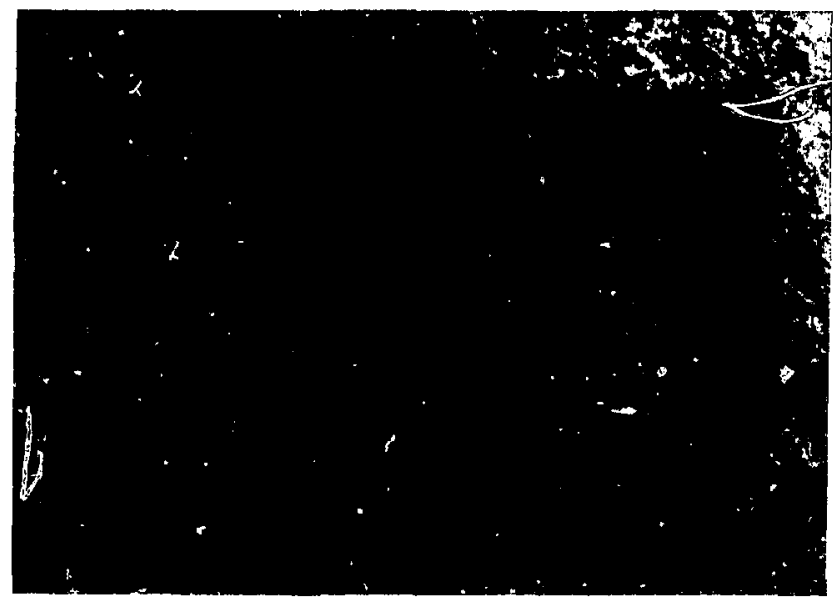

The 10-kV ailicon photoconductive switch used in pulse-shaping networks on the Nova laser. The awitch measures about 3 by 6 by $0.25 \mathrm{~mm}$. It can stand off more than $10000 \mathrm{~V}$ when turned off and can pass electrical pulses with 100-A peak currents and less than 100-ps rise times when switched on by a short laser pulse. The switch consists of a block of highiy resistive semiconductor material with contacts at two ends. An oxide coating reduces arcing through the air. 
I)I I NST I'RO(), R A MS

ENERGY PROGRAMS WORK FOR OTHERS
One of the aillcon components of an $x$-ray laser target thowing the flashlamp window, which consiste of a 150-nm slltcon nitride membrane coated with a 120-nm layer of manganese. The x-ray lacer target contains five omiler silicon components sandwiched together. The two outside components contain the flashlamp windowe, the next two loward the center conisin the vacuum windows, and the center component conlains the laser cavity.
- Processing ultrathin $(40 \mu \mathrm{m})$ silicon wafers without breakage.

- Patterning both sides of a silicon wafer with an alignment tolerance better than $1 \mu \mathrm{m}$.

- Constructing knife edges in silicon using anisotropic (directiorial) etching to achieve a knife-edge radius of less than $0.05 \mu \mathrm{m}$ and a knife-edge straightness of better than $1 \mu \mathrm{m}$.

- Constructing freenstanding, thin $(150-\mathrm{nm})$ silicon nitride menibranes capable of withstanding a differential pressure of greater than $10 \mathrm{~Pa}$.

Since wafer fabrication is a batch process, we fabricate many components simultaneously and thus reduce the cost per component. Currently, we can fabricate 12 components on a single, $7.5-\mathrm{cm}$ silicon wafer. We usually process four wafers per run (although as many as $\mathbf{2 5}$ can be handled). Laser program personnel then assemble the silicon components, evaporate the flashlamp material, and perform extensive characterization of the completed laser. $L$

Key Words: laser-target, x-rny: silicon wafer. including:

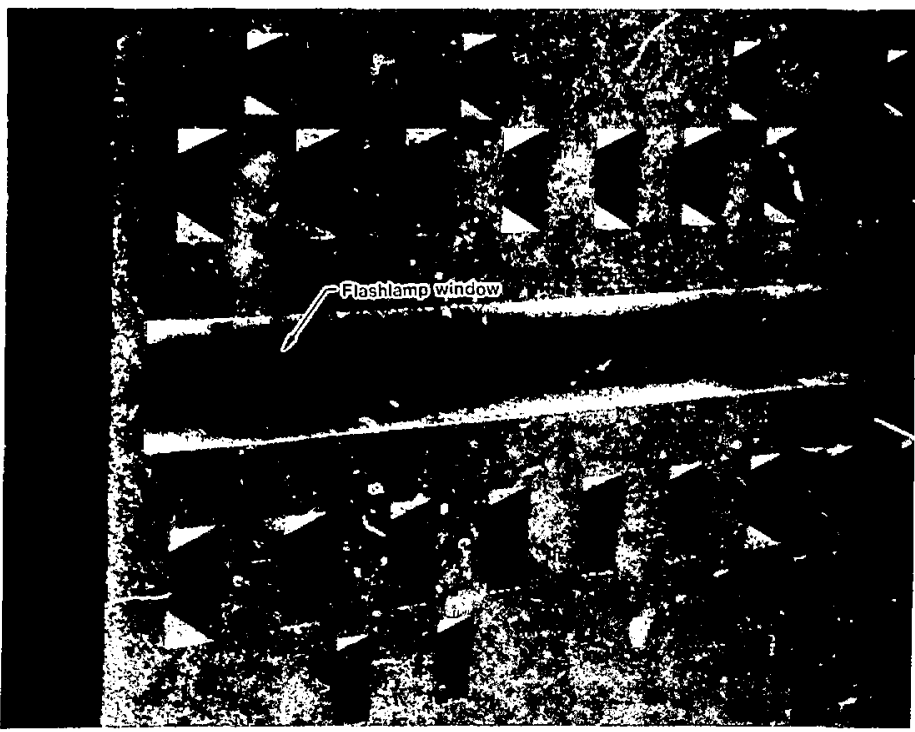


$\mathbf{L}$ aser Isotope Separation

We have made significant progress this year in optimizing the plant design for laser isotope separation (1.IS) of uranium and plutonium isotopes. Work on the separation of plutonium isotopes is supported by the Assistant Secretary for Defense Programs; the uranium-isotope separation effort is funded by the Assistant Secretary for Nuclear Energy.

Laser System Operations. We have been upgrading the SPP-il/Venus laser Facilities with dye lasers, dye amplifiers, and small-bore copper-vapor lasers of the latest technology. In addition, the operations staff has been expanded to support round-the-clock operation, five days a week, and we have been operating in this expanded mode since November 1983 . We recently completed an extended-operation demonstration of plutonium separation in the integrated LIS system that lasted for 150 consecutive hours of trouble-free operation. We were able to maintain all key operating parameters of the lasers throughout the demonstration, and the system returned immediately to full operation when we turned it on two days later.

Copper-Vapor Lasers. We have improved the reliability of copper-vapor lasers and have increased their power storage capability to $250 \mathrm{~W}$, a gain of more than $40 \%$. One of the major factors in this improvement is a scheme for recycling the copper vapor in the liscis and preventing its escape from the active region.

Copper vapor condenses at a very high temperature, far beyond the maximum temperature the ends of the laser can tolerate. Thus, we must avoid overheating the ends while maintaining the required copper-vapor pressure in the working volume of the laser. We do this by placing short, cylindrical metal wicks of a material that is wetted by copper at the ends of the active rcgion where copper will condense on them. The liquid copper then migrates by capillary action back toward the hotter region of the laser, where it evaporates and keeps the laser action going. We have developed a new material for these wicks that greatly improves their performance. With this new coppercontainment scheme, we have completed life tests of more than a thousand hours.

We have also made significant progress in improving the beam quality of copper-vapor lasers. We have inproved the beam optics and reduced the heam divergence by a factor of tell, attaining performance within less than ten times the diffraction limit over the entire laser pulse.

Dye Laser Prototype Facility. We have recently activated our new Dye Laser Prototype Facility. This laboratory, consisting of eight copper-vapor lasers feeding one dye laser for wavelorm generation, will be a full-scale prototype of the equipment to be used in LIS plants for separating isotopes of uranium or plutonium. One use of this facility will be to test plant-prototype dye master oscillator lasers and their controls and the high-efficiency dye-amplifier configurations iefore they are installed in the laser demonstration facility of the Special lsotope Separation Laboratory.

We will be using a recently proven dye-laser pumping scheme that involves transporting light from a copper-vapor laser through opticul-fiber calles. The optical fibers guido the light reliably, eliminating the distortion and refraction that would be caused by transmission through the air. The optical fibers also destroy the coherence of the light, but this is acceptable inasmuch as the pumping light must only be bright enough and of the right wavelength.

Plant Design and A nalysis. Major progress was made this year in understanding pild optimizing the design of an LIS plant. We have written a new design cod's that optimizes the laser architective and gives part counts and costs for a variety of design requirements. This code makes it possible to maximize the use of common Eomponents, thereby reducing the projected capital cost of a uranium LIS plant by hundreds of millions of dollars and ti.e projected operating cost by more than $20 \%$

Key Words: laser-dye, copper-yapor; laser isotope separation (LIS); uranium; plutonium.
DEFENSF PROGRAMS Muclear Mathiala ENERGY PROGRAMS WORK FOR OTHERS 


DFILNSI PROG,RANS
ENERGY PROGRAMS
WORK FOR OTHERS

A comparison of simultenesous selsmomoter records of the vertical groundmotion signal trom the Tomme Event, measured in Tennestes. (a) The signal from the Tennetees station of the Reglonal Solemic Test Network (RSTN). (b) The combined signale from the 13 seiamometers arrayed around the seme RSTN stalion. Eech of the 13 individuel siands looked whe (o), but combining them appropriataly suppreseed the random noive and enhences the signel.
$\mathbf{T}$

\section{7 reaty Verification Research}

During the past year, we designed the layout of a multimillion dollar seismic array to be emplaced in Norway. With an experiment carried out in Tennessee, we also demonstrated some of the advantages of an array over a single seismometer for detecting and identifying the weak seismic signals from a small, distant, underground nuclear test.

A Comprelnensive Test Ban Treaty (CTBT), should one be negotiated, would bar further testing of nuclear weapons in any envirnment. $A$ primary method of verifying compliance with such a treaty twould be by networks of seismic stations, operated by each signatory of the treaty inside the territory of the others. The ability of such an in-country network to detect, locate, and identify clandestine underground testing (and thus to deter it) would depend, among other things, on the characteristics of the stations of which it was composed.

The two general types of station usually envisioned are arrays and singleseismometer stations. An array is a cluster of 10 to 30 seismometers spread over an area from 2 to $10 \mathrm{~km}$ in diameter. The instruments may be either three-component seismometers that measure all components of earth motion or, to save money and satellite transmission bandwidth, simpler seismometers that measure vertical ground motion only. In either case, an array of seismometers should provide significantly better detection, location, and identification capabilities for weak signals, surh as those originating from small, clandestine, underground nuclear tests, by combining the many small signals from individual elements of the array in such a way as to reduce the random background noise.

To test the engineering feasibility and verification capabilities of arrays, we are participating, with Sandia National Laboratories, in a project funded jointly by the Department of Energy and the Defense Advanced Research Projects Agency, numely the development and deployment of a 25-element test array $3 \mathrm{~km}$ across. Designated the Regional Seismic Array System, it will be located in Norway to take advantage of previous

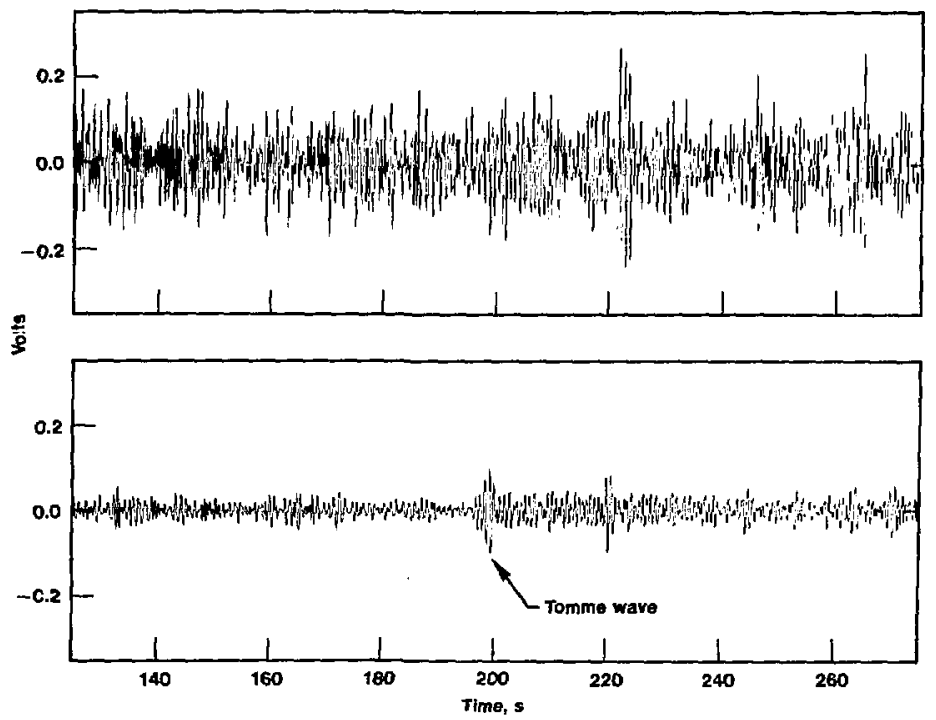


array experience there. The other advantage of the Norwegian location is that the geophysical properties of the region approximate those we would expect to find in much of the Soviet Union.

In a separate but related experiment, we deployed a temporary 13-element array around one station of the Regional Seismic Test Network or RSTN (Energy and Technology Review, UCRL-5200082-11, November 1982, p. 14) to compare its detection, location, and identification capabilities with those of the single station. (A network of such single threecomponent stations is currently planned as the primary seismic monitoring system of a CTBT.) Placing the array around the single station puts them both in the same geologic setting and eliminates any bias that might be introduced by placing them farther apart.

In theory, a network of arrays should give much better performance than a similar network of single stations. Because arrays are so much more expensive, however, it remains to be seen if the realized advantages of the array would justify the additional costs. The figure shows simultaneous records of vertical ground motion produced by the RSTN station and by the array. (Both the RSTN and the array used threeromponent seismometers, but we compared only the responses to vertical motion. We are still investigating the best way of combining the three-component signals from the array for maximum detection sensitivity.) The trace from the array clearly shows the signal from the Tomme Event, a small nuclear test at Rainier Mesa in the Nevada Test Site. In the trace from the single RSTN station, however, the signal is completely obscured by the normal background noise. The 13-element array boosted the signal-to-noise ratio by a factor of three or four, making the signal clearly detectable.

We expect the array in Norway to perform much better not only because it has twice as many elements but also because it has a more favorable location in a geophysical shield area far from background seismic noise sources. (A shield is composed of hard, homogeneous, relatively cool rock. Weak signals characteristic of snall explosions are known to travel with less attenuation in shields than in most other geologic environments.) Arrays like the one in Norway will provide the best available seismic means for detecting, locating, and identifying explosions at distances out to a few thousand kilometres. 5

Key Words: Comprehensive Test Ban Treaty (CTBT); scismometer-amay, single station; Tomme Event. 
I on Implantation Improves Surface Properties

Many metals with desirable bulk properties, such as strength, also have undesirable surface properties. For example, iron rusts, uranium reacts with water vapor, etc. Alloying can improve the surface properties, but it often degrades the desirable bulk properties. Covering the surface with a resistant roating often provides only temporary relief; coatings crack, chip, or peel off, exposing the bulk metal uriderneath to attack.

We are employing a new process for modifying the surface properties of metals without disturbing the bulk: properties. In this process, we accelerate jons of virtually any selected element to energies of up to $200 \mathrm{keV}$ and bombard the metal surface with them, inplanting the ions to depths of 20 to $200 \mathrm{~nm}$. Since the process gives us complete control over the implanted concentration, which we may vary from mere traces to more than $50 \%$, we can produce a subsurface layer very different in composition from the bulk metal. Because the ions are implanted beneath the surface of the metal and become incorporated into its structure, the layers thus formed adhere naturally and have no tendency to chip or peel. Furthermor, since the ion beams are scanned and accelerated electrostatically, we can make the coating completely uniform or give it any desired concentration gradient with deptl.

Precise electronic control over all parameters of the process provides a very high degree of reproducibility.

International interest in the beneficial effects of ion implantation on the surface properties of meials has been expanding rapidly because of demonstrated improvements in friction, wear, and corrosion resistance. Most of the corrosion studies have involved fluids or oxidizing gases. We have concentrated our efforts, to date, on modifying the responses of metals to gases such as tritium, hydrogen, and water vapor.

The permeation of tritium through the iron walls of a reaction vessel is an important consideration in the technology of weapons and of controlled fusion. We have found that we can reduce the permeation rate of tritium in iron at $200^{\circ} \mathrm{C}$ to less than $1 \%$ of its normal value by implanting aluminum tons in the iron and selectively oxidizing the surface to produce a layer rich in alumina $\left(\mathrm{Al}_{2} \mathrm{O}_{3}\right)$. This work represents the first-known use of ion implantation to recluce the permeation rate of a gaseous element.

Water vapor attacks a wide variety of metals, but few as actively as uranium. Adding $10 \%$ by weight of molybdenum produces an oxidation-resistant alloy but undesirably changes the bulk properties of uranium. However, by implanting molybdenum ions, we have produced a surface layer that closely approximates this composition without affecting the bulk properties. In accelerated corrosion studies involving exposure to water vapor at $13 \mathrm{kPa}$ and $80^{\circ} \mathrm{C}$ for 20 hours, this treatment reduced the oxidation rate by a factor of more than 800 .

$A$ other property of uranium is its tendency, when exposed to hydrogen gas, to form a hyciride spontaneously and exothermally. Because uranium oxides are more stable than urar.jum hydrides, we tried implanting large concen!rations of oxygen at room temperature to form a controlled layer of uranium oxide. The implantation significantly reduced the hydriding of uranium at $10 \mathrm{kPa}$ and $130^{\circ} \mathrm{C}$. This is the first time ion implantation has been used to modify the hydriding properties of a material.

We plan to continue these studies to improve our understanding of the mechanisms involved in modifying sultace propertes of metals with ion implantation and to refine the procedures. We also expect to expand the scope of such applications to the modification of other surface-dominated processes. $\mathbf{U}$

Key Words: ion implantation; surface properties-modification.
DFFENSE: PIROCIRAMS 1 aburaturs Revedah

ENERGY PROGRAMS

WORK FOR OTHERS 


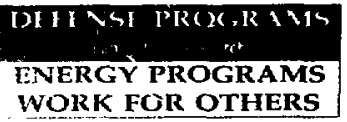

N ew State of Matter Much of our work in theoretical physics centers . around the behavior of "dense" plasmas, matter so hot that its atoms are ionized yet dense and cool enough that it acts like a liquid. Last year, we used our understanding of such plasmas to explain, for the first time, the nature of a new electron "condensate" discovered at Bell Telephone laboratories. We identified this as a new type of quantum liquid, the elementary excitations of which (quasi-electrons and quasi-holes) carry a charge of $1 / 3 \mathrm{e}$. Because quarks, the presumed building blocks of nuclear matter, also have charge $1 / 3 \mathrm{e}$, this discovery may shed light on some of the most fundamental questions of science.

The condensation phenomenon, called th : fractional quan' im Hall effect, occurs in imall electronic devices called heterojunctions. A heterojunction is a sandwich of two semiconductors, GaAs and $\mathrm{Ga}_{1-x} \mathrm{Al}_{x} \mathrm{As}$, fabricated with a new tecinnology called molecular beam ep :axy. The effect occurs at the interface between the two semiconductors.

Electrons are trapped quantummechanically on this interface but are free to move within it. The interface thus finctions as a two-dimensional metal. When a heterojunction is cooled to near absolute zero (about $1 \mathrm{~K}$ ) and placed in a strong magnetic field (about $10 \mathrm{~T}$ ), the electrons at the interface "lock in" at a particular distance from one another, as though they were holding hands. This is the fractional quantum Hall effect.

This effect is observed experimentally in two ways. In the first, as the temperature is lowered, the electrons begin to conduct electricity with no resistive loss, as they do in a superconductor. In the second, the Hall resistance of the electrons becomes quantized. (The Hall resistance is the ratio of the voltage drop across the sample perpendicular to the direction of current flow to the current itself.) In the fractional quantum Hall effect, the Hall resistance is not proportional to the magnetic field strength, as is typical in Hall effect measurements, but is constant over a range of field strengths. The quantized value of this parameter is, to high accuracy, a combination of fundamental constants.

We have advanced the undersianding of this fractional quantum Hall effect in several ways. We have identified the "quantum" measured in these experiments as the charge of the carriers. This point is subtle but important as Hall effect measurements typically are interpieted as measuring the charge Jensity. We have also proposed a good variational quantum-mechanical wavefunction for the ground state and have used plasma techniques to calculate, froni this wavefunction, the proper' es of the state, including its energy and density.

Finally, we have shown, on general grounds, that the quasi-particles of this system have charge $1 / 3 \mathrm{e}$. We have proposed wavefunctions for these quasiparticles from which we have calculated their properties, again using plasma techniques. Quasi-particles are not real particles; the only real particles of the system are the electrons with charge $1 \mathrm{c}$. Rather, the quasi-particles are motions of the fluid as a whole that mimic particle motion; they propagate through the fluid in much the same way as do positive charges (holes) in a semiconductor.

The ultimate significance of the fractional quantum Hall effect is not known. There is speculation that there may be a connection to quarks. The quantum $1 / 3 \mathrm{e}$ in these experiments appears to be "exact," and it is well known that the distinction between particles and quasi-particles becomes blurred in high-energy physics. However, no connection to quarks has yet been found. 6

Key Words: fractional quantum Hall effect; heterojunction; matter-new state; plasma; quark; quasi-particle; solid-state physics. 
$\mathbf{W}$ eighing the Neutrino Neutrinos, produced in radioactive decay, have no charge and (possibly) no mass; they interact so rarely with matter that they pass through the Earth as if it were empty space. The number of neutrinos in the universe is so large (there are at least 100 nillion of them per nucleon) that at a mass even as low as a few electron volts, neutrinos would outweigh the rest of the universe. The gravitational attraction of such a mass would drastically slow the expansion of the universe, perhaps event reversing it into a contraction that would end (billions of years from now) in a Big Crunch, the reverse of the Big Bang.

The existence of the neutrine ivas postulated more than fifty years ngo to preserve the conservation of energy and momentum in beta decay. The neutrino is assumed to be emitted simultaneously with the beta particle, which receives its maximum energy when the neutrino is emitted with zero momentum (standing still). The difference between the maximum energy of the beta particle and the cotal available energy of the nuclear uansformation is exactly the rest energy (mass) of the neutrino. Thus the shape of the beta-particle spectrum, especially at the high-energy end, depends on the neutrino mass.

Neutrinos are also produced when a nucleus captures an atomic electron. A small fraction of such electron-capture events also produces a continuous spectrum of $x$-ray photons, analagous to the electrons emitted in beta decay. Consequently, the shape of the highenergy end of the photon spectrum is also sensitive to the mass of the neutrino,

By far the most common method of attempting to measure the neutrino mass has been to study the high-energy end of the spectrum of electrons produced in the decay of tritium. Until recently, only upper limits for the neutrino mass had been established; the best experimental value was less than $50 \mathrm{eV}$ and might very well be zero. In :980, Sovist researchers reported, on the basis of tritium end-point measurements, not an upper limit but a value of $34 \pm 4 \mathrm{eV}$.
This report stimulated considerable controversy and prompted several new and more refined experiments throughout the world to verify or disprove the Suviet claim.

In 1981, we began a series of experiments focusing on measurement of the photon spectrim from the electroncapture decay of holmium-163. During the past year, we also designed a nextgeneration experiment to measure the and point of the tritium beta-deciny spectrum. We chose these two isotopes because, for a small neutrino mass, the modification to the end-point shape of the photon or electron spectrun will be most pronounced if the amount of energy available for decay (called the $Q$ value) is very small. The decays of both tritium and holniuni-163 have very smiall $Q$ values.

Although at least two other groups are studying the end point of the holmium-163 photon spectrum to measure the neutrino mass, until now there have been no reported results. The figure on this page shows our results for the end point of the holmium-163 photon spectrum plotted from a twoweek accumulation of data from this decay. To make the effects of a neutrino mass more prominent, we have factored out the well-determined underlying variation of the intensity due to nearby characteristic $x$ rays. The black curve through the data is a best-fit determination of the $Q$ value and the neutrino mass. Although with this data, we cannot distinguish the neutrino mass from zero, we can exclude a neutrino mass greater than $180 \mathrm{eV}$. The effect of a neutrino with mass is to cause the data to turn over more rapidiv with increasing mass. To illustrate this, the brown curve

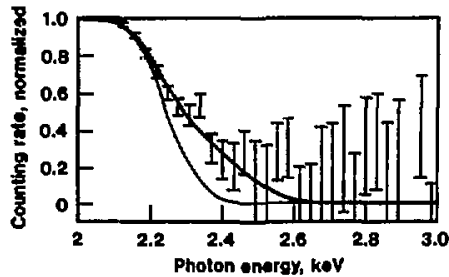

IDFFNSI PR()CIRAMS Iat int? in warch

ENERGY PROGRAMS WORK FOR OTHERS 
IOI I I NSI JRO), R A MS labirate., inc.,

ENERGY PROGRAMS WORK FOR OTHERS

A proposed atomic tritium beta source and a matching wide-angle, highresolution spectrometer for extremely precise measuremunts of tritium's beta spectrum. Eliminating the major difficulties encountered in previous attempls to measure the neutrino's mass, this opectrometer will bo sensitive to a mass as small as $5 \mathrm{eV}$. in the figure shows how the data would appear for a best-fit $Q$ value and an assumed neutrino mass of $300 \mathrm{eV}$. We are continuing with these measurements and are making a more intense source of holmium-163. We hope to be able to either verify or refute the claim by the Soviet group within a year.

Even if the Soviet claim is not verified, it still is not possible to rule out a neutrino mass greater than zero but less than $30 \mathrm{eV}$. Accordingly: our long-range plans include a significantly improved tritium experiment. The limitations of previous attempts to measure the neutrino's mass through tritium beta-decay experiments include pooriy understood solid-state effects in the heta source, insufficient spectrometer resolution, and high background levels. Because a radioactive element can decay not only to the ground state of its dnughter but also to excited states in the atom or the surrounding molecule, a large number of different heta endpoint energies are possible. This greatly complicates the search for the effect of neutrino mass.

One solution to these problems is to use an atomic tritium source to eliminate the complications of molecular excited states. Because the first excited state in the daughter helium-3 ion is at $41 \mathrm{eV}$, a measurement of the last $40 \mathrm{eV}$ of the beta spectrum can determine the neutrino mass free of uncertainties in atomic theory.

We have designed a high-resolution magnetic spectrometer with an atomic tritium source (figure below). The spectrometer would have an energy resolution of about $6 \mathrm{eV}$ in the range of interest and a very large acceptance solid angle. The latter is essential because only one tritium beta particle in ten billion falls in the last $6 \mathrm{eV}$ of the spectrum.

We can reduce the background counting rate by orters of magnitude by accelerating the beta electrons wilh a precisely known electric field immediately after they leave the atomic tritium source. Beta particles from the decay of molecular triticin in other parts of the system would not receive this acceleration. Hence, it will be easy to distinguish the "good" atomic tritium electrons from the "bad" molecular tritium electrons and eliminate the latter from the ? easurement. This new spectrometer $w_{1}$. eliminate the major difficulties encountered in previous attempts to measure the neutrino mass. It will be sensitive to a neutrino mass as small as $\mathbf{5 e V}$. L

Key Words: holmiun-16,3-decny; neutrino-mass, resi energy; $Q$ value; tritium-deciny.

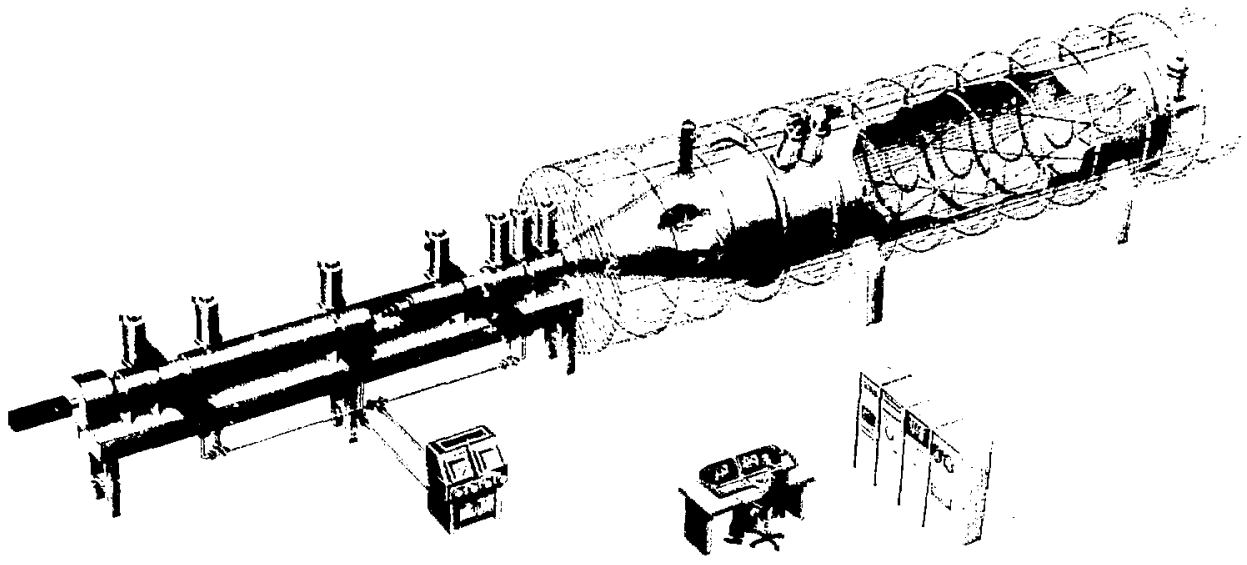


B ar-Code Technology During fiscal year 1983, bar-code trchnology was successfully intraduced at the Laboratory. This project interfaced portable data collection units with computers to achieve significant improvements in manpower usage and the ability to collect data both for operation of the Lalsoratory's Shop Stock storerooms and for managing equipment.

The new data-collection units are intelligent har-code readers that transmit data to Univac and Hewlett-Packard compulers. Buth tane Hewlett-Packardbased Shop Stock system and the Univac-based inventory management system have unique requirements and functions for which intelligent bar-code readers are very useful. The two systems became operational in August 1983.

Storerooms throughout the Laboratory and at Site 300 and the Nevada Test Site employ our Shop Stock system, in which a computer is used to manage storeroom stock. More than 120 areas in the three sites stock more than 15000 different line items for a total of 151000 items, making 154000 issues per year for a dollar value of $\$ 1837000$ and an average inventory of $\$ 662000$.

The renote data-collection subsystem for the Shop Stock system includes a computer code developed for the intelligent bar-code readers and an HP-3000 computer system. This code includes logic for data entry, validation, and transmission in the portable readers, and storeroom pick-ticket generation and inventory management in the host computer. Telxon laser-gun units prompt the material handler to reorder items in a given storeroom area. After the handler reviews the area and reorders the needed items, the information is transmitted to the host computer by telephone. The improvement in manpower usage is estimated at $600 \%$. Other manpower savings de: ive from the automation of pick tickets and the elimination of manual data entry. The Telxon units also provide the material handler with a number of other capabilities, such as generating the necessary transactions for replacing lar-code labels, creating labels for drawer fronts, tracking overstocked items, and adjusting the item-reorder quantity. These all help to reduce the average investment in items in the area shops.

The Univac-based system serves Property Management's program for inventory control of Laboratory equipment. The system uses preprinted har-code property-number labels, handheld data terminals, and laser scanners to inventory more than 120000 equipment items in a cost-efficient manner.

The data terminals are used to collect inventory data in the field for ultimate transmission to the Laboratory's main administrative computer, the Univac $1100 / 81$. The terminals can hold up to 1000 transactions at a time and can transmit them asyncironously over telephone lines. A protocol converter transforms the signal to a synchronous mode for the Univac. Transactions are then applies against the LLNL. equipment file for inventory management tracking.

We expect to complete the retagging of all the Laboratory's controlled equipment items with bar-code labels within two years. L

Key Words: bar-code technology: computerHP-3000. Univac I100/8:; inventory control; Shop Slock system.

I I I I NSI I'IROCIRAMS
labrin
ENERGY PROGRAMS
WORK FOR OTHERS




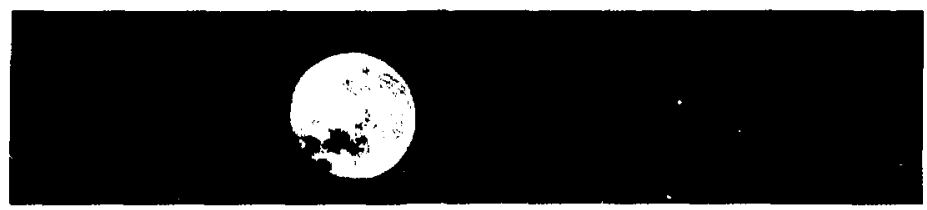

\section{Energy Programs}

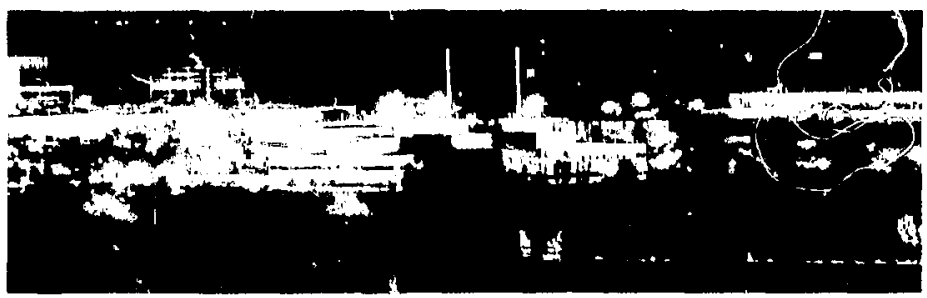

TX-Upgrade

The Tandem Mirror Expcriment-

Upgrade (TMX-U), which began

operation in 1982, is the Laboratory's latest experimental facility for testing the confinement of a plasma by electrostatic and magnetic forces. It is designed principally to demonstrate the thermalbarrier concept to be implemented in the MFTF-B, our large tandem-mirror machine currently under construction (see the following article).

Theory predicts that thermal baniers in the end plugs of a magneticaily confined plasma will improve both its microstability and confinement efficiency by isolating hot end-plug electrons from cooler central-cell electrons. In the TMX-U, end-plug ions are heated by beams of neutral deuterium atoms injected at precisely determined angles, and electrons are heated by microwave generators.

A schematic drawing of the current TMX-U configuration is shown on the bottom of the next page. The plasma, $50 \mathrm{~cm}$ in diameter and $14 \mathrm{~m}$ long, is confined by 24 magnets energized with $26 \mathrm{MW}$ of power. Power is delivered to the plasma by 24 neutral $\therefore$ ims with a total power of $5 \mathrm{MW}$, tw. 200-kW radiofrequency systems, and four gyrotron tubes each producing $200 \mathrm{~kW}$ of microwave power. Plasmas are sustained for as long as $0.1 \mathrm{~s}$.

During 1982, our experiments with neutral beams alone injected end-plug ions with energies up to $20 \mathrm{keV}\left(2 \times 10^{5}\right.$ degrees). As predicted, we observed a substantial improvement in the microst-bility of ions when the beams were iryected at an angle of $47 \mathrm{deg}$ to the magnetic field lines.

During the past year, we added the microwave gyrotron tubes to heat the end-plug electrons to over $100 \mathrm{keV}$ $\left(10^{9}\right.$ degrees). The average electron pressure reached our design objective of $15 \%$ of the magnetic-field pressure (top figure, next page).

Experiments in the summer of 1983 confirmed that the combination of neutral-beam injection and microwaveheated electrons produced the thermal barier we sought, greatly reducing the leakage of ions out of the ends of the device. This winter, we used a novel method to measure the electrical 
potential within the end-plug plasma. A beam of atoms of known energy was injected from the central cell into one of the end-plug regions. As the ions escaped from the opposite end of the device, we measured their energy and determined that the electrical potential within the end plug was depressed by more than $500 \mathrm{~V}$, indicating the existence of a thermal barrier (middle figure). This depression insulates the hot end-plug electrons from the cooler central-cell electrons and creates potentials as high as $2000 \mathrm{~V}$ to confine central-cell ions. Ir contrast, the naximum containing potential achieved in experiments with the old TMX device was $300 \mathrm{~V}$. It is clear that a moderate amount of microwave power enables us to generate large end-plug potentials.

In earlier experiments, the loss of ions along the magnetic field lines proved much more significant than the escape of ions in a radial direction. Having successfully established a thermal barrier that stopped axial losses, we began a series of experiments to reduce the leakage of ions across the field lines. We found that by charging plates at the end walls by 1 to $2 \mathrm{kV}$ negative, we could reduce the radial ion leakage, causing an increase in the plasma density. The negative potential prevents eiectrons troni escaping along the magnetic field lines; since the electrons are held more strongly by the field, they prevent ions from escaping radially.

During the coming year, we will continue to operate the TMX-U in the thermal-barrier configuration. Our primary objective will be to increase the density of the central plasma by increasing the amount of power delivered to it by neutral beams and by radiofrequency heating. $t$

Key Words: magnetic fusion; Tandem Mirror Experinient-Upgrade (TMX U); thermal barrier.
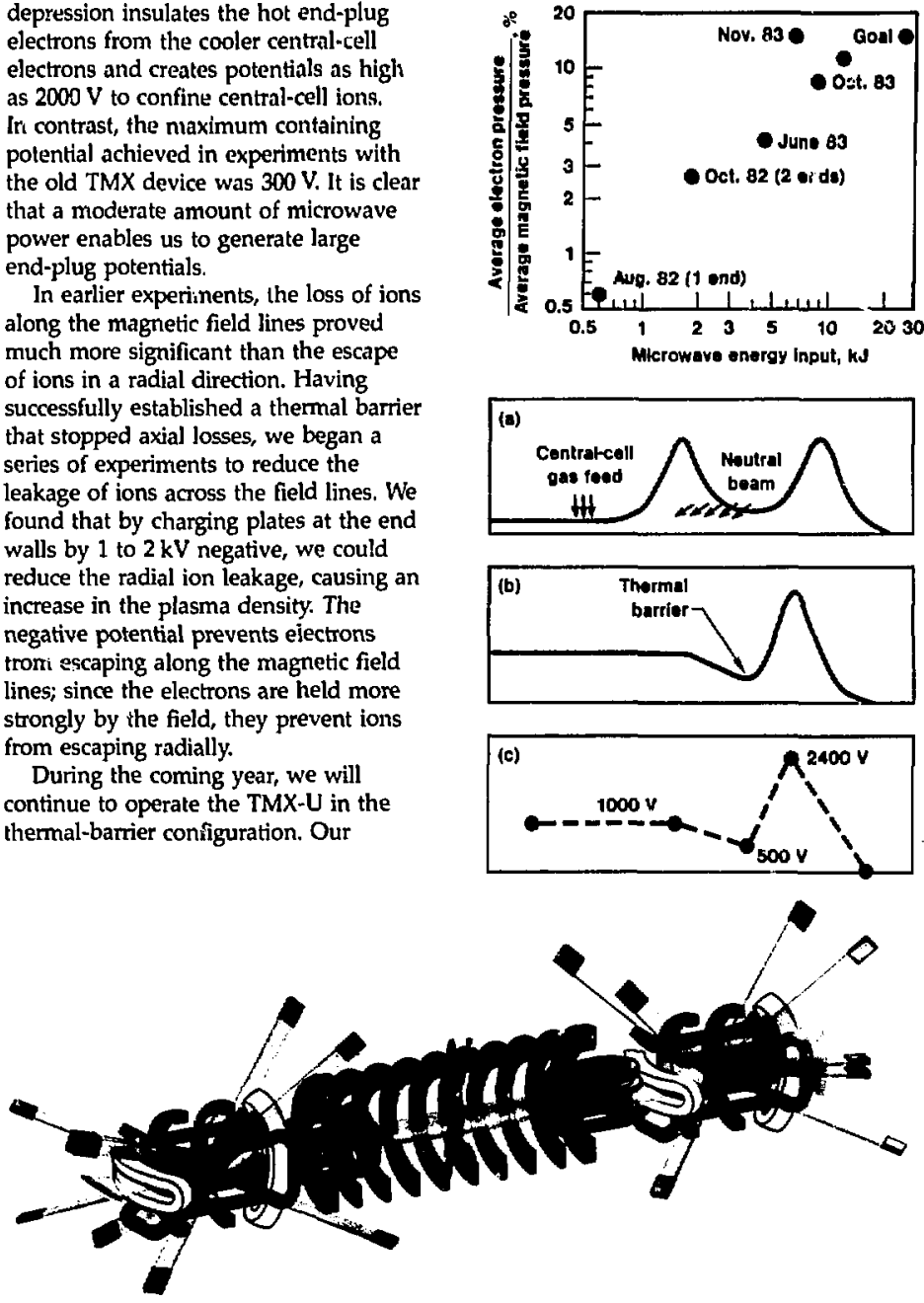

DEFENSE PROGRAMS I NIRC;Y I'ROC;RANIS

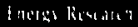

WORK FOR OTHERS

Wo have used microwave power to hat end-plug electrons to energies greater than $100 \mathrm{keV}$. The average presaure of thane hot electrons has reached $15 \%$ of the magnetic-field preseure, our design coal.

Electrical-potential meesurements in the TMX-U conflrm the existence of a thermal barrier. (a) Shape of the magnetic tleld in the end.plug region, show. Ing injection of the $5 \cdot \mathrm{keV}$ deuterlum neutral beam to measure the thermalbarrier voltage. Electrostatic ion analyzere measure the energy of lons emerg. Ing from the opposite and of the device. (b) Shape of the the rmal-barrier voltage predicted by theory. (c) Magnilude of the thermal-barrier voltage. The mea. sured depth of the thermal barrier was $500 \mathrm{~V}$.
Schematic drawing of the TMX-U machine, thowing the magnet coils, the neutral-beam Injectors (all almed at oblique angles to the machine $\mathrm{ax}(\mathrm{s})$, and the plasma bundie. 
DEFENSE PROGRAMS ENP'RC:Y PIRO $x . R \times 14$ inint finstis. WORK FOR OTHERS
M irror Fusion Test Facility

In the tandem-mirror approach to magnetically confined nuclear fusion, the central plasma is isolated ly magnetic and electrostatic fields that prevent the escape of ions from the ends of the reactor, thereby substantially improving its confinement time. Construction of the MITTF-B, our Mirror Fusion Test Facility, began in 1980. The latest in the Laboratory's evolutionary series of experiments designed to study the play sics of al magnetic fusion reactor, the MFTF- $B$ is intended to demonstrate scientific fensibility in a near-reactor regime for details, see the August 1983 Energy and Technology Review, UCRL-50000-83-8, p. 20). A computer-generated illustration of one-half of the current magnet configuration for the MFTF-B is shown on the opposite page.

The MFTF-B project made excellint design and construction progress this past year. Despite schedule, funding, and design changes, we were able to avert additional delay in full operations startup. Construction of project elements is $79 \%$ complete, and the auxiliary component and experiment optimization support tasks are nearly $40 \%$ complete. All major systems are on schedule; the integrated systems test is planned for late $1985,0.5-$ s testing will begin in 1986, and start-up of full 30-s operations is schectuled for 1987. We present here some highlights of the past year's accomplisliments.

Major Construction. The most visible progress was completion of the MFTF-B vault, the western extension of the building structure and the roofing over its high bay, and the crane rail, as well as erection of the west vacuum vessel and the center vessel supports. Both east and west vessels are now in place, modifications have been made, and the transition cones have been installed (see photograph). The design of the vacuum vessel was updated to the axicell configuration, including stiffening to satisfy the new interface systems loads.

Magnet Systems. We completed design of the major magnet systems and fabrication of several major components.
The two $\mathrm{C}$-coils of the east yin-yang magnet were wound and assembled in the elongated $(5.3 \mathrm{~m}$ between magnetic mirrors) yin-yang configuration of the axicell MFTF-B. Manufacture of the twelve 5-m-dianeter solenoid magnet coils was completed, and the coils were drslivered to L.L.NL. The new magnets for the trim, transition, and axicell colls were designed, and construction is well underway. the trim coils, new to the MFTJ:- $B$ magnet configuration (see th,ure), will enable the adjustment of fisid alignments to at least a factor of five better than with mechanical alignment alone, thereby stemming the radial loss of iuns from the plasma. The new niobrim-tin production length of the 12-T insert coil conductor was qualified by low-temperature testing in a 12.5-T field to verify that the critical current for superconduction surpassed our specification.

Plasma Ionization, Injection, and Heating. The target plasma is provited by the flow of ionized gas from the anchor (end) regions and by ionization in the central cell of deuterium gas that nows from two gas boxes inside each inner axicell magnel. During 1983, we adjusted the axicell configuration to the latest plasma optimization. New multiregion, Fokker-Planck computer codes provided a tool to verify power balance and particle balance in the plasma. We decided to use radiofrequency heating of ions and electrons to supplement or replace neutral-heam heating. The $20-\mathrm{keV}$ start-up injectors were replaced with radiofrequency ion heaters, and the plasma streaming guns were deleted from the design on the basis of TMX-U results.

For plasma start-up, we will use electron-cyclotron resonance heating (ECRH) in the yin-yang anchor regions at 28,35 , and $56 \mathrm{GHz}$. These frequencies vill provide absorbed power in the plasma of 100,100 , and $450 \mathrm{~kW}$, respectively. Plasma start-up will be aided by ion-cyclotron resonance heating $(\mathrm{ICRH})$, which will ionize injected deuterium gas, together with the ten $80-\mathrm{keV}, 0.5-\mathrm{s}$ neutral-beam injectors in the central cell. We used TMX-U results 
to confirm the start-up and sustaining plasma models, giving us confidence in our MFTF-B operational scenarios.

The ECRH system reached a milestone in 1983 as we completed, installed, and tested the first power supply for a gyrotron tube that will generate up to $200 \mathrm{~kW}$. We decided to use a quasi-optical tecinique rather than mechanical waveguides to transmit the nutput of the gyrotron tube to the plasma. In addition, the first 28. $\mathrm{GH}_{2}$ gyrotron was fabricated and installed; by February 1984, we had nade more than 50000 shots with a wide range of parameter values that included pulse widths and duty cycles, using the prototype gyrotron socket.

Control Systems. With completion of acceptance testing of its backup 1-Mbyte shared memory, the MFTF-B Supervisory Control and Diagnostic System was fully installed. To meet requirements of the axice!! configuration, we upgraded and modified the Lical Controls and Diagnostic System, including its operating system.

Programmable controllers were added to the magnet pr.wer supply and protection system and to the cryogeniss and extemal vicuum systems.

Recognition. Ii October 1983, LLNL's Magnetic Fusion Energy (MFE) I'rogram received, for the second year in a row, the highest evaluation by the Office of Fusion Energy anong this country's nine

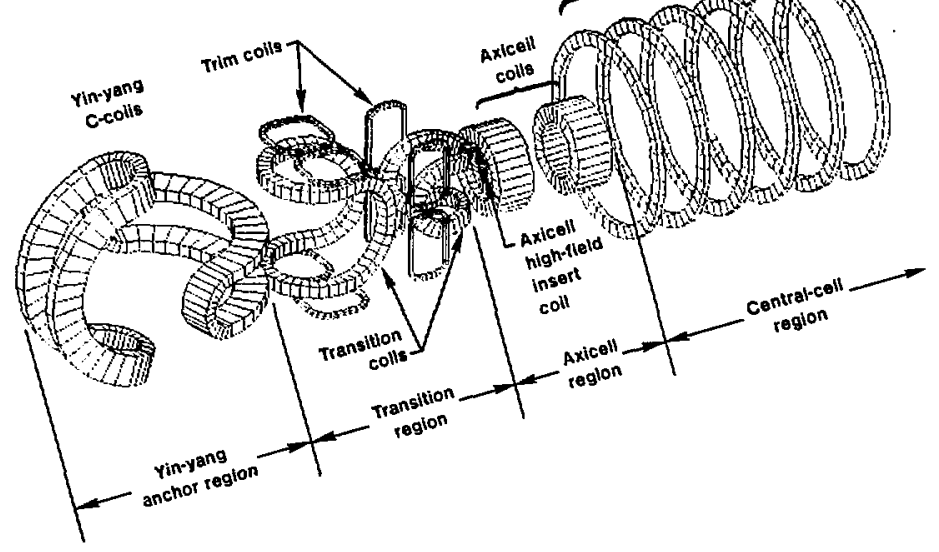

major MFE program participants. The recognition included the MFTF-B Project, the National MFE Computer Center, and the TMX-Upgrade I'roject. The MFTF-B Project received 15 superior and 8 excellent ratings in a total of 25 categories, including superior ratings in each of the five Sijentific Excellence categories. Overall performance was judged excellent/superior, an improvement over the previous year's lating of excellent. th

Key Words: axioull somfiguration; clactron-cyciotron

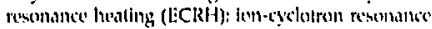
healing (ICleH); nitginetic fusion energy ( NITI:B; Mirror litusion Test lacility:

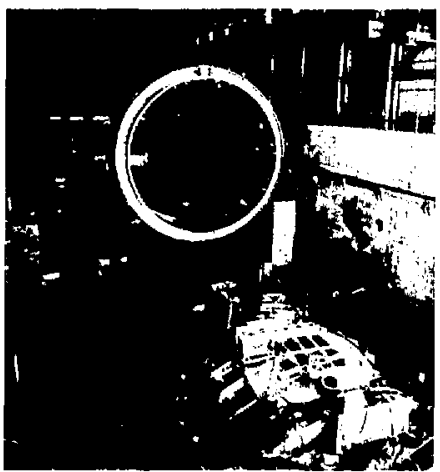

Photograph shovving the completed western extenston of the MFTF-B building. The crane rall and the yacuum ves. sel supports are also In place. Segments of the west vessel (seen here) were installed this spring. Now, both east and west vessels are in place, and the transition cones also have been installed.
Computer drawing of one-half of the magnetic coils for the axicell MFTF-B, showing the -?cently added trim coils (four around each of the transition coils). The 16 Irim coils in the complete configuration will signiticantly reduce Ion losses across flold lines by enabling correction of the position and direction of magnetic field lines to within $\pm 0.1 \mathrm{~cm}$ and $\pm 0.1 \mathrm{deg}$, respectively. 


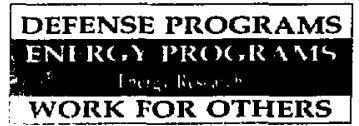

WORK FOR OTHERS
Large neutretberm source modules in the forepround are awaiting hotellation in the MFTF-B, now under contruction. The smeiler units, which have seen sarvice in the TuX-U, have been relurblehed and will be ovinstulind in the TinX-U as needed.
$\mathbf{N}$ eutral Beam Shop A neutral beam is a "fuel injector" that increases the energy and density in a fusion plasma. A neutral-beam source module uses an arc discharge to ionize deuterium gas and then electrostatically beams the ions toward a fusion machine's plasma region. Before the deuterium ions reach the plasma-confining magnetic field, they are neutralized in a charge-exchange cell, enabling them to penetrate the field and finally to reach the plasma.

To maintain its neutral-beam source modules, LLNL's magnetic fusion program operates the Netıtral Beam Shop, a facility unique in the world's fusion community, Led by a mechanical engineer, a staff of five technicians performs all service operations on the modules, from replacing a minor part to complete refurbishment. Parts and even entire modules also can be manufactured. The current inventory consists of 53 serviceable modules; 35 of these, which fit the TMX-U, operate at a $20-\mathrm{keV}$ accelerating potential, and the rest are new $80-\mathrm{keV}$ units for the MFTF-B (figure). Another $14 \mathrm{MFTF-B}$ units remain to be delivered.

So far, only the TMX-U units have seen significant service, some for as many as 12 years, undergoing a total of about 120 maintenance operations per year. is many as 24 of these units are installed at one time, while the rest are being repaired, tested, or held in reserve as ready replacements.

The modules are built to exceptionally close dimensionai tolerances-in some

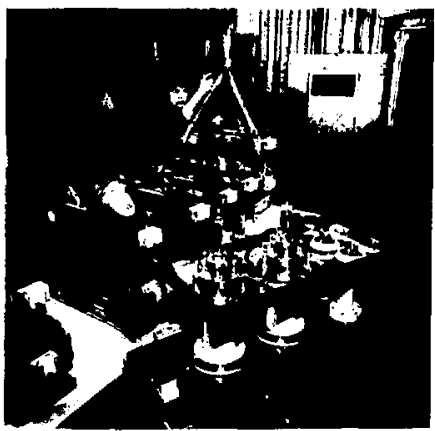

cases as small as a few microns. Verification of such precision is made possible by two coordinate-measuring machines (acquired this past year) and an optical comparator, all featuring computer-aided data analysis, and two computer-cuntrolled milling machines, one of which can make parts to the closest tolerances required.

Most of our maintenance and manufacturing procedures are unique to beam-source work and were developed by the staff in the 10 years since the Neutral Beam Shop was established. Much of the shop's work is done in laninar-flow clean rooms to minimize contamination of the modules' inner surfaces. The reliable operation of the modules depends on the cleanliness of these surfaces.

The shop works within a rigorous quality-assurance program that is supported by equipment ranging from the coordinate-measuring machines to a "hi-potter" that can apply an electrical potential of as much as $100 \mathrm{kV}$ to module assemblies. All findings and repairs are formally 'scumented and permanently archive $d$, making it possible not only to achieve high performance reliability but also to correlate the modules' operating characteristics with their design, assembly practices, and internal dimensions. Before finished modules are accepted for installation, quality assurance is validated by operating them at full performance levels on a test stand. The success of our quality-assurance program is demonstrated by the virtually complete elimination of the catastrophic failures that were common during the TMX-U's start-up phase. Life between maintenance cycles has increased from an average of just a few hundred shots to almost two thousand and continues to improve.

In anticipation of the start-up and operation of the MFTF-B, we will soon relocate the Neutral Beam Shop to a larger facility and will convert its entire archive to a computer data base. 6

Key Words: MFTF-B; neutral beam; neutral-beam source module; Neutral Beam Shop; TMX-U. 


\section{H} igh-Field Test Facility The High-Field Test Facility (HFTF) is a completely superconducting, niobium-tin and niobium-titanium magnetic coil system designed to produce the highest magnetic field ever in a magnet of its massive size (18 tonnes and a hore $40 \mathrm{~cm}$ in diameter). Construction and testing of the HFTF, completed in May 1983, was an unqualified success; a maximum field strength of $11.4 \mathrm{~T}$ was achieved, surpassing the predicted strength of $11.2 \mathrm{~T}$.

The Laboratory undertook the HFTF project in 1978 to satisfy several requirements of the MFTF program. The first requirement was to establish a manufacturing capability for a highcurrent, cryostable niobium-tin conductor. The second was to design, manufacture, and (after winding) test the conductor. Finally, the magnet had to be constructed as a split solenoid to enable us to insert and test small coils with altemative conductor designs in the high-field volume provided by the HFTF.

Future HFTF plans include the performance testing of two insert coils, a liquid-helium, forced-flow conductor and a niolium-titanium-tantalum conductor coil that is cooled with pressurized $(\sim 122-\mathrm{kPa})$ superfluid helium-II. Our major goal is to test the stability of the conductor while each magnet is bathed in the background field of the 11.4-T coil. Later, we may design and test high-field superconduclors and coils for foreign fusion rescarchers.

A significant research achievement in its own right, the HFTF also is a stepping stome to solenoid coils with the even larger diameters and stronger flelds needed for future tandem-mirror fusion reactors, such as the Mirror Advanced Reactor Study device and the Engineering Test Reactor. Future research will focus on two new technologies:

- Superfluid helium-[I as a coi] coolant with an effective thermal conductivity several thousand times that of copper.

- Advanced, high-strength stainless steels incorporated within the conductor's winding. pack to react against the much higher magnetic forces. $1:$

Key Words: Engineering Tust Reactor; High-Field Test Facility (HITF); magnelic fusion; Mirror Advanced Reactor Study; superconducting magnets.
DEFENSE PROGRAMS

I NI RC; I'IROC;RAMS incres kixidati

WORK FOR OTHERS 
DEFENSE PROGRAMS

INIRO, PROX,1R I MS

WORK FOR OTHERS
$\mathbf{R}$ otating Target Neutron Source

A magnetic fusion reactor capable of sustained operation must incorporate materials resistant to degradation by high-energy neutrons, The Laboratory's RTNS-II Facility is the world's only 14-MeV neutron source dedicated to materials research. It has been operated from its inception as a user facility. Since 1979, workers from throughout the fusion materials community have been conducting approved experiments under the auspices of the Department of Energy's Office of Fusion Energy.

Early in 1982, the governments of Japan and the United States agreed to jointly support the operation of the RTNS-II and to share in its use. The RTNS-II Facility contains two acceleratorbased, deuterium-tritium neutron sources. In 1983, operations were expanded to provide round-the-clock running of one neutron source. During that time, the RTNS-ll reached a production peak of $3.0 \times 10^{13}$ neutrons per second, a new record for neutron source strength.

The experimental program at the RTNS-Il Facility covers a broad range of materials and applications. Many experiments are directed toward understanding neutron spectral effects in metals; radiation effects in insulators are a growing concern. A group from Osaka University, Japan, has studied a number of diagnostic and electronic devices with applications to today's fusion experiments and future reactors, including fiber optics, transistor diodes, photomultipliers, and radiation detectors.

One area that is of particular importance to the design of magnetic fusion reactors is the behavior of magnet conductors, both normal and superconducting. For example, copper samples containing various impurities and subjected to pretreatments typical of magnet stabilizer material have been studied in a variety of radiation fields. From these data, it is now possible to predict the magnetnresistive behavior of copper stabilizer matental under expected fusion reactor conditions, induding periodic room-temperature anneals.

The performance of superconducting materials will strongly affect fusion reactor performance and cost. One important performance parameter is critical current, that is, the maximum current density a conductor can carry while remaining in a superconducting state. The value of this parameter changes in the presence of a magnetic field. During the past year, we used the RTNS-II to repeatedly irradiate samples of superconducting materials (including both bronze-process monofilament and in situ process niobium-tin) with a total fluence of $1.35 \times 10^{18}$ neutrons $/ \mathrm{cm}^{2}$ at a sustained temperature of 4 to $5 \mathrm{~K}$. At several intermediate doses, we were able to measure critical current in transverse magnetic fields up to $12 \mathrm{~T}$ without observing significant warming. At the maximum fluence, the critical current of the in situ sample declined significantly when the field strength was relatively low but decreased only $15 \%$ at $12 \mathrm{~T}$. The critical current of the monofilament niobium-tin was reduced by irradiation and did not fully recover when the sample was annealed at room temperature.

Key Words: materials - magnetic fusion reactor; neutron source--14-MeV; Rotating Targel Neutron Source-ll (RTNS-II). 
$\mathbf{E}$ nergy Research Scientists Compute at NMFECC In recent years, Department of Energy scientists working in nuclear and high-energy physics, basic energy sciences, and health and environmental research have had little access to Class VI supercomputers, such as the Cray 1 computers in the National Magnetic Fusion Energy Computer Center (NMFECC). A recent study by the DOE's Office of Energy Research has concluded that because of this lack of access, these researchers have not been able to tackle some urgent problems in their fields. The study considered only requests for computer time on Class VI computers, and these requests totaled more than 10000 hours for fiscal year 1984.

The nation's energy scientists are geographically dispersed across the U.S., and many are located at DOE laboratories, universities, and industries already being served by the national MFE network (see figure). The best means available, therefore, for getting the largest number of users access to Class VI computers in the shortest time and for the lowest cost is to allocate them time on the national MFE network. To this end, scientists supported by the Office of Energy Research were allocated and used about 300 hours of computer time on the national MFE network in the last quarter of fiscal year 1983. They also have requested the use of more than 10000 hours in the 1984 fiscal year, of which only about 800 hours are available and have been allocated. In addition, to help meet the needs of these scientists, acquisition of an additional Class VI computer (Cray 1 or Cray X-MP) by the NMFECC was approved for fiscal year 1984 by the Office of Energy Reseach, and approval of an even more advanced computer, the Cray 2, for magnetic fusion research is expecticu in fiscal year 1985. The Cray 2 is a multiprocessor system with many millions of words of memory.

Currently, the NMFECC supports the nationwide research program in magnetic fusion energy by providing the largescale resources of a CDC 7600 and two Cray 1 computers. Some 2000 MFE researchers actoss the country enjoy access to the computer center via a data communications network designed, installed, and operaied by the NMFECC staff.

Use of the national MFE: network is, at present, only an interim solution, however. Three principal options exist for satisfying the supercomputer requirements of the energy research scientists:

- Installation of Class VI computers at several energy research laboratories.

- Interim use of the national MFE network until a new compuler center at a new location is initiated in fiscal year 1986.

- Permanent use of the national MFE network.

The Office of Energy Reseach is assessing the computer capacity and capability requirements of the energy researchers to decide which option is most appropriate.

Key Words: computer-Class VI, Cray X-MP. Cray 1, Cray 2; energy resenrch; National Magnetic Fusion Energy Computer Center (NMFECC)
DEFENSE PROGRAMS I NIIR , Y I'IR ) , IR A AS

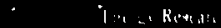

WORK FOR OTHERS
National MFE nelwork as of 1984 . Many of the nation's energy research iclentists who need accese to supercomputere, such as the Cray $t$, work at the locations already being served by the notwork.

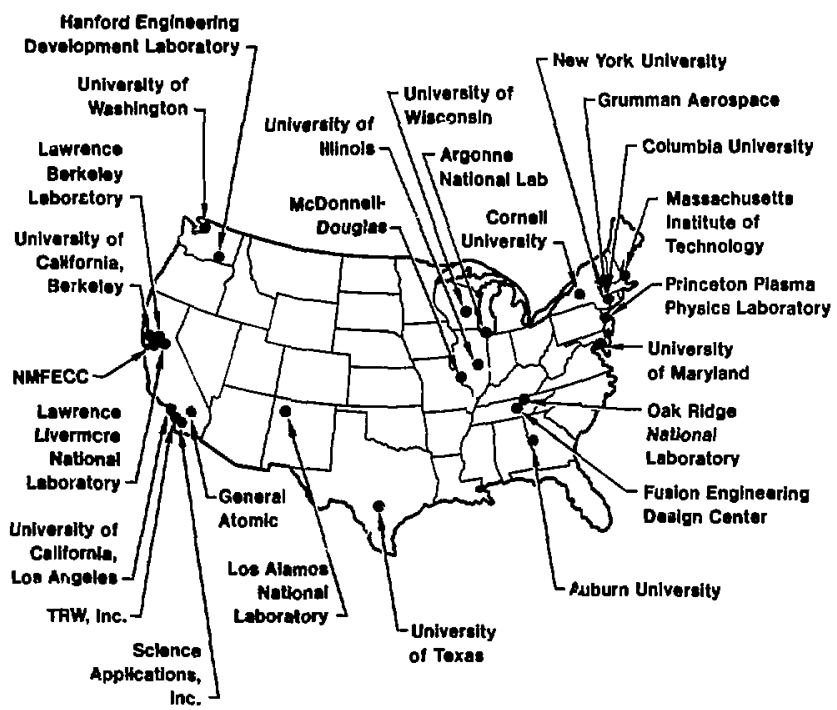


DEFFNSE PROGRAMS INI.R(, ) IPRC $x$, RAM14 तitip WORK FOR OTHERS
$\mathbf{E}$ Ifects of Increased Carbon Dinxide on Crop Yields We are studying the hypothesis that worldwide increases in atmospheric carbon dioxide levels might increase crop production by providing more carbon dioxide for photosynthesis and by causing physiological changes that improve water-use efficiency. As part of a cooperative research program invo!ving North Carolina State University, Duke University, the University of California at Riverside and at Davis, and the U.S. Department of Agr' :ulture field site at Paleigh, North Carolina, we have been conducting field studies to determine the functional dependencies of various crops on carbon dioxide concentration while maintaining the equally important dependencies on light, temperarure, humidity, water availability, and nutrient supply.

Factors that influence the response of plants to increased carbon dioxide concentrations sinclude leaf physiology, type of metabolin: pathway, and particular carbon allocation stràtegies. To test our nypothesis, therefore, we. must know the experimental doseresponse functions for particular plant species of interest. In previous studies of soybeans, we obtained data on which we based a predictive ecological model that we used to estimate the effect of carbon dioxide on soybean yield in the U.S. Corn Belt region. We found that triping the carbon dioxide level would double the marketable yield of soybeans, allowing for normal drought-stress and other growth factors. The response to increased carbon dioxide concentrations, in terms of dry-matter production and seed yield, was linear to a carbon dioxide concentration of three times present atmospheric levels. These results were apparently insensitive to the complexities of plant physiology, weather, and other uncertainties.

To validate our models and continue our experimental studies, during the summer of 1983, we extended the soybean studies to field-grown corn. These experiments were designed to investigate the relationships between carbon dioxide level, stress (infreque. it watering), yield, water-use efficiency, and rate of maturity. To perform our physiological measurements, we developed extremely precise gasexchange methods (e.g, leaf-diffusion porometry, improved dispersive infrared absorption spectrometry).

A commercial cultivar of com (Zea mays) was field grown (see figure) at four different levels of carbon dioxide in air, from normal ( $350 \mathrm{ppm}$ ) up to nearly twice normal carbon dioxide concentrations. The com plants were divided into two groups-well-watered and infrequently watered (stressed). The experimental design included replications and controls.

Greater than normal concentrations of carbon dioxide produced either a slight or an insignificant increase in yield, depending on the degree of water stress. Thus, con plants that were under extreme water stress and did not yield as much as did well-watered plants nevertheless responded to increased carbon dioxide: doubling the carbon dioxide concentration over ambient levels increased the yield of stressed plants by about $35 \%$. Well-wątered plants did show a trend toward increased yield with higher carbon dioxide concentrations, but this was not statistically significant.

We found a relative increase in wateruse efficiency with increasing carbon dioxide that was about the same for both well-watered and stressed corn plants. That is, additional carbon dioxide caused all corn plants to require less water per unit mass of yield. However, this effect apparently was diminished as the carbon dioxide concentration increased, so the response was not linear.

As an approximation, we would say mathematically that the relative change in water-use efficiency of the com was about equal to the (natural) logarithm of the square root of the relative carbon dioxide level. For example, 1.5 tirs is the normal carbon dioxide would increase the water-use efficiency of corn by about $20 \%$, while doubling the carbon dioxide would increase water-use efficiency about $35 \%$.

There were other effects of carbon cioxide. Increased levels produced a slightly increased rate of maturation, although this effect was difficult to 
quantify in the face of water stress and natural variability. Other researchers have found that doubling the carbon dioxide concentration produces a reduction in the corn growing season of 5 to $10 \%$ (about one week in a 100 - to 120-day corn crop).

Physiological changes observed in this and other experinents could explain the effects of carbon dioxide. Photosynthesis was not affected, but carbon dioxide reduced the loss of water by closing stomatal pores. Reduced water loss means that for a given amount of available water, those metabolic functions that are often rate limited at the celluiar level can proceed at a normal rate, and yield will be increased even though carbon dioxide has not increased the rate of photosynthesis directly. These results have been confirmed by the work of other scientists, most notably an independent New Zealand study reported by K. King and D. Greer at the American Society of Agronomy Meetings, Washington, D.C., August 1983.

The results of the experiments we have described here and of other experiments may be interpreted to predict that with expecter future increases in atmospheric carb!n dioxide levels, coriı will requirc less water and a shorter growing stason to prolluce yields equivalent to those of today. Corn could therefore be cultivated in more arid or shorter-season climates that, at present, limit its range, 4

Key Words: carbon dioxide-atmospheric level; com-physiology, rate of maturation, yield; water use-efficiency; crop production; metaholism.

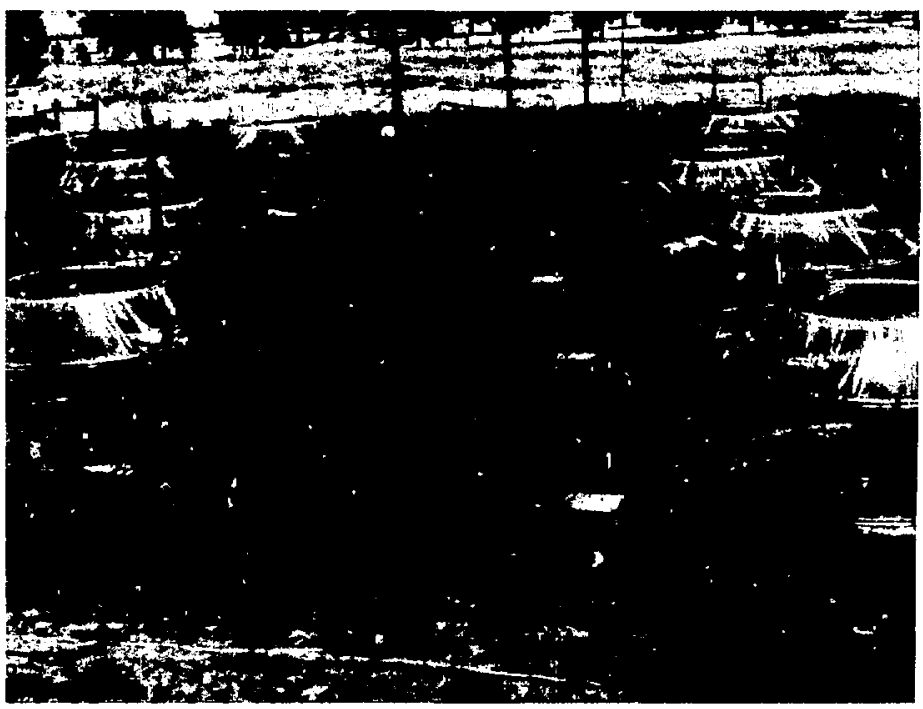

Field studies of com (Zea mays) being grown at different levels of carbon dioxide in air. The corn plants were . .vided into two groups-well-watered and infrequently watered. 
DEFENSE PROGRAMS

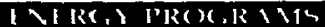
VORK FOR ÓTHERS
Ramote-enalyalo ther-optice system. Light trom a laser source passes through an eperture and is focused on the end of the opticel fiber by 900 motric beem sputter. The Hght pasese throwgh the fiber, intaracte with the cemple to be mosured, and relurn: (now incoherent) to be reflected by mirror Into computerized Raman. thoorecence scattering spectromeler for enebyeit. Meseurements are made at the semple by an optrode or by the bere theer lerminu, which cem be costed to thuoreces in reeponse to certen cubetences.
$\mathbf{R}$ emote Measurement Over Optical Fibers

1. Many phenomena of interest, such as conditions in an underground nuclear-waste-disposal site, the inside of a furnace, ar:d numerous industrial processes, cannot be measured with conventional instruments because they are too hot, too cold, too radioactive, or otherwise inaccessible to direct observation. Taking advantage of recent advances in optical communication fibers that enable visible light to be efficlently transmitted long distances, we have developed a new technology that makes it possible to obtain data on the state of numerous probed regions $(\mathrm{pH}$, temperature, pressure, etc.) or to

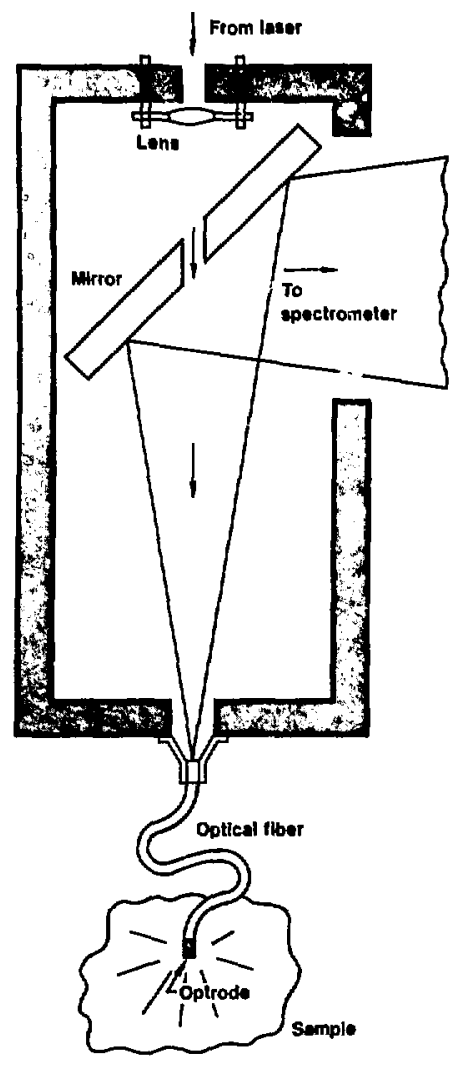

determine the presence of specific chemical compounds from one remote location.

This new concept in analytical chemistry uses long-distance fiber optics to transmit laser-excited fluorescence to a spectrometer for analysis. In this system, called remote fiber fluorimetry (RFF), optical fibers are terminated in a specific geometry or with fluorescent target molecules in an optrode (see figure). (An optrode is a measuring device coupled to the fiber and containing sensitive chemical layers that interact with specific compounds in the sample and. quantitatively produce fluorescent products.) The small size of optrodes and the use of optical fibets enable a wide variety of measurements to be made in inimical and restrictive environments.

Applications of RFF include in situ monitoring of well waters, waste repositories (nuclear and nonnuclear), reactors, process-control parameters, and the workplace, and in vivo measurements in the human circulatory system. For example, with one sophisticated central instrument, we might well be able to multiplex fibers to many locations within a facility to monitor for hazardous compounds such as formaldehyde, hydrogen sulfide, or chloroform.

With fibers located in and about the groundwater near waste repositories, we could continuously monitor freshwater resources for the incursion of toxic compounds. This would be more timely, more accurate, and much less expensive than drilling wells and periodically sampling the water.

A Laboratory-generated patent on RFF has been licensed by two corporations that will develop and market RFF for industrial process-control applications and for in vivo monitoring of blood pressure, $\mathrm{pH}$, and dissolved oxygen and carbon dioxide in the human circulatory system. The combination of RFF with modem immunochemical fluorescent analytic techniques could create virtually limitless applications in biomedicine, $t$

Key Words: analytical chemistry; biomedicine; optical fiber, optrode; remote fiber fluorimetry (RFF). 
$\mathbf{M}$ etabolism of Hazardous Compounds by Molluscs In studies carried out for the Department of Energy's Office of Health and Environmental Research, we have developed experimental protocols that can be used to assess the in vivo metabolic processing of a variety of chemicals by marine invertebrates. Such basic information is needed because our knowledge of chemical metabolism has been based largely on studies of vertebrate organisms and may not directly apply to invertebrate species. With increased understanding of biotransformation by marine organisms, we will be better able to predict the biological effects of energy-related chemicals fourd in polluted ecosystems.

Marine bivalve molluses efficiently concentrate chemicals present in the water. Whether an organism will be harmed by accumulated pollutants is determined largely by its ability to metabolically transform them into more water-soluble (detoxified) forms. Some metabolic transformations result in the production of activated compounds that are more toxic than the original pollutants.

For our experiments, we chose to study the metabolic transformations by marine molluscs of a model aromatic amine (a-toluidine) whose structure is representative of a broad class of potentially mutagenic energy-related pollutants. The live mussels, oysters, and abalone that we used rapidly accumulated o-toluidine and eliminated metabolites that were significantly different from those produced by vertebrate organisms (figure).

Molluscs and vertebrates form different metabolites because they have different detoxification mechanisms. In addition to producing activated (nitrogen-oxidized) metabolites, the bivalve molluses were able to add a single carbon atom to the nitrogen and form a novel detoxification product, $\mathrm{N}$-formyl-o-toluidine. This nitrogenmetabo'izing pathway represents a significant departure from the twocarbon addition (acetylation) that is usually observed in vertebrate species, and most likely represents a primitive version of this common detoxification pathway. In humans, the existence of this pathway has been shown to be responsible for anemic blood disorders following exposure to o-toluidine. Surprisingly, the abalone was found to be capable only of nitrogen-oxidizing o-toluidine and, therefore, may be more likely to exhibit effects of aromatic amine intoxication than are bivalves that possess detoxification pathways. The common carbon-oxidizing metabolic pathways that we expect to occur in mammals were not found in the molluses studied; however, we did verify our experimental techniques by isolating these metabolites from a rat injected with o-toluidine (rigure).

These studies have added to our limited information concerning the metabolism of organic chemicals in marine invertebrates. Furthermore, it seems reasonable to assume that because of the consequent mutagenic and carcinogenic effects, the ability of these molluses to bioactivate aromatic amines by nitrogen oxidation ultimately may reduce their ability to survive. 1

Key Words: tintransformation; detoxification melabolism-invertebrate; inollusc; nitmgen oxidation; pollutant.
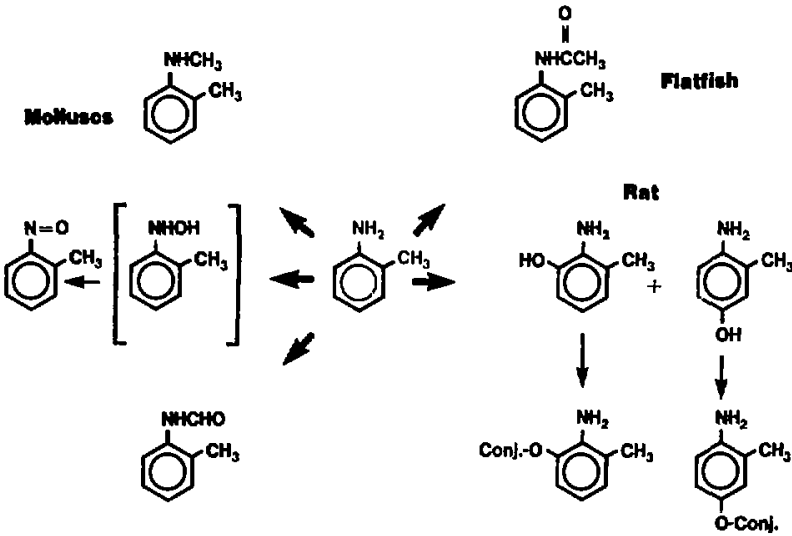

The błotransformation of a model sromatic amine (o-toluidine) by marme and lorroutrial organieme. The nitrogen-oxidizing capebility of molluses is elgnificant inamuch as it is thought that all cercinogenic aromatic amines require moteboltc ectivation via this pathway. That is, the sromatic amines themselves are not hamflu but their nitrogenoxldized motabolltes are cepe ble of causing damage. 
DEFENSE PROGRAMS

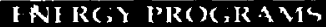
$121+4 t^{+}+4 x$ WORK FOR OTHERS

(a)

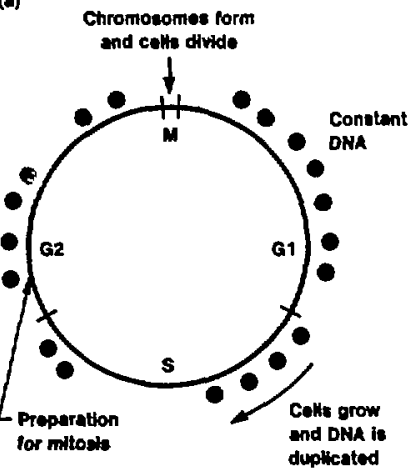

uantitating Cell-Cycle Parameters

In the past year, we have developed a procedure with which we can rapidly and precisely determine the cytokinetic properties of cell populations. This method promises to minimize linitations in classical cytokinetic techniques that have made it difficult to obtain accurate and timely information about the growth rales of cells.

The growth characleristics of normal and tumor cells are of interest as a hasis for optimizing cancer chemotherapeutis treatment schedules, $\Lambda$ s cells grow and stivide, they pass through a cycle of four phases of increasing maturity. We can take advantage of two facts about this cell cycle to kill cancer cells selectively. First, normal cells and tumor cells move at different rates through the four plases, and, second, many cytotoxic agents used for the treatment of cancer affect cells predominantly in one phase of the cell cycle. The timing of cancer treatments in relation to cell-cycle traverse is an important factor in therapy (see figure). Our goal is to develop principles that will provide a rational

(b)

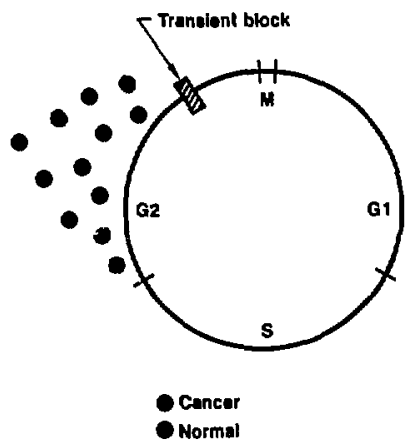

basis for the selection of rancer treatment schedules to replace present trial-anderror selection.

Oncologists have attempted to improve cancer treatment schedules by using cytotoxic agents that act selectively in the S phase of cell growth (in which deoxyribonucleic acid, DNA, is synthesized), administering these agents when the experimentally tetermined frequency of tumor cells in 5 phase is maximal. However, traditional methods for estimating the frequency of S-phase cells and the rates at which cells move through the cell cycle are extremely labor intensive and time consuning, often requiring montlis for completion. The procedure developed by LI/NL's cellcycle analysis project, with support from the National Institutes of Health, offers several advantages over the classical methodologies: the analysis time is short, since several million celts can be analyzed in a few minutes, and discrimination can be made hetween labeled cells and unlabeled cells with an S-phase DNA content.

Classical methods estimate the frequency of S-phase cells either by

(c)

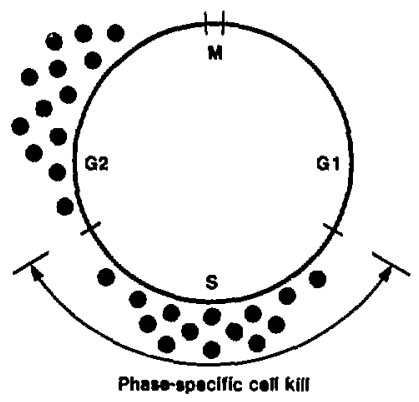

The wae of cell-crcle-traverae concepts to salectively kill eancer ceiv. (a) The cell cycle of normal and cencer cellw. The w phese is mitosis, when chromosomes form and the cellu divids. Esch dividing cell forme two deughter cella, and thees enter the Gi phese, $k$ which the Bul conlent of the celle is constent. To reproduce themeolves, culle enter the 8 phwe (DNh-oynthevis phase), double their DNA content, then pere into the 62 phese and prepere to enter miloela. Mormel (oray) and cancer (brown) cellu, whown randomby distributed through all four pheses of the cycle of cell growth, weuclly mowe through the cycle at different reles, normel celie mowng fasior than cencer colle. (b) A hypoltheticel cell-cycl-based cencer treatment. Many cuncer-thorapy agenis are mest effective in only one phace of the cell cycle and can be used to selectively kill cencer celle thel have been made to accumulate in that phase. In this hypothetteal iratument procedure, a blocking agant produces a treaslent accumulation of sll cells in the 62 phape. When the cella are permitted to resume their movement through the cycle, the faster movement of the normel calls resulte in a separation of normal and cancur cella. The cancer-killing egent la given when only the cancer colle are concentroted in the $S$ phase and thus will be killed by on agent that is Sphose specillc (c). 
determining the fraction of cells that appear labeled after the administration of a DNA precursor (for exainple, tritiated thymidine) or by measuring the S-phase fraction as determined by flowcytometric analy'sis of DNA distributions. Rates of cell-cycle traverse have been estimated by the procedure called "fraction of labeled mitoses," which determines the frequency of mitotic cells that appear radionctively labeled in samples taken periodically after tritiated thymidine has been administered. The amount of tritiated thynidine incorporated into cells is typically estimated by liquid scintillation counting or by autoradiography. Autoradiography may take months, and discrimination of weakly labeled and unlabeled cells is subjective. liquid scintillation counting does not provide information about the distribution of radioactivity incorporation among cells of the population. Analyses of DNA distributions are suboptimal because no information is available alrout the rate of DNA synthesis or about the frequency of actively synthesizing cells and quiescent cells with an S-phase DNA content.

Our new procedure is based on the simultaneous flow-cytometric measurenent of cellular DNA content and bromodeoxyuridine (BrtLrd) incorporated into DNA. BrdUrd is an analog of thymidine; thus, its incorporaticn into DNA can be used as an indicator of DNA synthesis. Flowcytometric measurements are displayed as bivariate distributions of DNA content vs BrdUrd content. These bivariate distributions readily show the relative amounts of BrdUrd incorporated into the various phases of the cell cycle. The procedure is sufficiently sensitive to allow quantification of a very low level of BrdUrd. In addition, it allows discrimination between DNA synthesizing cells and nonsynthesizing cells with an S-phase DNA content.

We have utilized this technique to analyze the cytokinetic properties of mammalian cells grown in vitro and of bone marrow cells from mice treated with cytosine arabinoside, an anticancer agent used clinically for the treatment of leukemia. In addition, we have applied the technique to multiparameter analyses of mouse bone-marrow subpopulations discrirninated on the basis of lectin affinity (which provides differential binding to subpopulations of interest) and light-scaltering properties.

in these studies, we used the dualbean flow cytometer to simultaneously measure DNA conlent, lectin binding, and BrdUrd incorporated into DNA. Using list-mode data processing, we were able to measure the cytukinelic properties of the proliferating erythroid and granulocyte cell subpopulations without having to resort to cell sorting for subsequent analyses of precursor incorporation into DNA. Recently, we have shown that sinultaneous staining with the anti-BrdUrd antibody and a DNA-specific dye can be used to measure sister-chromatict exchanges, such as would occur following exposure to mutagenic agents.

Our measurements can be performed using commonly available flow cytometers and, since BrdUrd is believed to be less toxic than madionctive DN $\wedge$ precursors, it becomes feasible to perform cytokinetic studies in the clinic. This teclmnique will also he useful to clinical oncologists interested in the detection of low-frequency hyperdiploid G1-cell-phase populations (normally obscured by the diploid S-phase cells), which should now readily he visible in a bivariate distribution of DNA content vs BrdUrd incorporated into DNA.

In sumnary, the livariate BrdUrd vs DNA content flow-cytometric technique promises to facilitate studies of the cytokinetic properties of normal and tumor cells in both the steady and drugperturbed states. Future studies will focus on methods for improving this methodology and on extending this approach to the development of probes to quantitate the incorporation of cancer chemotherapeutic drugs into DNA.

Key Words: bromodeox uridine (BrdUrd); cancer; cell cycle; cell properties - mammalian; DNA; fow cylometry. 
DEFENSE PROGRAMS I NI RG I'ROK, IR ITS

WORK FOR OTHERS
$\mathbf{H}$ uman DNA Repair Genes

In human cells, as in those of other animals, there are enzymes (proteins) that can repair damage produced in the genetic material, deoxyribonucleic acid (DNA), by radiation and chemicals from the environment. As part of our study of human genetics and gettetic toxicology, we have developed ways of identifying the chromosomal locations of the human repair genes and of isolating these important genes so that they can be studied and better understood.

If damage to the genetic material goes unrepaired, the result can be heritable mutations in germ cells. in somatic cells, such damage may trigger the complex process of carcinogenesis. The repair enzymes, like all other proteins in a cell, are controlled by specific genes. For example, there are certain human genetic disorders in which the individuals are known to be at a greatly increased risk for developing cancers. When the cells from these people are analyzed, they show defects in the ability to repair DNA molecules. These naturally occurring mutations, with the loss of the ability to repair the DNA molecules, have made the cells highly vulnerable to further mutations and to death. Identification of the repair genes and the proteins they control will undoubtedly have a major impact on studies of the origin of mutations and chromosomal abnormalities.

We first isolated, in a Chinese hamster cell line that has favorable experimental properties, mutations analogous to the human repair defects. We learned that the repair genes that are altered in the hamster cells have direct counterparts in human cells. This similarity was demonstrated by constructing special hybrid cells, fusing hamster cells carrying a repair mutation with the blood lymphocytes from a normal person. This procedure produced hybrid cells that contained all the hamster chromosomes and as few as one human chromosome. We found the presence of one particulinr human chromosome to be associated with the ability of the hyirrid cells to repair INA damage. In this way, we locate. the first repair gene on one of the smallest human chromosomes, number 19. We concluded that this chromosome complemented, or corrected, the hamster-cell repair defect by providing the nissing genetic information.

The hamster mutant cells carrying the correcting human chromosome provided a means for separating the human repair gene from the hundreds of thousands of other human genes. This was done by purifying the DNA from the hybrid cells and introducing it into the original mutant hamster cells. About one cell in ten million was able to use the foreign gene as if it were a native one. This ability of the altered cells, called transferants, allowed them to multiply from several cells to many ritilions in the presence of a DNA-darnaging chemical in the culture medium. We verified that the DNA of these transferant cells contained the human repair getre. We are now using the techniques of genetic engineering to isolate, or clone, this gene. Once the gene is purified in quantity, we will use it to leam more about how cells suffer genetic damage. 4

Key Words: cancer; cell-Chinese hamster, human blood, hybrid, transferant; DNA; chromosome; genetic damage; gene-human repair; mutation; protein. 


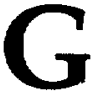
enetic Effects of Chemical and Radiation Exposure

One important goal of the Laburatory's Biomedical Sciences Program is to quantitate the accumulated genetic effect of chemical and radiation exposure in individual people. We are developing an assay that detects integrated mutagenic damage to the erythroid stem-cell population (the generalizer! cells whose descendants will become red blood cells) in the bone marrow. This assay counts variant red cells that fail to properly express one form of a cell-surface glycoprotein called glycophorin A.

Genes are segments of the genetic material deoxyribonucleic acid (DNA) in each cell's chromosomes that act as "blueprints" for the synthesis of the protein molecules that make up the structure and metabolic machinery of the cell. There are two glycophorin A genes normally present in each human somatic (nonreproductive) cell. Stem cells can undergo a mutation that alters the expression of one of these two genes, and the result can be variant circulating red cells that are partially deficient in glycophorin $A$. The frequency of these variant red cells is a measure of the genetic damage that has occurred to this part of the genome the complete set of DNA sequences contained in the haploid assortment of chromosomes). Thus, to the extent that the glycophorin A gene is representative of tive entire human genome, the frequency of these variant red cells reflects the integrated mutational damage incurred by an individual. The glycophorin A genes

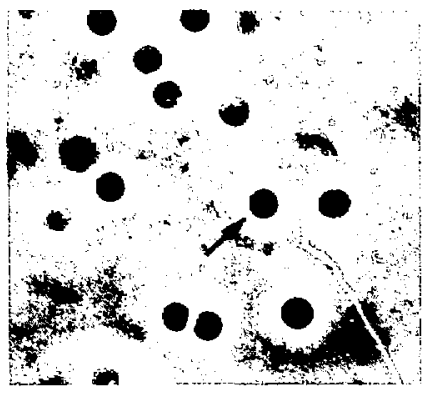

Phacecontrast micrograph function in our assay as in vivo biological dosimeters in each person.

Using highly specific antibodies to immunofluorescently label variant cells and high-speed flow cytofluorometric analysis to count them, we have been able to make quantitative measurements of the frequency of rare red cells that appear to express glycophorin A mutations. To detect the loss of expression of one of the two glycophorin A genes, we use two kinds of antibody, each of which recognizes and binds tightly to only one of the two forms of the protein specified by these two genes. Seven such antibodies have been isolated and characterized for application in the assay system.

For an assay, two different antibodies are conjugated with dyes that fluoresce different colors, green or red, when excited with laser light. When incubated with the red blood cells, both antibodies bind to the normal cells that contain the two forms of glycophorin A, whereas only one or the other of the antibodies binds to the variant cells that fail to present one of the two forms (see figure). We then analyze the cell population by means of flow cytofluorometry. The normal cells that bind both antibodies produce the two independently detectable red and green fluorescence signals, but the variant cells produce only a red or a green signal.

With this assay system, we can analyze cell samples at a rate of about a thousand cells per second. Preliminary measurements indicate that the frequency of variant cells in norma: individuals is in the range of one to ten

\begin{tabular}{|c|}
\hline DEFENSE PROGRAMS \\
\hline I NI REA PROGIRAMS \\
WORK FOR OTHERS \\
\hline
\end{tabular}

Phase-contrast and fluorescence mlcrographs of a sample of red blood celle that includes both normal and variant ceils. This sample containe cells that have been Incubaled with two different antibodies labeled with dyes that fluo. resce different colors (green or red) when excited with laser llght. Normal celle bind to both of the labeled antlbodles and so display both green and red fluorencence. Varlant celle in this sample bind only to the antibody that displays green tluorescence. One varlant cell (indicated by the arrow) appears in these micrographe.

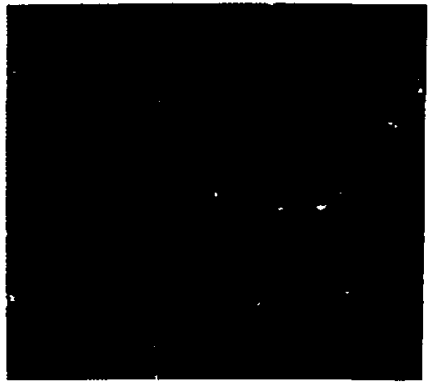

Green fluorescence

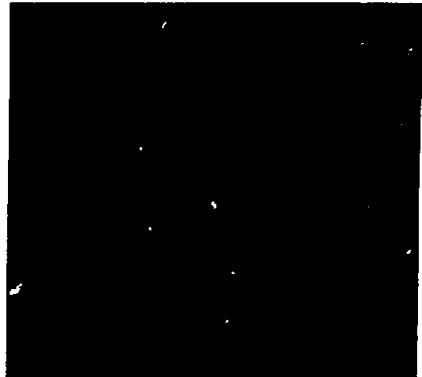

Red fluorescence 
DEFENSE PROGRAMS

FNIRC, I'IROX, IR A 15

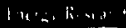

WORK FOR OTHERS in a million. Thus, several million red blood cells from each person are required and can be analyzed in about 30

minutes.

In collaboration with oncologists at Children's Hospital in Oakland and the University of California at San Francisco, we are analyzing blood samples from cancer patients who have been exposed to high levels of nutagenic chemicals while undergoing chemotherapy. Initial results indicate that these blood samples do contain elevated numbers of variant cells, suggesting that the assay can detect the increased genetic damage induced by chenotherapeutic agents.

When the assay system has been optinized and can be verified using this population of chemotherapy patients, our studies will be extended to the analysis of individuals in the general population. By conducting assays on a large number of people, we can better define the normal background frequency of variant cells, determine whether the background frequenry increases with age as the longlived stem cells accumulate mutations, and, ultimately, identify sonve individuals with a higher-than-average incidence of genetic damage who have been exposed to increased levels of damaging radiation or chemicals in the envirumment, or perhaps are deficient in the normal capacity to repair genetic damage as it occurs. In either case, these individuals may be at increased risk for later health consequences of genetic damage, lhe most important of which is cancer. Early detection of such cases, facilitated by this assay, would allow for effective medical surveillance and diagnosis of affected inctividuals.

Key Words: anlihody; blood; cancer; flow cytometry; genetic effect; glycophorin A; mutation; protein. 


\section{luminum-Air Power Cell}

Since 1979, the Laboratory has led a combined government and corporate research effort to develop the aluminum-air power cell and determine its economic feasibility. The aluminum-air power cell generates electricity from aluminum, water, and atmospheric oxygen and produces a reusable reaction product. This power cell appears to he particularly suitable for vehicle applications because of its high specific energy (over $300 \mathrm{~W} \cdot \mathrm{h} / \mathrm{kg}$ ) and high specific power (150 to $200 \mathrm{~W} / \mathrm{kg}$ ) and because it can be rapidly and conveniently refueted.

During 1983, we made substantial progress in two key areas:

- The development of the wedgeshaped cell, our preferred design for a vehicle battery, and the design of a second-generation wedge cell, which will be used to standardize full-scale tests of aluminum anodes and air electrodes.

- The investigation of integrated cell-and-crystallizer separator systems, including the evaluation of alternative separators to extract aluminum trihydroxide granules from the electrolyte.

The aluminum-air power cell consists of two main components, the cell stack and the precipitator-crystallizer (figure). Wedge-shaped cells are formed by positinning two air-electrode cassettes at an angle of 3 to $6 \mathrm{deg}$. As the aluminum plate is consumed, it is fed by gravity into the wedge. high-conductivity copper tracks support the aluminum wedge and provide a permanent solution-side current collector. The shape of the current collector was selected to obtain a uniform currert distribution. Tests of this configuration showed uniform consumption and feeding of the aluminum plate.

The secoad-generation wedge-cell design consists of a series of identical modules that can be assembled to create the 100-cell stack required for an electric vehicle. The modular design allows for easy replacement and repair; a five-cell stack will be tested this year.

While the design of an integrated celland-crystallizer separator system still requires considerable development work, we made good progress last year in the selection of prototype components that can be scaled to the needs of a full vehicle system. In particular, hydrocyclones were selected from among a number of alternatives for separating the crystallized aluminum hydroxide from the electrolyte. A main goal of this year's research program is to be able to predict the behavior of an integraied cell-and-crystallizer separator system.

By competitive bidding, Eltech Systems, Inc, was selected to be the prime industrial subcontractc. to pursue the research and development of the power cell for commercial applications. The Laboratory will continute to manage the program for the Department of Energy, working within DOE guidelines to set major milestones and funding levels, to monitor and interpret progress, and to continue research on the fundamental scientific and engineering aspects of the aluminum-air poner cell. L

Key Words: aluminum-air power cell; battery; fuel.

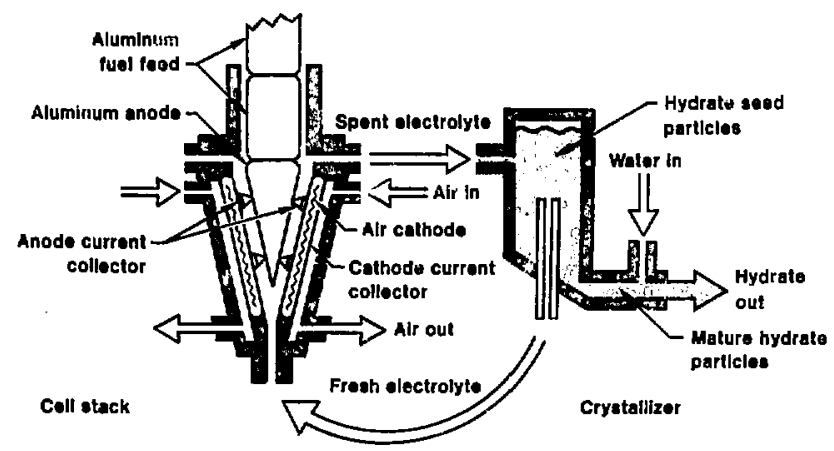

The centrel feature of the wedge cell is the wedge-eheped aluminum anodn between the two ar-cathode cesestes. As the rusclion procesde, the aluminum anode diasolvas on the taces next to the cathodes and, still in wedge form, gradually alfee into the cell. Second-generation wedge-shaped cells incorporate air and electrolyte distribution menitolding Into replaceable trapezoldal caseattes. Individual casaltes can be removed and replaced following dysfunction or fallure. The cells wiH provide a reproducible balle for tenting advanced ofectrodes in full ucalo. 
DEFENSE PROGRAMS ENFRC; P'ROX,RAML Consetsatum and $h$ WORK FOR OTHERS
$S$ trategic Metals from Brines For the past several years, we have been engaged in a project to evaluate natural brines from salt domes and geothermal wells as a possible source of strategic metals. The elements souglit include chromium, cobalt, gold, lithium, manganese, niobiun, platinum, silver, strontitum, tantalum, tin, and vanadiuns. Platinum, in particular, is valued as a catalyst in many inclustrial chemical processe's and in automotive smog devices and is obtained almost entirely from overseas sources.

Large quantities of these brines are bring brought to the surface for power production. After passing through the turbines, the spent (cooled) brine must be pumped lack underground to avoid environmental damage. Because the brines are cooler, the dissolved solids tend to come out of solution and plug the pores in the rock surrounding the injection well. One of the major obstacles to getting power from these geothermal sources has been the difficulty in finding an economicaily feasible pretreatment for the spent brine that will prevent this plugging.

Another possible source of brines is solution-mining of large underground cavities. One attractive method of forming a caven large enough to hold significant quantities of crude oil for the Strategic Petroleum Reserve Project is to circulale water into a deep silt dome and pump out the resulting brine. If the salt dome happens to contain desirable metal impurities, it may be worthwhile to develop methods to recover them.

One of the firt problems we encountered in this rertarch was the lack of accurate assay methods to measure trace amounts of desired metals in the presence of overwhelming concentrations of salt. The brines found in the Salton Sea Geothermal Resource, Imperial Valley, California, for example, contain 15 to $20 \%$ of dissolved solids, mostly chlorides of sodium, potassium, and calcium. We finally settled on neutronactivation analysis with carrier separation as the only reliable method for determining low levels of gold and platirum in these hypersaline brines.
The brines from this region were known from previous studies to be rich in lithium, manganese, and strontium, the latter in concentrations up to about $900 \mathrm{mg} / \mathrm{kg}$. We also detected traces of gold and silver in solution. In the output of the well producing the hottest and most concentrated brine in the Salton Sea Geothermal Resource, we also detected platinum at comeentrations of $56 \mu \mathrm{g} / \mathrm{kg}$.

At the concentrations present in these brines, it is unlikely that it would ever be practical to drill wells and process brines for their content of strntegic metils alone. However, if an efficient process for nuetal extraction can be combined with the process of power generation, the value of the minerals recovered may affset other costs and help to improve the economic feasibility of the entire system. Possible ways that we have considered to extract the platinum include the use of activated charcoal, reduction by iron or by commercially available. resins, and electrolysis.

To evaluate these and other extraction methods, we set up a series of benchscale laboratory experiments using a representative synthetic brine under conditions of temperature and pressure enrountered in the field. We obtained only fair extraction results with commercially available resins and activated charcoals, partly becnuse the resins deteriorated at the high temperatures of the brine. However, we were able to develop a pretreated activated charcoal that removed more than $95 \%$ of the platinum in the brine with a contact time of less than 30 minutes. This new product also significantly increased the adsorption capacity of the activated charcoal.

This extraction method should be extremely cost effective and can be operated at high flow rates. We are planning a small field test, in cooperation with a geothermal energy developer whose brine contains platinum traces, to further evaluate the method's potential. $t$

Key Words: activated charcoul; brine-zeothermal, salt; metal extraction; strategic metal. 
entralia Partial-Seam CRIP Test

Underground coal gasification (UCG) offers a way to obtain energy from the vast reserves of coal that are inaccessible to conventional mining methods. Under the sponsorship of the Department of Energy, LLNL has carried out several series of underground coal gasification tests, beginning with the Hoe Creek series in Gillette, Wyonning, tiom 1976 through 1979, and continuing through the large-llock series of tests conducted at the Wasnungton Irrigation and Development Cimpany (WIDCO) coal mine near Centralia, $W_{\text {ashington, in }}$ January 1982. One experiment in the large-block series demonstrated our Controlled Retracting Injection Point (CRII') system to improve gas production from a ivell. The results indicated that this process might provide the control needed for successful commercialization of UCG. The latest series of tests being conducted at the WIDCO mine began in the fall of 1983 with a proof-of-concept test of the CRIP method. This was designed to operate in half the thickness of the coal seam, allow for four or five injection-point withdrawals, and study the composition of the produc, gas and the efficiency of recovering energy from the coal.

With UCG, we burn the coal in place underground, supplving oxygen from the surface through ai. injection well and drawing off through a production well the large volumes of combustible gases evolved in the gasification process. The CRIP system is a refinement that extends the useful life of the injection well. We start a new burn zone in fresh coal by cutting off the injection pipe at a point upstream of the old cavity and then reigniting the coal seam. Without the CRIP system, roof collapse causes heat loss, reducing the heating value of the product gas; with the CRIP system, we can ignite a series of burn cavities without drilling a new injection well for each one, (The layout 0 , the instrumentation wells, production wells, and injection well for the partial-seam CRIP test was illustrated in the March 1984 Energy and Technology Review, UCRL-52000-84-3, p. iii.)
On Octoler 16, 1983, we ignited the coal seam with our silane igniter and began the partial-seam CRIP test. Oxygen-enriched air was supplied throughout the day; the product gas thus generated had a heating value of 7.5 to $8.3 \mathrm{MJ} / \mathrm{m}^{3}$ (200 to $220 \mathrm{BTU} / \mathrm{scr}$ ). On Octoler 17, we hegan steam/oxygen injection and experienced smooth operation, except for a two-day shutdown to service equipment parlially plugged lyy coal dust. We obtained very' good product gas with o heating value of about $9.3 \mathrm{MJ} / \mathrm{m}^{3}(250 \mathrm{BTU} / \mathrm{scf})$. Air injected for brief periods kept the fire burning during power outages and stean.-boiler repairs.

After using a vertical production well until day 12 of the experiment (October 28), we switched to a slant production well. The changeover went snoothly, and we observed an improvement in product-gas quality. On Octoher 30, we executed the controlled retraction maneuver and estalslished a new cavity, with the expected improvement in product-gas quality. We continued steam/oxygen gasification using the new bun cavity and the slant protiuction well until we shut down the experiment on November 14.

We gasified allout 1000 tonnes of coal with each cavity, for a total of 2000 tonnes. Good thermal responses were obtained in several instrumentation wells. From this highly successfu] underground cral gasification test, we conclude that:

- The Centralia site is favorable for UCG.

- The large partial-seam test produced results sinilar to those obtained in the much smaller-scale tests we conducted two years ago at the same site, proving that the small-scale experiments have precictive capabilities for UCG.

- The use of a slant production well is adva: itageous for UCG.

- The CRIP method was successful and inproved UCG performance as expected. $\mathbf{L}$

Key Words: coal mining; underground coal gasification (UCG); Controlled Retracting Injection Point (CRIP) - system, partial-seam test. 


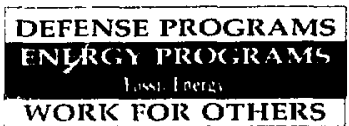

WORK FOI OTHERS

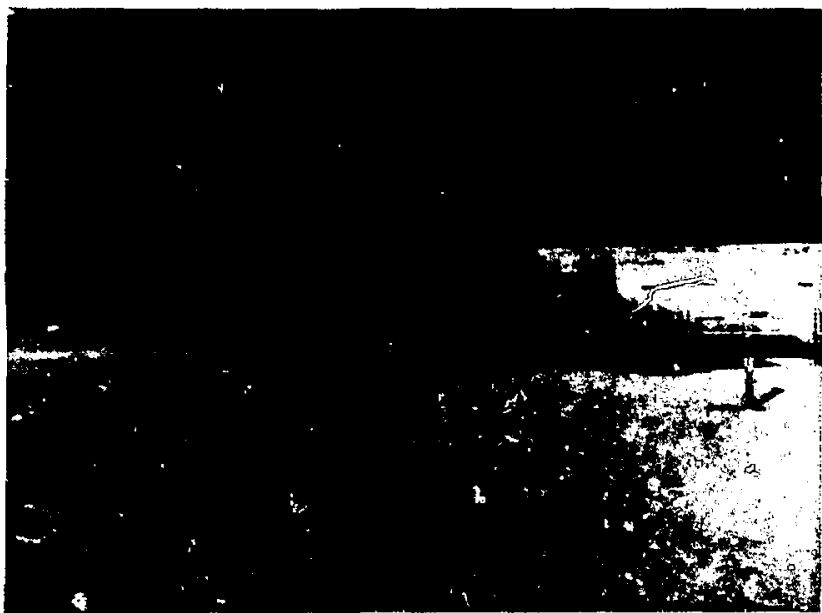

Diepersion Ieat in the Eegle lent eeries of a spil of nitrogen totroxide on the dry lakebed of Frenchman Fint at the NTS (the spil potnt is at the right edge of the photograph). The DOE devignated this ares as the ste of the LGF Spul Test Facilly for condlisting and interpreting spill setety experiments with a veriaty of toxic and/or combustlbte liqualied gasese. transition, and the combustion

characteristics of the vapor.

In 1983, we conducted two series of tests on the dispersion of toxic liquefied gases at the proposed site. These tests verified the desirability of the site and served to develop experience and procedures for testing spills there. To colled the data, we employed the multistation, remolo-data-acquisition system devedoped previously for the DOE-sponsorext liçuefied natural gas tests that we performed at China Lake, California, in 1980 and 1981.

The first test series, Desert Tortoise, was funded by the U.S. Coast Guard and The Fertilizer Institute and comprised four releases of ammonia. These tests simulated a small railroad accident and spilled up to $40 \mathrm{~m}^{3}$ of ammonia at rates up to $10 \mathrm{~m} / \mathrm{min}$. Much of the escaping ammonia was in the form of a heavierthan-air aerosol that was transported downwind before it was eventually evaporated. Two circumstances, an extended source and a heavier-than-air mixture, amplified the safety prohlems associated with handling and storing anmonia. Our results indicate that hazardous concentrations of ammonia extended beyond $2.8 \mathrm{~km}$.

The second test series, Eagle, funded by the U.S. Air Force, comprised six releases of liquid nitrogen tetroxide $\left(\mathrm{N}_{2} \mathrm{O}_{4}\right)$. The largest spill was about $4 \mathrm{~m}^{3}$ of liquid. Nitrogen tetroxide is a rocket propellant oxidizer for the Titan II missile. Nitrogen tetroxide vapor is toxic at concentrations of a few tens of parts per million and is heavier than air at ambient temperatures. Upon release to the atrinosphere, nitrogen tetroxide rapidly decomposes to form nitrogen dioxide, which is also toxic and heavier than air (see figure). Our test results indicate that the dispersion process is further complicated by the formation of a dense nitric acid mist near the spill point. We believe the mist results from a reaction of the nitrogen dioxide vapor with water vapor in the air. $t$

Key Words: ammonia; liquefied gaseous fuel; nitrozen tetroxide; safety-toxic spill. 
$\mathbf{N}$ uclear Waste Management

The major task of the Department of Energy's Nevada Nuclear Waste Storage Investigations (NNWSI) project is the evaluation of a potential repository system for high-level waste to be localed on er adjacent to the Novada Test Site. Within the NNWS1 project, the Laboralory has been assigned two major responsibilities:

- The development and qualification of tesigns for waste packiges suitable to implacentent in a jepository localed above the water table in a thick sequence of volca: ac tuff beds at Yucca Mountain.

- The test storage of nuclear wastes in Climax granite at the NTS.

During the past year, we completed a number of thermal, structural, and economic analyses on several alternative waste-package derigns and hegan postretrieval studies or the three-year storage phase, completed in 1983, of the Climax granite test.

Waste-Package Design. The topics that must be ardressed to establish the viability of waste-package designs can be grouped into four broad, interacting categories: the package environnent, the package structural materials, the package design, and the testing and analysis of the package performance under expected repository conditions. We have developed and analyzed a set of package-design concepts that reflects a range of package alternatives (lhat is, differest repository designs, different structural rinaterials, different waste forms, etc.).

In order to analyze waste-package performance over long periods of time, we need a thorough knowledge of the package enviromant under expected repository conditions. Envirommental parameters currently being evaluated include the geochenical properties of the Yucca Mountain tuff (rock composed of compacted volcanic ash) and of the valdose water (water that is in the earth's crust above the permanent groundwater level) present in the tuff, the variations in the thermal and thermomechanical properties of the tuff, and the response of the interstitial water to the thermal energy and the nuclear radiation emanating from the radioactive waste.

High-level waste paikages contnin three major components: the metailic containment barriers, the waste form. and other materials (such as packing material, emplacement-hole liners, etc.).

The figure illustrates three reference waste-package designs. The metallic containment harriers are the prinary.
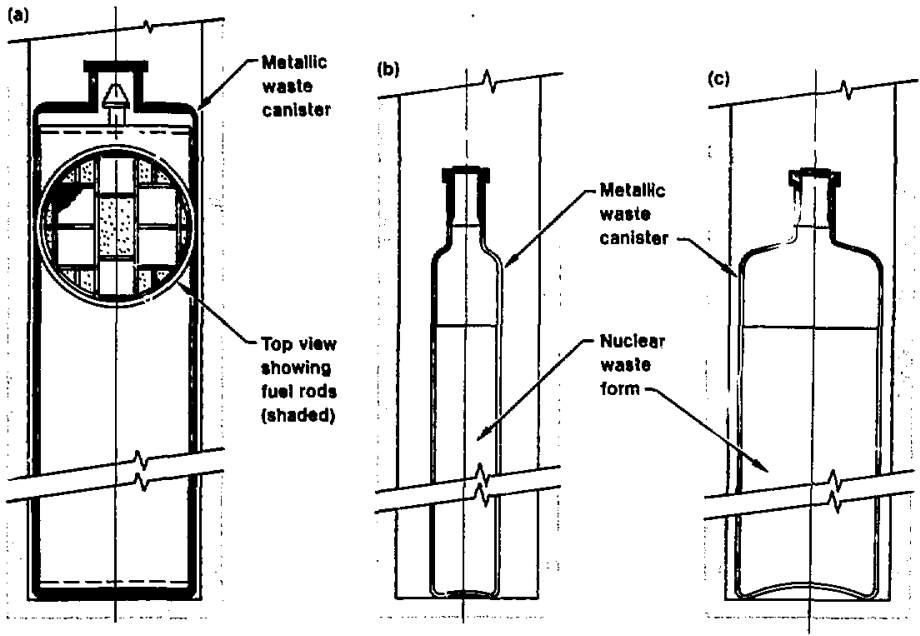

Rejcrence waste-package designs tor emplacement in verlical boreholes: (a) for spent fuel from a boiling water reactor, (b) for commercial high-leve nuclear waste, and (c) for defense high-level nuclear waste.

DEFENSE PIROGRAMS FNIRC;Y PROCIRAMS Yucled* Lne'gs

WORK FOR OTHERS 
DEFENSE PROGRAMS

ENHIRC;Y P'R() ,RAMS

Vuintion

WORK FOR OTHEISS waste-package structural materials and are intended to provide substantially complete containment of the nuclear waste for three hundred to a thousand ycars after emplacement. During the waste isolation (post-containment) period that extends for thousands of years after the metallic containment barriers are breached, we expect the waste form to provide the primary control of relense rates of radioactive waste inte the immediate repository environment. The other materials aie those that may be required by the overall package and repository design.

Primary candidate matorials for metallic containment barriers are the austenitic stainless steel alloys. The corrosion properties of these materials are being intensively investigated under expected repository conditions (steam or vadose water at temperatures up to $150^{\circ} \mathrm{C}$ in the presence of tuff, with and without gamma radiation fields). We are Ilso investigating, under expected .epository conditions, radionuclide release rates from two waste-form classes (reprocessed waste contained in borosilicate glass, and spent fuel with zirconium-alloy cladding). Tc date, only preliminary experimental work has been undertaken on other materials that may be used in the waste-package design.

During the past year, we completed a number of thermal, structural, and economic analyses on several of these alternative designs; these analyses are continuing. We are also modeling wasteparkage performance and developing codes. Existing models and codes that were formulated for use in a saturated environment are being revised, verified, and validated for use in the unsaturated tuffaceous rock of the Yucca Mountain repository site. We are formulating fieldtest plans for performance testing of prototype waste-package designs in the Yucca Mountain Exploratory Shaft.

Underground Storage. The test of underground storage of spent nuclear fuel that is being conducted in quartzmonzonite rock in Area 15 of the NTS is another of the Laboratory's responsibilities under the NNWSI project. Results from this field test, which involves the storage of spent-fuel elements deep underground in the Climax granite over a period of three years will be directly applicable to the design of a high-level nuclear waste repository situated in a crystalline host rock. The three-year storage phase for this test was completeci in 1983, and the 11 canisters containing radioactive (spent) fuel elements were successfully retrieved.

For a six-month period following fuel retrieval, we made post-removal measurements of the 'lal and thermophysical effects in the host rock; subsequent to this measurement period, we calibrated sensors, studied the corrosion of structural materials, and analyzed data. These activities will continue through fiscal year 1985, with the objectives of documenting the accuracy of our modeling techniquses, detecting any changes in the rock mass and the various metals used in the test facility resulting from the storage of high-level nuclear waste, and evaluating some instrumentation failures that occurred during the three-year vest just completed. With the Climax spent fuel test coming to its conclusion, we are investigating other scientific uses for this unique underground facility.

In support of the Department of Energy's efforts to develop a repusitory system for high-ievel waste, the Laboratory has, during the past year, successfully completed a number of analyses of alternative designs for waste packages and has begun post-retrieval studies aimed at obtaining technical data for use in designing a granite repository and evaluating granite as a medium for deep geologic disposal of high-level reactor waste. 16

Key Words: Climax granite; Nevada Nuclear Waste Storage lnvestigations (NNWSI); nuclear waste-canister design, repository, storage; spent nuclear fiel; Yucca Mountain. 
$S$ trength of Salt

For forty years, ever since the first nuclear reactor was started, high-level radioactive waste has been accumulating. The debate over what to do with these wastes has been going on for almost as long. The Department of Energy has indicated that construction of the first nuclear waste repository could begin in 1993. The currently favored geologic medium for long-term isolation of high-level reactor waste is deeply buried rock salt. Bedded and domal salt deposits have survived hundreds of millions of years, so they presumably will endure a few thousand years more. Furthermore, because rock salt is weaker and more ductile than most other rocks, cracking would be suppressed in the repository region because any voids would tend to heal (fill back in) rather than grow' 'rger.

However; the Nuclear Regulatory Commission requires that any proposed method of waste isolation include provision for retrieving the waste canisters for at least 50 years after emplacement. Hence, it is vitally important to be able to predict accurately how fast undergiound workings in rock salt will close. There is wide disagreement among different investigators over the rheological behavior (time-dependent flow under stress) of salt.

We have been investigating the possibility that the origin of thic disagreement may lie in the variable composition of natural rock salt. Upon mechanical testing and chemical analysis, we found that salt from most sources was relatively pure and weak, with less than $0.01 \%$ each of potassium and magnesium. However, salt from two sources had about $0.1 \%$ of potassium and about $0.6 \%$ of magnesium, respectively, and were two to three times stronger than pure salt. Studies on metals and ceramics suggest that the strength of rock salt might be strongly influenced by such relatively minor impurities.

To investigate the effects of such trace concentrations of cations on the strength of salt, we prepared synthetic samples using pure chlorides of sodium, potassium, and magnesium. (In this way, we avoided the inclusions and other defects likely to be present in natural rock salt, which might have interfered with our measurements.) When we examined the rheological behavior of these samples at ambient to moderate temperatures, the results were strikingiy different from those for pure sodium chloride (figure).

Translated into a practical example, these results show that, at normal temperatures, a cavern mined at a depth of $850 \mathrm{~m}$ in rock salt containing $0.6 \%$ of magnesium would close up ten million times more slowly than a similar cavem in pure salt. For salt containing $0.1 \%$ of potassium, the corresponding figure is ten billion times slower. At a temperature of $200^{\circ} \mathrm{C}$, about the highest repository temperature envisioned, the corresponding rates are one thousand and ten thousand times, respectively.

On the basis of these results, it appears vitally important to repository design and operation to determine exactly what kind of salt is present in any proposed location and to design with that salt's particular properties in mind rather than to rely on measurements that may have been performed on a quite different material. 1

Key Words: nuclear waste-repository, storage: salt-deposit, impurities, strength.

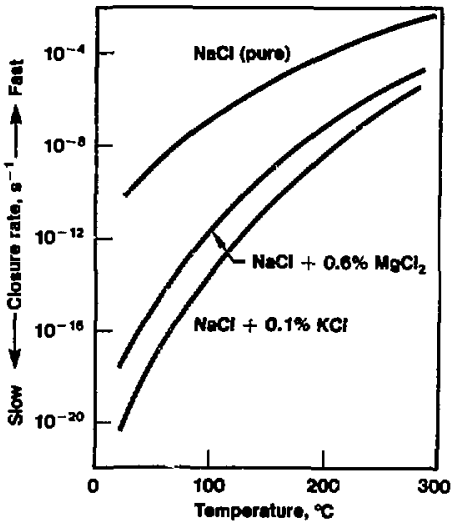

DEFENSE PROGRAMS FNERGY'PROCIRAMS yuclear I nomes

WORK FOR OTHERS
Closure rates (logerithmic scalo) tor cavities in salt at dopth with various lovele of impurities. Pure codlum chloride deforms relatively culckly, but minor amounte of magneslum or potassium chloriden can tow deformation by a factor of as much as ten thoueand at $200^{\circ} \mathrm{C}$ and ten billior at room temperature. 


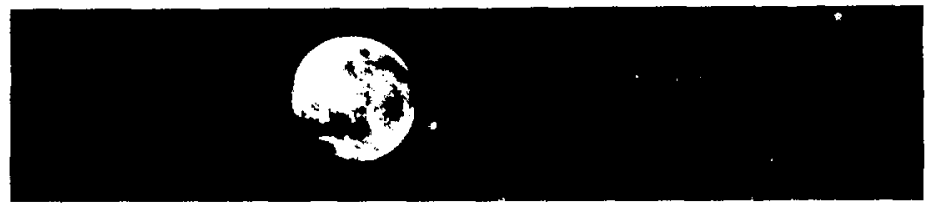

\section{Work for Others}

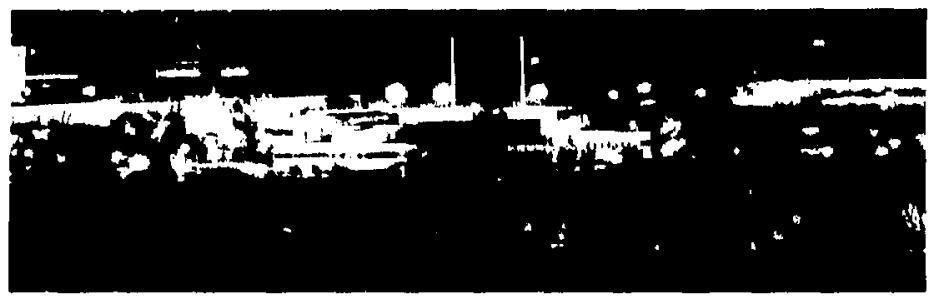

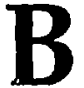

eam Research Program

Under the sponsorship of the Defense Advanced Research

Projects Agency (DARPA), the Laboratory's Beam Research Prozam continued to investigate the feasibility of an intense charged-particle beam as an endoatmo:spheric point-defense weapon. The centerpiece of this program is the Advanced Test Accelerator (ATA), a high-current, linear-induction accelerator located at the Laboratory's Site 300 .

Performance of the ATA continues to improve as we gain further understanding of the physics of transporting intense electron beams in the accelerator. The accelerator is now operating at its full design specifications of $50 \mathrm{MeV}$ and $10 \mathrm{kA}$. Strictly speaking, the degree to which beam-transport instabilities limit the beam current is governed by the uriformity of the beam when it is injected into the the 85-mlong accelerator structure. Recent changes in the beam-generation process have significantly improved the transport characteristics and have shown the way to further advances.

During the past year, we have demonstrated advanced beam-control techniques on the Labor-', ry's 5-MeV Experimental Test Accelerator (ETA). We will soon apply these techniques to the ATA. Together with improved beamgeneration techniques, they will enable us to achieve full $10-\mathrm{kA}$ operation while completely suppressing unwanted beamtranspurt phenomena.

Also under DARPA sponsorship, we have initiated a program to develop a free-electron laser (FEL) and to evaluate the feasibility of using high-gain FEL amplifiers for defensive weapon applications. We are currently mounting an aggressive effort to develop very bright electron-beam sources for driving the free-electron las?r. We are also adding $93 \mathrm{~m}^{2}$ of floor space to the ATA facility to provide a new beam line for laser-related ATA studies.

Closely associated with the freeelectron laser is a microwave experiment currently being tested on the ETA. A 
collaborative effort with Lawrence Berkeley Laboratory, the microwave experiment was initiated by the Department of Energy to study the feasibility of using the free-electron laser to produce high-power, millimetrewavelength radiation for magnetic fusion and advanced accelerator applications.

This experiment already has

demonstrated emittance control techniques and the importance of transport phenomena for intense beams; it has produced a gain of about 3000 with transport of about $350 \mathrm{~A}$ through the free-electron laser device. In the most recent experiments, we have measured an output power in excess of $80 \mathrm{MW}$ at $35 \mathrm{GHz}$ from an untapered wiggler (a periodic array of magnets used in the free-electron laser). We will soon conduct experiments in a tapered wiggler, with which we expect to achieve gains of about 10000 with $20 \%$ conversion of electron-beam energy to microwaves. 15

Key Words: Advarced Tesl Arcelerator (ATA); clectron beam; Experimental Test Aceclerator (ETA); free-clectron lasur (l'EL); microwave.

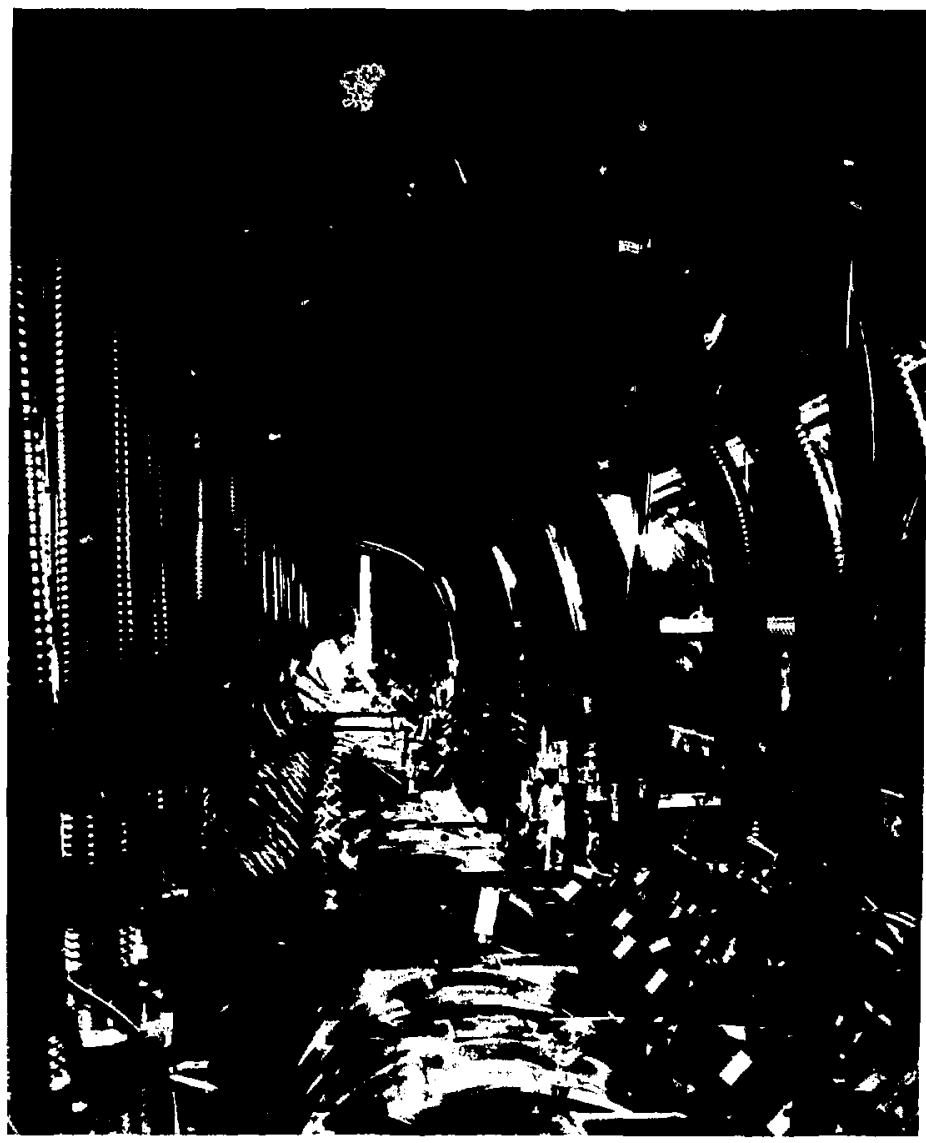

Looking fown the Laboratory's 85-mlong Advanin- Test Accelerator toward the experimesic lank. Highrvaltege pulses are tranenilted through the cosxial lines shown here to ferrite corat Inelde a series of chambers, driving the electron besm a it paseese Irom one chamber to the next. Wh are investlgating the festbillty of waing an intense charged-particle beem on endoatomosphric ballietic-misaile datente. 

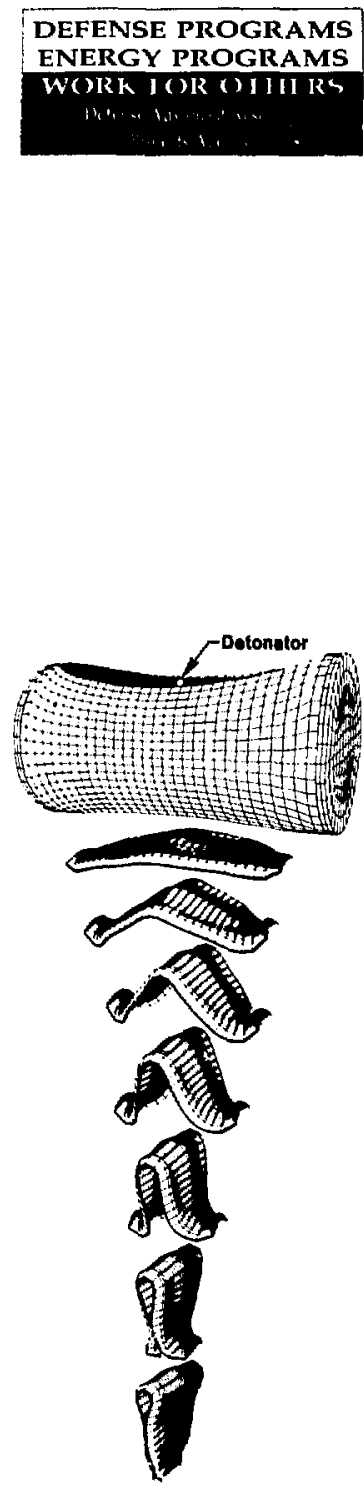

The mathematical model of the nonaxisymmetric wathead before dotonation and the formation of the diek-eheped projectis.
$\mathbf{N}$ onnuclear Ordnance We have continued, during the past year, to contribute to the Department of Defense's conventional-warhead technology through a number of reimbursable programs. We expect these programs to expand somewhat during fiscal year 1985 with the provision of $\$ 3$ to 10 million in level-of-effort funds from the DOD.

Our accomplishments this year include:

- A computer design study and an experimental lest of a nonaxisymmetric warheat that explosively forms and propels in a desired direction a massive disk-shaped projectile (figure). This enables a lrorizontally flying projectile to attack tank armor from above, where it is weaker. For this nonaxisymmetric design, we exploited our threedimensional hydrodyramic computer codes to maximize the warhead mass in the limited diameter.

- Demonstration of the formulation, loading, and firing of high-energy extrusion-cast explosive in anti-armor munitions for the Air Force. The extrusion-cast explosive is a precision explosive that is void-free and extraordinarily uniform in composition. Its energy matches that of plastic-honded explosive, but it can be loaded at low pressures and cured to final shape without machining.

- Contributions to the development of a new process for making $H M X$, a high-energy explosive coming into increasing use in conventional munitions and rocket propellants. This process 'was recently selected by the Army for iesring at the pilot-plant scale and for possible exploitation in a production facility that would double the nation's HMX production.

- Mechanical measurements, at moderate pressure, of the equations of state of various explosives suitable for use in guns (e.g., a standard propellant, one that is a liquid, and another that burns very fast) to provide basic data for characterization and for constitutive modeling.

- A significant new study of the interactions between missile warheads and rocket propellant in various hazard scenarios involving the Trident II and the Peacekeeper (MX) missiles, undertaken to address questions of vulnerability and high-explosive hazards.

- An assessment of rocket-motor and warhead hazards, in conjunction with the Air Force, for the advanced small ICBM proposed by the Presidential Commission on Strategic Forces (the Scowcroft comnission) and now being designed by the Air Force.

- Developiment of a low-cost way to make high-strength aluminum nitride ceramics (used in arnor) by explosive compaction with nitromethane. The conventional (and expensive) method involves heating the unconsolidated powder to high temperature in a highpressure die. Our process produces completely compacted rods, free of cracks and voids, and we are working to translate the technique to planar geometry for making flat plates.

- Flash $x$-ray studies of how highvelocity rod-shaped projectiles penetrate armor (usually with erosion of both target and projectile). We have found conditions under which the projectile continues to penetrate (at late times) without further erosion, and even sume in which penetration continues (by flow) after there is nothing left of the projectile. This information is important in the design of both better armor and belter penetrating projectiles.

There is a synergism between our activity in conventional munitions and the Laboratory's nuclear mission. We are responding to an important national requirement to upgrade muritions technology so that deterrence can be based on nennuclear capability wherever possible. Work on advanced conventional munitions reinforces and broadens our unique capabilities in materials and implosion physics, highexplosive chemistry, and mechanical and electrical engineering. 1.

Key Words: explosively formed projectile; extrusion-cast explosive; HiMX production; nonnuclear ordnance. 
$\mathbf{P}$ recision Engineering Research Lathes

We have developed two small, precision engineering research lathes (PERL I and PERL II) for suprorting the Laboratory's programs. PERL $]$ is used for fabricating small (less than $8 \mathrm{~cm}$ ) contoured parts. PERL II, part of our Large Optics Diamond Tuming Facility, is used as a research lool for performing culting studies for the Department of Defense and the Laboratory. The rutting studies are aimed at obtaining a basic understanding of the process, with en.phasis on inproved form and finish for high-precision parts by proper choice of the cutting process, tool material, cutting edge preparation, etc.

Although there are slight differences between the two machines, they share major design features including the use of a T-configuration, hydrostatic oil slides, capstan slide drives, air-bearing spindles, and laser interferometer position feedback. The following features are particularly noteworthy:

- To obtain the required accuracy and friction characteristics, the two linear slides are supported by $10-\mathrm{cm}$-travel hydrostatic bearings developed at LLNL.

- To minimize backlash and friction, we use capsta". drives to provide the slide mctions. Laser interferometers operating at $25 \mathrm{~nm}$ resolution provide position teedback for the slides of PERL I.

- To obtain the best surface firish possible, we minimize asynchronous (nonrepeatable) spindle motion by driving the spindle directly with a brushless dc torque motor.

The size of the lathes is minimized to reduce sensitivity to temperature variations. This, combined with internal water cooling of the spindle motor, the only major heat source on the machine, permits us to use air-shower temperature control. (This approach is a departure from previous designs for larger machines where liquid shower systems are used.) We built an enclosure around each machine through which we recirculate air at $0.28 \mathrm{~m}^{3} / \mathrm{s}$, which is temperature controlled by an air-to-water heat exchanger. We can limit thermal drift to less than $13 \mathrm{~nm}$ in 24 hours.
PERL I operates under a closed-loop, two-axis computerized numerical control system with a $25-\mathrm{nm}$ position-feedback resolution. We developed our own computerized numerical control system because the designs of conventional, commercial systems were inadequate for our special needs. The contour accuracy of PERL1 is about $100 \mathrm{~nm}$ peak-to-valley on a 5 (m)-diameter hemispherical copper part cut with a diamond tool (see figure). The surface finisis of this part is about $25 \mathrm{~nm}$ peak-to-valley. These figures are estimates because the accuracy of the lathe exceeds our ability to measure the resultant part accurately.

PERL Il operates in single-axis mode. Using tacing cuts on copper with a diamond tool, we have achieved surface finishes of $7.5 \mathrm{~nm}$ peak-to-valley $(1.5 \mathrm{~nm}$ rms). We are working to improve this valute. A'so, we plan to incorporate a two-axis numerical control system, a)though in this case, we will use a programming and feedback resolution of $2.5 \mathrm{~nm}$, ter times smaller than PERL I. This will improve the surface finish and contour accuracy of the parts. 6

Key Words: lathe-optics, diamond tuming, PERL.

\section{DEFENSE PROGRAMS ENERGX PROGRAMS W()RK IC)R ()ITIFIRS

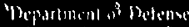

Hemispherical copper part $(5 \mathrm{~cm}$ in $\mathrm{dr}$ ameter) cut with a dlamond tool using PERL I. The contour accuracy is aboul $100 \mathrm{~nm}$ peak-th-valloy, and the surface flnish is about $25 \mathrm{~nm}$ pesk-to-valioy.

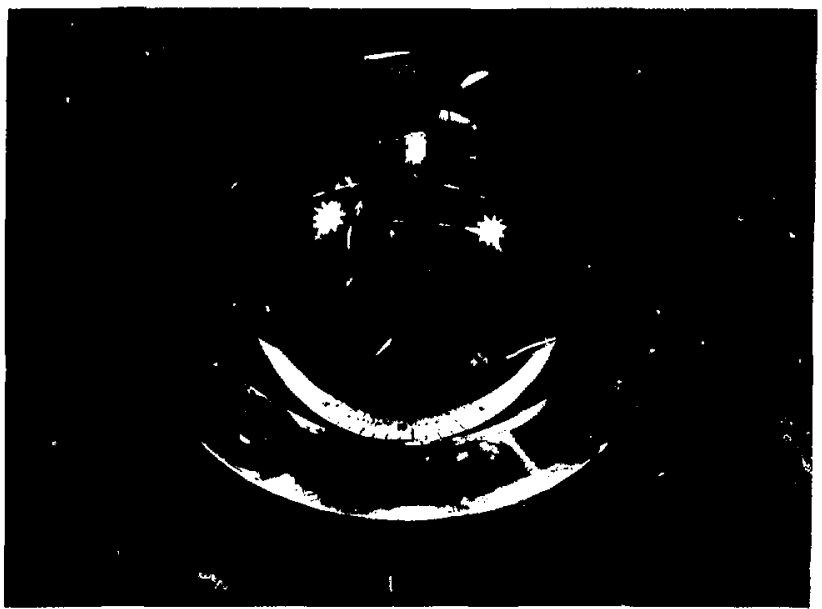


DEFENSE PROGRAMS

ENERGY PROGRAMS

WORK_JOR OIIIIRS

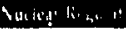

F lexible Piping Design Favored We are performing a reliability analysis of nuclear reactor piping systems for the U.S. Nuclear Regulatory Commission (NRC) to compare stiff vs fexible piping. The overall objective is to develop modified design requirements and criteria that will improve piping reliability and minimize the use of pipe supports, smubbers, and pipe-whip restraints in nuclear power-plant piping. The results of this project will provide input to the NRC Piping Review Committee for changes to piping design regulations. This project is one of 40 projects the Laboratory's Nuclear Systems Safety Propram conducts for the NRC, the Departme.t of Energy, and the Federal Emergency Management Agency.

Current design criteria for piping, which address specific load types individually, evolved under the presumption that higher seismic margins necessarily improve plant reliability. Conservative design against earthquake loads has relied increasingly on rigis supports, snubbers, and other types of seismic restraint to stiffen piping systems. The resultant decrease in flexibility, however, results in higher normal operating stresses because of the restraint of thermal expansion 'and does not fully utilize the ductility and damping characteristics of tise pipe to enhance its load-bearing capacity. Furthermore, because of the large uncertainty inherent in predicting seismic effects (compared to that in predicting thermal effects), seismic loads dominate the design, even though seismic loads occur very infrequently. As a result, stiffening a pipe system to improve its resistance to seismic loads may actually decrease its overall reliability during normal operation.

A corroborative piping-reliability assessment of stiff vs flexible piping systems, which we performed in 1983, indicated that the removal of rigid supports and snubbers generally will improve the overall piping reliability. Our findings generally favor the flexible piping design. However certain changes in the piping design procedure are required to allow more flexible nuclear piping systems to be clesigned. The Steering and Technical Comniltees on Piping Systems, estahlished by the Pressure Vessel Research Committee of the Welding Rescarch Council, have investigated and recommended changes to be implemented in the NRC regulatory guides that specify damping and floor-response spectra for the seismic design of nuclear power plants. We adopted these changes in our study, evaluated their impact, and drew the following conclusions:

- These changes reduced calculated piping responses substantially while retaining sufficient margins of conservatism.

- The proposed changes allowed piping redesigns with a significant reduction in the number of seismic supports without violating American Society of Meciranical Engineers code requirements.

- The more flexible piping as redesigned was capable of exhibiting reliability levels equal to or higher than the original stiffer designs.

Key Words: nuclear reartor-safety: power-plant piping Nucluar Regulatory Commission (NRC). 
F ault Graphs

We are using fault graphs to model failure scenarios for nuclear power-plant systems to assist the Nuclear Regulatory Commission in evaluating the impact of the scenarios on plant safety. The reliability and structure of large complex systems are often difficult to model and evaluate, especially when they contain cyclic effects such as feedhack loops or bidirectional flow. To address this problem, we developed the fault graph as a new modeling tool.

A fault graph is a failure-oriented directed graph with logic connectives that allows cycles. We construct the fault graph to resemble the piping and insirumentation drawing of the system, but with logical AND and OR conditions added (see figure). Then, we evaluate the fault graph with computer codes based on graph-theoretic methods.

lault graphs are the natural evolutionary next step from traditional fault-tree models. Traditional fault-tree computer codes manipulate Boolean equations, but they are limited because they cannot evaluate models that are either very large or contain cycles. Faultgraph computer codes, however, are hased on graph concepts such as path set (a set of nodes traveled on a path from one node to another) and reachability (the complete set of all possibie paths between any two nodes). These codes wre used to find the cut-sets (any minimal set of component failures that will fail the system) and to evaluate the systom reliability.

The fault graph often leads to a better integraied logical representation of a large complex sysim, and fault-graph compuler codes have proved to be hath fast and efficient when run on both main frame computers and miniconputers. $L$

Key Words: tuult graph; nuclear renctos-puser plant watery; Nuclear Reyulatory. Comminsum (NRC)
DEFENSE PROGRAMS

ENERGY PROGRAMS

WORK FOIR OTIIERS

Iuclear Regulatori Commission
(C)

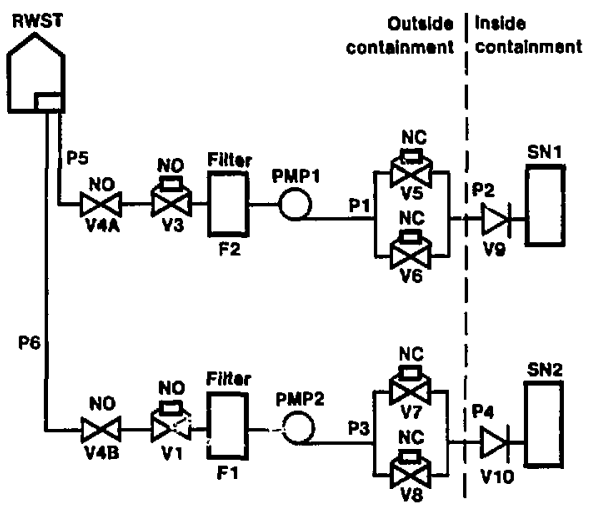

(b)

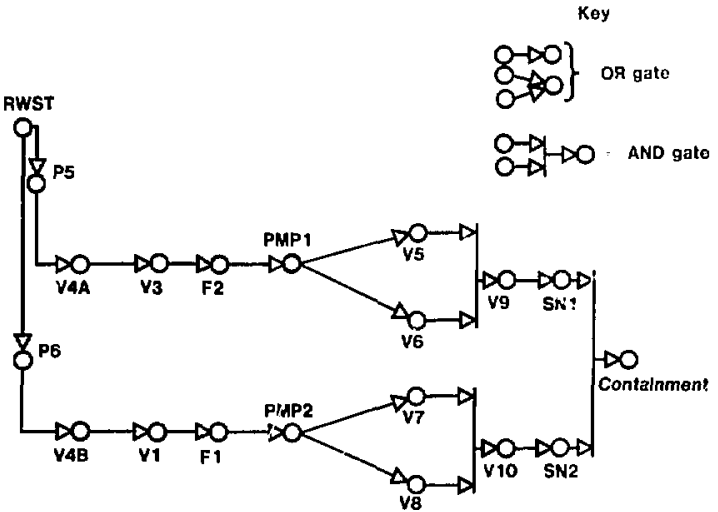

(a) Piping and insteumentation drawing of a simplified containment epray system. The refueling water storage tenks (RWST) supply water to two epray nozzles (SN1 and SW2) through two pumps (PMP1 and PMP2); other components are pipe (P), fiter (F), and valve (V). Yalves are marked nor- mally open (NO) and normally closed (NC). (b) The sault graph of thls system shows that the containment node is connected to the spray nozzles by an AND gate; thus, for the contalnment to fall, flow from both spray nozzles must fall. 


\section{Laboratory Achievements Index}

Advanced Arr-to-Surface Mlissile, 35

Aluminum-Air ower Coll, 73

Antisubmarine Warfare, 35

Bar-Ci fo Techutolegy, 55

Anom-Driven Dinde Eyreriments, 27

Beim Research P'rogrnm, 80

1383 and WR4, 30

Coscakle, 44

Centralia l'artial-5eam Clili' Test, 75

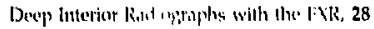

Design of lijssion Devietes, 23

Liffects of Increaned C.mbon Dinide an Crop riclits, 64

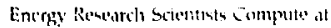

NMIIFCC, 6.3

Fault Ciroplis, 85

Flexible Piping Design Havored. 84

Gallium Arsenide Bmplifier. 12

Genetic Eefferts of Chemical and Rastiation

Expostute, 71

Gl.AN, 22

Gy paran Plugs for Emplowement Hollen, 13

High: Hehd Fest Hacility: or

Human DNA Repair Gunes, 70

Improved Calculations of lom Traneport, 20

Improving Fibur.Optum Diagnostics, 7

In Implantation Improsess Surface Propeyteds, 51

I.aser lsolope Separatum, 47

Laser Optical l.ine of Sight, 18

L.aser-Plasma Interactions, 42

line Trunsport Therery 25

Measuring Radiugentic Helium-t, 14

Metaloslistn of Harardeus Compounds by

Molluses, 67

Metalhurgy and Directed-Fnerge Processing, 50
Mininture Dryer, 37

Nieror Fusion Test Facility, 58

Neutral Besm Shep, 60

Nentron Transpert Mosteding, 24

Now Comma-Ray Diagnomitio 11

New Cits Silmpling Condtut, 16

Now Stake of Miller 52

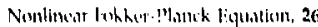

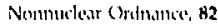

Nown laser linility; 41

Nonente laser. 40

Nuclear Imperdance Mntibhe Fyeriment, 29

Nuclear Wistc Managrimemt. 77

Padekenger Wiarhead, 3.3

Photosondus:ive Switches, 45

J'rexisten limginnering Rentarch lathes, 83

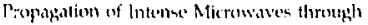
Air. 36

Quan:atating: Coll-Cycle [ausmeters, 68

Remote Mlewarement Mer Optical Hibuss, 66

Rotating Target Neutrm Source. 62

Small tulercomtimental Ballistic Mlissile, 34

hal Civ Contin: 43

Spull Tont bicitity at NTS, 76

stratege Melasle from Brinke, 74

Strategic Ponetrator tVeapun, 32

Strenglit isf Soll, 79

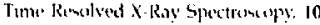

ThI Lipgrates 56

Trancitiont Radiation, 39

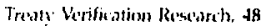

Mighhing the Noutrins, 53

Workd.Wide liffects ai a Nuclen: Exchange, 38

W82 Acomplisltments, 34

$x$-kay Latier Targels, 46 


\section{Disclaimer}

This document was prepared as an arcount of work sponsored by an agency of the Uniled States Government. Neither the United States Gotemment nor the University of Califomia noe any of their employes, makes any warranty, express or intiled, or assuntes any legal lialility or resporisibility of any Information, apparatus, procituct, or process disclosed, or nepresents that its use would not infringe privately ownted rights. Reference herein to any specific commercial products, process, or service hy trade name, trademark, manufacturer, or otherwise', does not necessarily constitute or imply its endorsement, recommendation, or favoring by the United States Govemment or the University of Califorria. The views and opiniuns of authors expressed herein do not necessanily state or reflect those of the United States Govermment thereof, and shall not be used for advertising or product endo sement purposes.

Trinted in the United States of America Availablu from

National Technical Information Service

U.S. Department of Commerce

52855 Port Royal Road

Springfield, Virginia 22161

['rice: ['rinted Copy \$11.50, Mictofiche $\$ 4.50$ 